\title{
ASSESSMENT AND DEVELOPMENT OF AN ADVANCED HEAT PUMP FOR RECOVERY OF VOLATILE ORGANIC COMPOUNDS
}

\section{Final Report}

June 1992

Work Performed Under Coritract No. DE-FC07-881D12788

\author{
Prepared for the \\ U.S. Department of Energy \\ Under DOE Idaho Field Office \\ Sponsored by the Office of the Assistant Secretary \\ for Conservation and Renewable Energy \\ office of Industrial Technologies \\ Washington, D.C. \\ Prepared by \\ Mechanical Technology Incorporated \\ 968 Albany-Shaker Road \\ Latham, New York 12110
}


Loss of volatile organic compounds (VOCs) to the atmosphere represents a significant energy, economic, and environmental concem for government and industry. Reliable and economical ways of recovering these materials for reuse could be crucial to the economic viability and competitiveness of affected industries as environmental regulations are tightened. The U.S. Department of Energy (DOE) has sponsored several advanced heat pump development projects directed at the recovery of VOCs from solvent-laden air (SLA) streams. DOE's interest in this technology is primarily in the energy embodied in the recovered solvents, bnth in terms of the energy required for their manufacture and for their environmentally acceptable recovery or disposal. This report documents Phase I of a project conducted by Mechanical Technology Incorporated (MTI) for the assessment and development of an advanced heat pump for recovery of VOC solvents from process gas streams. The objective of this project is to develop a system that is economically attractive to the industrial user and will result in widespread replication. In Phase I, MTI has evaluated solvent recovery applications within New York State (NYS), identified host sites willing to implement their application, and conducted a preliminary design of the equipment required. In addition, the design and applications were evaluated for technical and economic feasibility.

The solvent recovery heat pump system concept resulting from the Phase I work is one of a mobile unit that would service multiple stationary adsoners. The NYS study showed that a large percentage of solvent recovery applications within the state can be serviced by on-site carbon bed adsorbers that are desorbed at frequencies ranging from once per day to once per month. In this way, many users can effectively "share" the substantial capital investment associated with the system's reverse Brayton hardware, providing it can be packaged as a mobile unit (see Figure S-1).

In a typical operating scenario, a carbon adsorption rnodule will be located permanently at the industrial site. The SLA will be ducted through the adsorber and the solvents removed, thus eliminating an air emission problem. Prior to VOC breakthrough, by schedule or by request, the mobile unit would arrive at the site to recover the concentrated solvent. An engine driven, natural gas fueled systern, the mobile unit utilizes conditioned engine exhaust gases as the inert gas for desorption. Hot inert gas is directed through the carbon bed, heating it and volatilizing the adsorbed solvent. Using a reverse Brayton-cycle refrigeration system to create low temperatures, the solvent vapors are condensed and collected from the inert gas stream. The solvent can then be recycled to the production process or sold for other uses and the adsorber returned to service.

The Brayton-cycle turbomachine, a key subsystem of the mobile unit, is discussed in detail in Sections 3.0 and 4.0. The integrated machinery approach emphasizes reliability and cost reduction through reduced compiexity (fewer parts), elimination of wearprone parts (gears and seals), and the use of proven components in critical service (bearings, aerodynamic components, and motor).

MTI has conducted an extensive review of solvent recovery applications in NYS using a data base compiled for this project from a NYS Department of Environmental Conservation (DEC) data base. The DEC data base contains 65,000 emission points taken from 


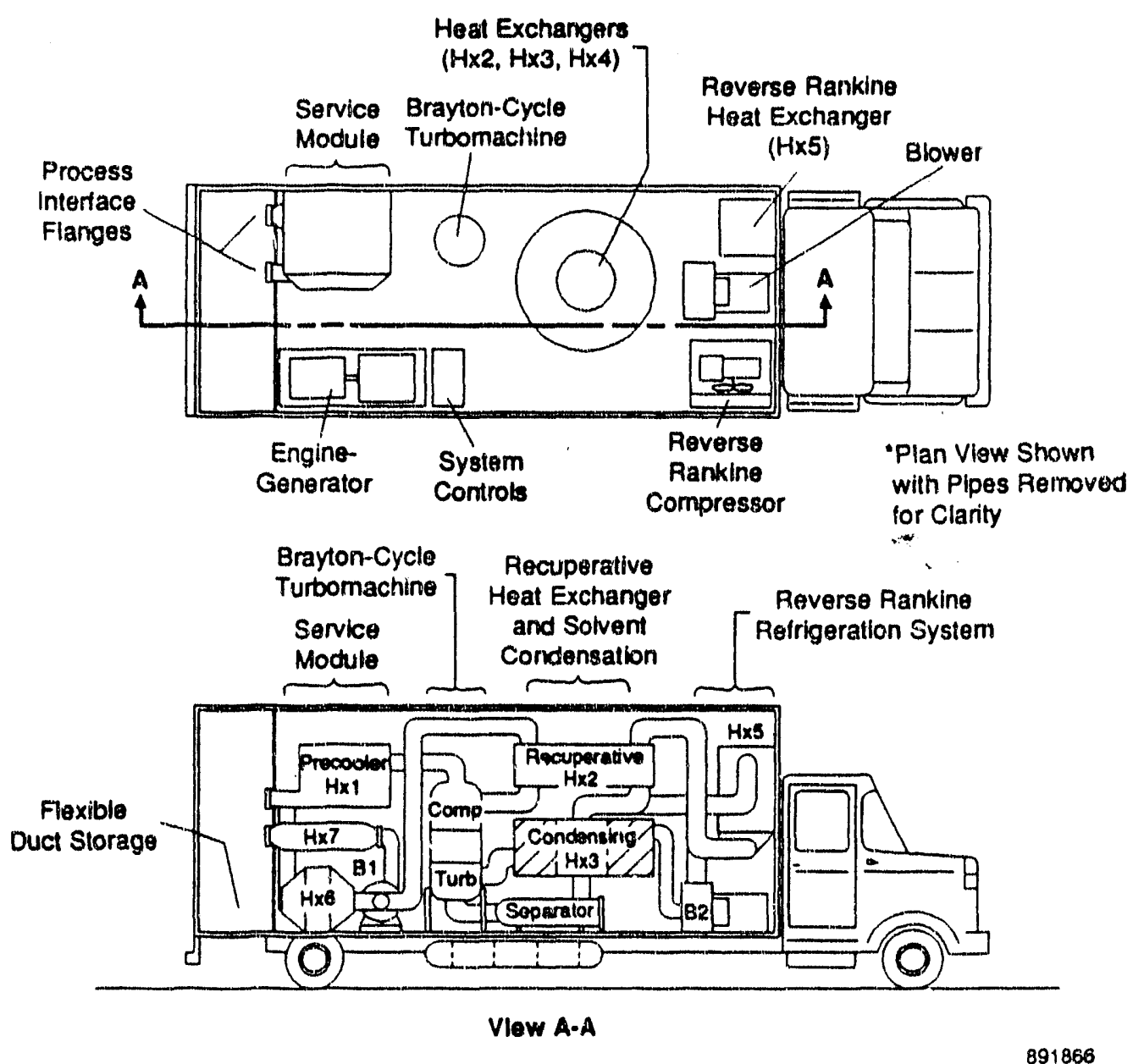

Figure S-1. Solvent Recovery Heat Pump System: Design Concept for Mobile Unit

air quality permit applications and includes many that are not applicable to solvent recovery. By applying relevant sort criteria, a smaller, more germane data base was generated and used for the study and preliminary identification of host site candidates. Results of the study indicated an extensive need for solvent recovery and reuse as the state and nation enter an era of increasing concern for the environment. The study identified two areas that will need to be addressed in the near term: moderate-sized emission strearns that cannot fully utilize a dedicated recovery system, and emission streams in the lower concentration range of less than $200 \mathrm{ppm}$. The mobile unit described above addresses both of these future needs.

The NYS applications study revealed that as regulations are made more stringent there will be an increasing need for solvent recovery technologies that are not economically feasible today. Existing solvent recovery techniques require substantial capital investment and have a poor return in terms of the value of solvemt recovered. Therefore, industry and the small- to medium-sized company in particular will not adopt these measures until regulated to do so and then only at significant risk to their financial health. A second 
area in need of new recovery technology is that of low concentration emissions. In the past, these have been viewed as insignificant on a local basis. Now it is recognized that the bing-term cumulative effect of these sources is a global problem, and regulations are moving in this direction. The only current technology that can effectively remove solvents in concentrations below $200 \mathrm{ppm}$ is adsorption. However, here again, the cost has been prohibitively high for most large streams.

The MTI mobile unit concept offers a new approach to these two problems and specifically addresses the economic feasibility issue. The mobile unit can be provided on a fee-for-service basis to the small- and medium-sized user who could not afford to purchase the complete system. The combination of dedicated and mobile plants provides the potential for wide-spread utilization to achieve a favorable energy and environmental impact for the nation. 


\section{TABLE OF CONTENTS}

SECTION

PAGE

EXECUTIVE SUMMARY $\ldots \ldots \ldots \ldots \ldots \ldots \ldots \ldots \ldots \ldots \ldots \ldots \ldots \ldots$

LIST OF FIGURES $\ldots \ldots \ldots \ldots \ldots \ldots \ldots \ldots \ldots \ldots \ldots \ldots \ldots \ldots \ldots \ldots \ldots$

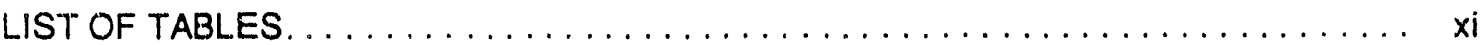

1.0 INTRODUCTION ................................ 1-1

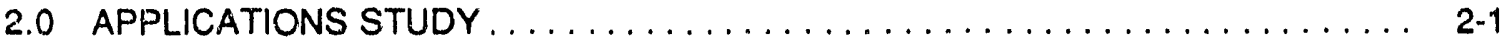

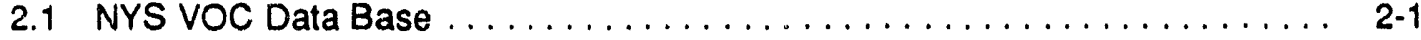

2.1 .1 Key Process Groups . . . . . . . . . . . . . . . . . . . . 2-4

2.2 Applications Selection Criteria . . . . . . . . . . . . . . . . . . . . . . 2-6

2.3 Host Site Candidates . . . . . . . . . . . . . . . . . . . . . . . . $2-6$

3.0 TURBOMACHINE DESIGN BASIS $\ldots \ldots \ldots \ldots \ldots \ldots \ldots \ldots \ldots \ldots \ldots \ldots \ldots$

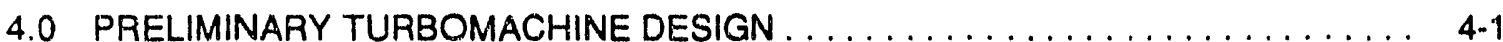

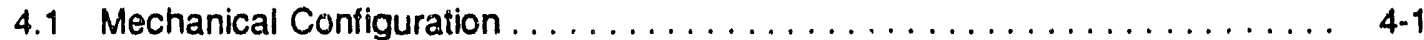

4.2 Preliminary Layout . . . . . . . . . . . . . . . . . . . . . . . . . 4-2

4.3 Turbomachine Performance ........................ 4-5

4.4 Gas Bearing System. . . . . . . . . . . . . . . . . . . . . . 4.8

4.4.1 Gas Bearing Theory. . . . . . . . . . . . . . . . . . . . . 4-8

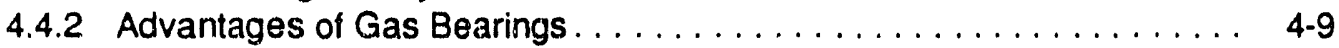

4.4 .3 Design Parameters . . . . . . . . . . . . . . . . . . . . . . . . 4-11

4.4.4 Selection of Bearing Configurations and Load Analysis . . . . . . . . . . 4-11

4.4 .5 Frictional Power Losses. . . . . . . . . . . . . . . . . . . . . 4.13

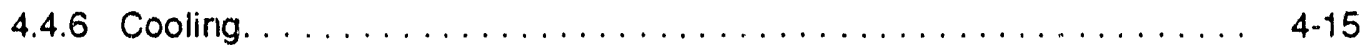

4.4 .7 Coatings . . . . . . . . . . . . . . . . . . . . . . 4-16

4.4 .8 Issues for Final Design $\ldots \ldots \ldots \ldots \ldots \ldots \ldots \ldots \ldots \ldots \ldots$

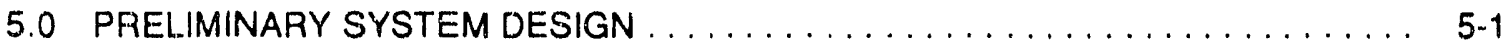

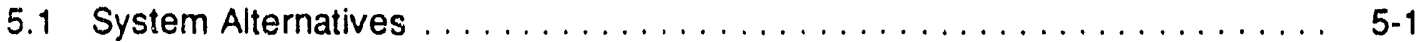

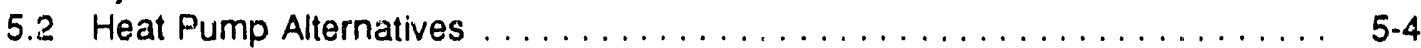

5.2.1 Electric versus Thermal Engine-Driven Systems . . . . . . . . . . . . . . . 5-5

5.2.2 Multiple-Level versus Single-Level Refrigeration Systems . . . . . . . . . 5-5

5.3 Process Flow Diagram . . . . . . . . . . . . . . . . . . . . . . . . . 5-9

5.4 System Simulation Model . . . . . . . . . . . . . . . . . . . . . . . . $5-10$

5.4 .1 Performance ............................ $5-12$

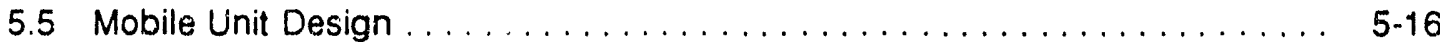

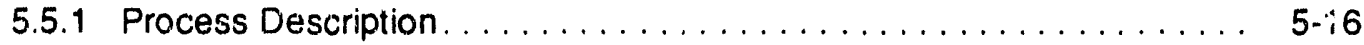

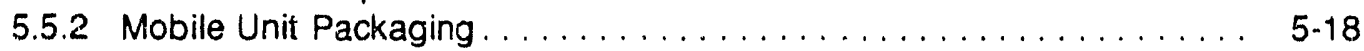

5.5 .3 System Controls. . . . . . . . . . . . . . . . . . . . . . . 5-19

5.6 Balance of Plant Equipment . . . . . . . . . . . . . . . . . . . . . . . . . 5-19

5.6.1 Reverse Rankine Refrigeration System. . . . . . . . . . . . . . . . . . . . . . 5-29

5.6 .2 Service Module Equiprnent . . . . . . . . . . . . . . . . . . . . . . . . 5-29

5.6.3 Recuperative Heat Exchanger and Solvent Condensation Module . . . . 5-31 


\section{TABLE OF CONTENTS (continued)}

SECTION PAGE
PAT

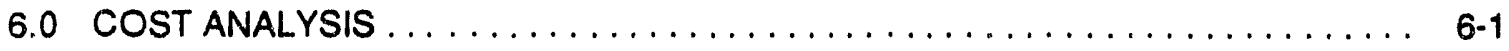

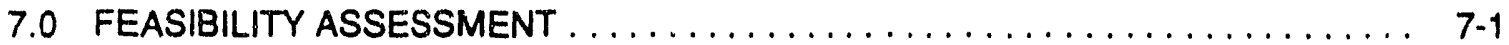

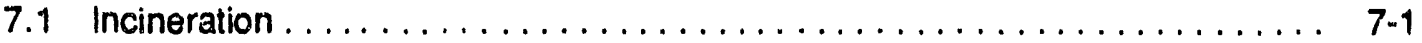

7.1.1 Thermal Incineration ........................ $7-2$

7.1 .2 Catalytic Incineration ............................. $7-3$

7.2 Conventional Condensation Technology .................... $7-4$

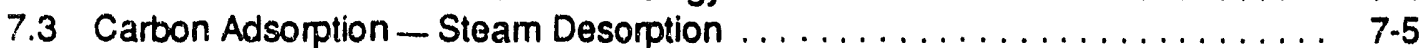

8.0 MARKET ASSESSMENT $\ldots \ldots \ldots \ldots \ldots \ldots \ldots \ldots \ldots \ldots \ldots \ldots \ldots \ldots \ldots . \ldots \ldots$

8.1 Multipliers . . . . . . . . . . . . .

8.2 Urgency of RD\&D Program. . . . . . . .

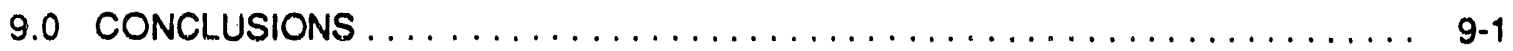


2-1

2-2

3-1

3-2

3-3

4-1

4-2

4-3

4-4

4.5

4-6

4-7

4-8

$4-9$

4-10

5-1

$5-2$

5-3

5-4

5-5

5-6

$5-7$

$5-8$

5-9

5-10

5-11

5-12

$5 \cdot 13$

5-14

5-15

5-16

$5-17$

$5-18$

$5-19$

$6-1$

$6-2$

$7 \cdot 1$

$7-2$

$7-3$

$8-1$

SLA Flow Rates for NYS Emission Points $\ldots \ldots \ldots \ldots \ldots \ldots \ldots \ldots$ Control Technology Breakdown for NYS Emission Points . . . . . . . . . . . Baseline Solvent Recovery Heat Pump Schematic . . . . . . . . . . . . . Relationship Between Tasks of Phase I Design Effort . . . . . . . . . . . . . Relationship Between Turbomachine Speed and Flow for Various

System Pressure Ratios ........................... $3-4$

Turbomachine Critical Speed Map . . . . . . . . . . . . . . . . . 4-2

Cross Section of Preliminary Layout of Brayton-Cycle Turbomachine . . . . . . 4 4-3

Turbine End Labyrinth Seal Arrangement. . . . . . . . . . . . . . . . . . . 4-4

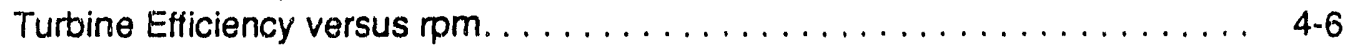

Compressor Performance Map. . . . . . . . . . . . . . . . . . . . . . 4.7

Load Support for Journal and Thrust Bearings. . . . . . . . . . . . . . . 4-9

The MTI Hydresil' ${ }^{T M}$ Compliant Foil-Type Air Bearing . . . . . . . . . . . . . 4-10

Preliminary Concept for Foil Journal Bearing (Compressor End) . . . . . . . . . . 4-12

Preliminary Concept for Foil Thrust Bearings ..................... 4-14

Foil Thrust Bearing: Operating Gas Film Thickness as a Function of Load . . . 4-14

Solvent Recovery Heat Pump System Used with Molecular Sieve

VOC Solvent . . . . . . . . . . . . . . . . . . . . . . . . . . . $5-2$

Solvent Recovery Heat Pump System Used for Carbon Bed Desorption. . . . . . 5-3

Comparison of Electric versus Thermal Engine-Driven Systems . . . . . . . . 5 5-6 .

Brayton-Cycle Pressure Ratio versus Inlet Concentration of Methylene

Chloride Solvent. . . . . . . . . . . . . . . . . . . . . . . 5-7

Comparison of Refrigeration Cycle . . . . . . . . . . . . . . . . . . 5-8

Process Flow Schematic of Solvent Recovery Heat Pump System . . . . . . . . 5 5-9

Schematic of Combined Brayton-Rankine Process Model . . . . . . . . . . . . . . 5-12

System Performance for Methylene Chloride . . . . . . . . . . . . . . . . . . 5-13

System Performance for Toluene . . . . . . . . . . . . . . . . . . . . . . . . . . 5-13

System Performance for Acetone . . . . . . . . . . . . . . . . . . . . . . . . . 5.14

System Performance for Tetrahydrofuran. . . . . . . . . . . . . . . . 5-14

System Performance for Trichloroethylene. . . . . . . . . . . . . . . . 5 5-15

System Performance for Perchloroethylene . . . . . . . . . . . . . . . . . 5-15

System Performance for Methyl Ethyl Ketone . . . . . . . . . . . . . . . . . 5 5-16

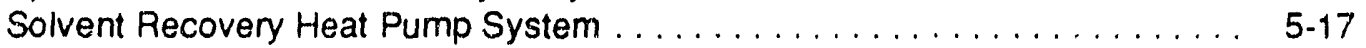

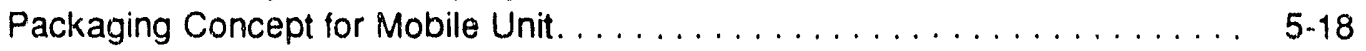

System Piping and Instrumentation Schematic . . . . . . . . . . . . . 5-20

System Operating Logic Diagram. . . . . . . . . . . . . . . . . . . . . 5-21

Power Supply System. . . . . . . . . . . . . . . . . . . . . . 5-30

Turbomachine cost in Production Quantities . . . . . . . . . . . . . . . 6-2

Production Unit Cost versus Capacity . . . . . . . . . . . . . . . . 6-2

Thermal Incineration with Primary Heat Recovery . . . . . . . . . . . . . . . $7-2$

Catalytic Incineration with Primary Heat Source . . . . . . . . . . . . . . . 7-3

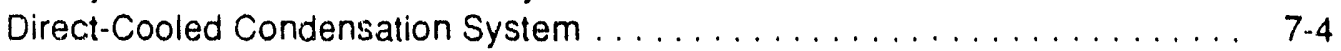

Principal Market Areas . . . . . . . . . . . . . . . . . . . . . . . . . . . . 8-2 


\section{LIST OF TABLES}

NUMBER

PAGE

2-1 Solvents Used for Screening the DEC Data Base $\ldots \ldots \ldots \ldots \ldots \ldots \ldots \ldots$ 2-2

$2-2$ Solvent Emissions in New York State........................ 2-3

2-3 Summary of Companies Screened as Host Site Candidates ........... 2-6

2-4 Host Site Candidates ............................. 2-8

3-1 Brayton-Cycle Turbomachine Operational Envelope .............. 3-5

4-1 Performance at Nominal Design Conditions . . . . . . . . . . . . . . . .

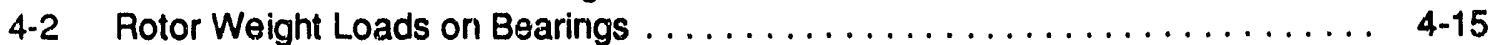

5-1 Optimized Brayton-Cycle Heat Pump Applications ............... 5-4

5-2 Baseline Process Conditions ......................... 5-11

5-3 Thermal Duties and Performance of Heat Exchanger and

Separation Equipment .......................... $5-31$

5-4 Data Sheet for Precooler Heat Exchanger $(H \times 1) \ldots \ldots \ldots \ldots \ldots \ldots \ldots \ldots . \quad 5-32$

5-5 Data Sheet for Aftercooler Heat Exchanger (HX2) . . . . . . . . . . . 5-33

5-6 Data Sheet for Recuperative Condenser Heat Exchanger $(\mathrm{H} \times 3) \ldots \ldots \ldots \ldots .5$. . . . . .

5-7 Data Sheet for Recuperative Condenser Heat Exchanger $(\mathrm{HX} 4) \ldots \ldots \ldots \ldots$. . . . . . . . .

6-1 Preliminary Production System Cost Estimate . . . . . . . . . . . . . . . . 6-1

$7-1$ Estimated Incinerator Costs .......................... $7-3$

7-2 Cost of Carbon Adsorption Systems, Not Installed............... 7.5

8.1 Annual Emissions in Selected States . . . . . . . . . . . . . 


\subsection{INTRODUCTION}

This report describes the results of the Phase I preliminary design and economic evaluation for an advanced heat pump for recovery of volatile organic compounds from process gas streams. The overall objective of the project is to design, build, install, and field test a system that is economically attractive to the user and will result in widespread utilization. The project consists of the following three phases:

Phase I - Preliminary Design and Economic Evaluation (This phase is reported herein)

Phase II - Final Design, Fabrication, and Performance Testing

Phase III - Industrial Installation and Operational Evaluation.

The Phase I report is structured as follows. Section 2.0 discusses the results of the New York State application study and the selection of host site candidates. Sections 3.0, 4.0, and 5.0, document the preliminary design concept and provide background analysis and trade-off studies that preceded the design conclusions. Section 6.0 presents cost information for the turbomachine and the system.

Section 7.0 describes altemative methods of emission control and solvent recovery for comparison to the Brayton cycle. Risks and benefits of the system are also discussed in this section. Section 8.0 projects the national market for the proposed solvent recovery system based on the New York State application work. Section 9.0 presents the conclusions and recommendations for Phase $\mathrm{I}$. 


\subsection{APPLICATIONS STUDY}

VOCs are used as solvents in many of the following processes and industries:

- Coating processes such as painting, tape and film manufacturing, printing, and textile manufacturing

- Cleaning processes such as manufacture of printed circuit boards, electronic parts, mechanical parts, and textiles

- Production of polymeric materials such as plastics and rubber

- Fuel production and distribution

- Foam blowing

- Production and use of refrigerants

- Manufacture of wood products such as plywsod, particle board, and furniture.

In many processes, the solvent ends its cycle as a vapor component in a warm air stream. Until recently, the majority of these SLA streams were unregulated and often subject to uncontrolied release to the atmosphere. With increasing concern for the environment, associated with the greenhouse effect and the ozone layer depletion, regulations are becoming more stringent. The changing regulatory environment has left manufacturers with three choices:

- Eliminate organic and halogenated organic solvents from the process

- Incinerate solvents before release

- Recover solvents from the SLA and recycle them to the process.

Elimination of solvents is the preferred solution if it can be done without a deleterious effect on product quality. Incineration is not a long-term solution, since it simply substitutes one regulated emission for another that would soon be regulated. Due to new emission regulations anticipated for the future, the recovery and recycling of solvents is expected to play a larger role for those industries with VOC emissions. Recovery of solvents can be accomplished by direct condensation by air, water, reverse Rankine or Brayton cycle, or by carbon desorption using steam or inert gas. Each recovery process has its range of application, as well as advantages and disadvantages. The applications study summarized herein, which is based on NYS data, had two purposes: to characterize the solvent recovery needs of NYS manufacturers, and to identify field test sites for the first unit.

\subsection{NYS VOC Data Base}

In cooperation with DOE, the New York Slate Energy Research and Development Authority (NYSERDA) funded a study to characterize the solvent recovery needs of NYS. A full report on this study will be available from NYSERDA; a summary of the results is presented below.

Several sources of information were investigated to identify solvent emission sources within the state. Federal data bases, such as the U.S. Environmental Protection 
Agency Background Information Documents and the Toxic Release Inventory, were found to break the solvent emissions into broad groups, states, or regions (for example, the Now England region), but provided no insight into individual emission sources.

MTI then focused the search on NYS, which led to the New York State Department of Environmental Conservation and their data base of 65,000 emission points. These 65,000 emission points are based on air quality permit applications and represent all emissions into the atmosphere, whether organic solvents, hydrocarbons, or products of combustion. In order to limit the search to solvents of interest, the data base was queried for emission sources involving 26 specific solvents in large-scale use (see Table 2-1 for a listing of these solvents).

Table 2-1. Solvents Used for Screening the DEC Data Base

\begin{tabular}{|l|l|}
\hline Ethanol & Butane Acetate \\
Methanol & Xylene \\
Isopropyl Alcohol & Naptha \\
Dimethyl Ketone & Butanol \\
$1,1,2-$ Trichloro $-1,2,2-$ Trifluoro & Ethane \\
Ethane (Freon 11) & Dichloromethane \\
Methyl Ethyl Ketone (MEK) & Trichloroethylene \\
$1,2-$ Ethane Diol (Ethylene Glycol) & Ceilosolve \\
Methyl Isobutyl Ketone (MIBK) & Ethyl Acetate \\
Toluene & Ligroine (Mineral Spirits) \\
Tetrahydrofuran & Glycol Monobutyl Ether \\
Cyclohexanone & \\
Hexane & \\
Acetone & \\
Perchloroethylene & \\
Heptane & \\
\hline
\end{tabular}

The resulting data base contains 207 companies operating 2318 solvent streams emitted to the atmosphere through 522 emission points. Thus, the typical atmospheric, emission point contains 4 or 5 different solvents. When an emission point included solvents in addition to those listed in Table 2-1, these were also included in the data base. The total emissions covered by the data base is $62 \times 10^{8} \mathrm{lb} / \mathrm{yr}$. The U.S. Toxic Release inventory shows about $68 \times 10^{6} \mathrm{lb} / \mathrm{yr}$ of organic and halogenated organics for NYS, indicating that the MTI VOC data base is in close agreement with the national figures. Exercising the data base provides an overview of the distribution of emission points in NYS by solvent type, SLA flow rates, and control technologies.

Table 2-2 lists the 30 solvents with the highest reported emissions in the MTI data base. It is notable that many of the top solvents, including the alcohols and ketones, have been identified as particularly suitable for recovery by the Brayton cycle. This is discussed in more detail in Section 2.2.

Figure 2-1 shows the distribution of emission points as a function of the total volume flow rate of the SLA. The emission points cover a wide range of volume flows, with nearly one-third having a volume flow of less than $2000 \mathrm{~cm}$ and one-quarter having volume flows over $10,000 \mathrm{ctm}$. 
Table 2-2. Solvent Emissions in New York State

\begin{tabular}{|c|c|}
\hline Solvent & $\mathbf{I b} / \mathbf{y r}$ \\
\hline $\begin{array}{l}\text { Methanol } \\
\text { Acetone } \\
\text { Methylene Chloride } \\
\text { Toluene } \\
\text { Ethanol } \\
\text { Xylene } \\
\text { Methyl Ethyl Ketone } \\
\text { Methyl Chlorotorm } \\
\text { Isopropyl Alcohol } \\
\text { Hexane } \\
\text { Ethyl Acetate } \\
\text { N-Heptane } \\
\text { Methyl Isobutyl } \\
\text { Trichloroethylene } \\
\text { Tetrachloroethylene } \\
\text { Propyl Acetate } \\
\text { Butyl Alcohol } \\
\text { Ligroine } \\
\text { Ethylene Glycol Monobutyl Ether } \\
\text { Propanol } \\
\text { Isopropyl Ether } \\
\text { Acetonitrile } \\
\text { Ethylene Glycol Monoethyl Ether } \\
\text { Naptha } \\
\text { Isoheptane } \\
\text { Butyl Acetate } \\
\text { Acetic Acid } \\
\text { Isopropyl Acetate } \\
\text { Tetrahydrofuran } \\
\text { Cyclohexanone }\end{array}$ & $\begin{array}{r}7,949,569 \\
6,529,591 \\
6,415,853 \\
5,483,914 \\
4,896,274 \\
3,081,882 \\
2,885,952 \\
2,614,476 \\
2,283,656 \\
2,170,324 \\
1,711,710 \\
1,707,647 \\
1,104,598 \\
1,087,505 \\
929,411 \\
700,137 \\
672,088 \\
635,059 \\
494,258 \\
450,464 \\
341,248 \\
355,462 \\
225,746 \\
214,742 \\
191,000 \\
190,436 \\
175,505 \\
144,865 \\
127,411 \\
100,988\end{array}$ \\
\hline Total & $55,851,771$ \\
\hline
\end{tabular}




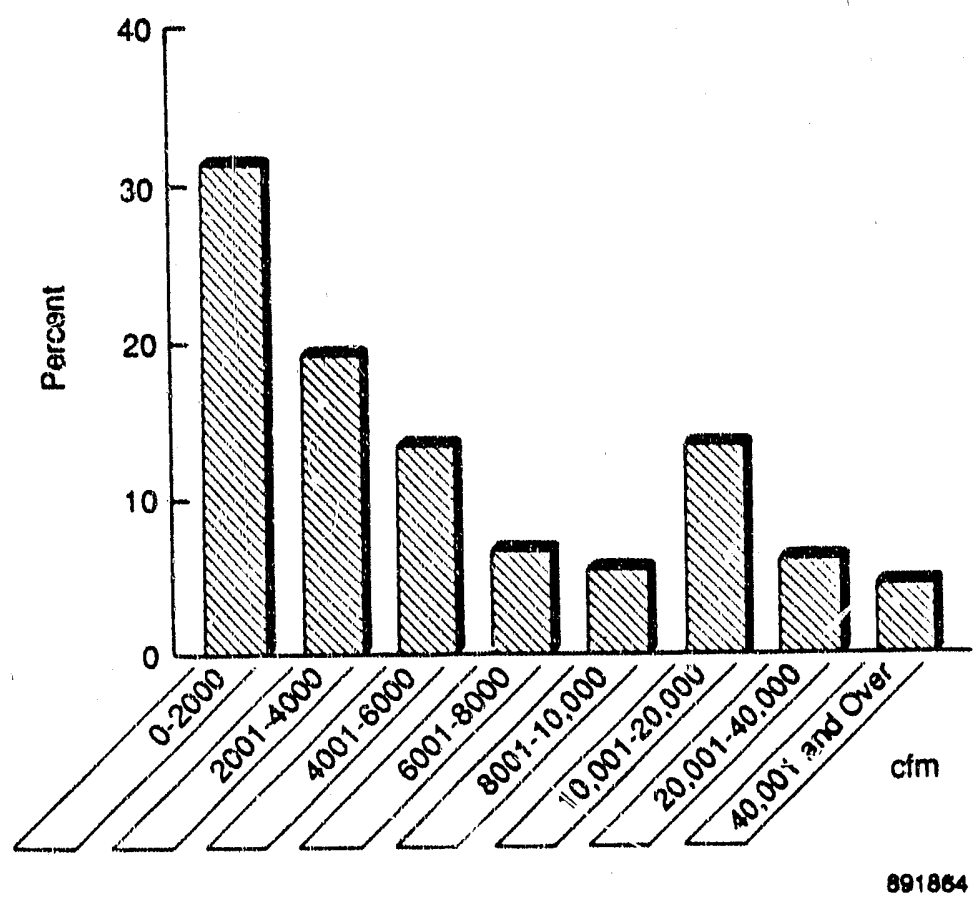

Figure 2.1. SLA Flow Rates for NYS Emission Points

The size of the MTI mobile unit was determined by commercially available comporients (see Section 3.0) and the technical market as depicted in Figure 2-1. With a carton adsorber, a 2500-cim turbomachine can be applied to a 10,000-cfm SLA stream. As shown in Figure 2-1, approximately $80 \%$ of the emission points are below $10,000 \mathrm{ctm}$ and, thus, would be covered by this machine.

Technologies for controlling organic, solvent emissions include carton bed adsorbers, vapor condensers, thermal incinerators, and scrubbers. According to the data base, only $10 \%$ of the emission points have any form of control. As shown in Figure 2-2, the most popular control technology is vapor condensers, followed by carbon bed adsorbers and thermal incineration. Nearly half of the emission points have a fan to assist in exhausting the solvent to the atmosphere. Fans are utilized to control solvent concentrations to a safe level ivithin a building but provide no control on global emissions. With $90 \%$ of VOCs being emitted without control, there will be a significant need for new control technologies as regulations become more stringent in the future.

\subsubsection{Key Process Groups}

Sorting the data base according to Standand industrial Classification (SIC) codes allows the key user groups in NYS to be identified. The results of this analysis are presented in Table 2-2 and can be further reduced to six key groups: photographic equipment and supplies, printing, chemicals, electronics, paper and fabric coating, and metal coating and cleaning. 


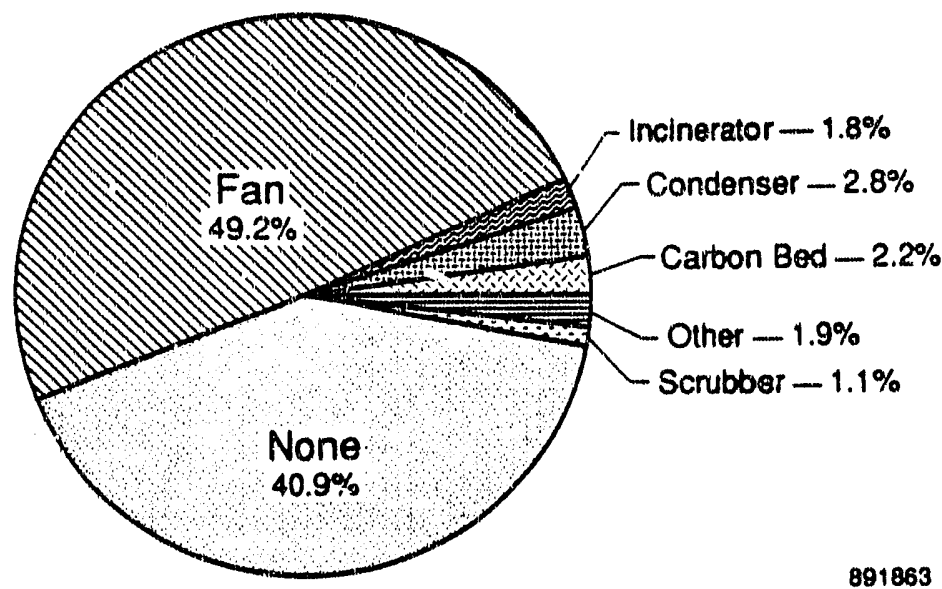

Figure 2-2. Control Technology. Breakdown for NYS Emission Points

Photographic equipment and processing suppliers in the state comprise the largest organic solvent user group. This industry, which uses a large variely of solvents, tends to operate their processes around the clock.

The printing industry (SIC codes 273, 275, 264, and 265) iricludes rotogravure and lithographic processes. The printing process utilizes a mixture of solvents to provide good coverage of ink on the paper or fabric in order to prod!se bright, bold covers. The switch to water-based inks can have a ma;or effect on product quality and has only penetrated certain segments of the industry. A wide viriety of solvents are used, with the more popular including acetone, toluene, propyl acetate, methyl isobutyl, methanol, and $\epsilon$ thanol. Printing operations tend to operate around the clocik and have a high level of fugitive emissions due to their design and operating characteristics.

The chemical manufacturers comprise another key user group in NYS. Although many operate around the clock, some companies switch between batch processes according to market dernand. Thus, many solvents are utilized during the year, but the individual emissions are relatively small. Some basic processes operate continuously, and significant usage of acetone, toluene, methanol, and ethanol is observed.

Closely related to the New York chemical industry are the drug and pharmaceutical manufacturers. The general operating pattern of the drug manufacturers is a large number of small batch productions, each with its own unique solvent requirement. Because manufacturing tolerances are extremely tight in the drug business, the emission of solvents tends to be small. Therefore, while the drug manufacturers represent a significant number of emission points, they comprise a small amount of the total solvent emissions.

The final key user group are those industries that involve metal coating and cleaning. These include aerospace and automotive assembly operations, industrial equipment manulacturers, and fabricators. Popular solvents inciude trichloroethylene and tetrachloroethylene. Solvent usage in these industries is characterized by large dip lanks widely scattered throughout the manufacturing operation. Operating cycles are typically two shifts a day, five days a week. 


\subsection{Applications Selection Criteria}

The NYS applications data base created under the NYSERDA study provides a source of field test site candidates for the first unit. The following selection criteria have been defined to identify those processes best suited to the operating characteristics of the solvent recovery heat pump system designed under this project.

- Air flow rates: 500 - to 2500-acim direct condensation, 1000 to 40,000 acfm with concentrator.

- Concentrations: greater than 5000 ppmv (or $40 \%$ lower explosive limit (LEL)) direct condensation possible, less than $5000 \mathrm{ppmv}$ (or $40 \%$ LEL) concentrator required.

- Solvents: solvents that are difficult to recover by other methods were targeted for the Brayton cycle. The following were identified because they are miscible in water, require low condensing temperatures, or react negatively with carbon beds: ethanol, methanol, acetone, trichloroethylene, methylene chloride, methyl ethyl ketone, and naptha.

- Operating times: greater than $6000 \mathrm{hr}$ for direct condensation. This is not a limitation when a carbon concentrator is used in conjunction with a mobile desorption unit because the concentrator can be sized for the expected flow rate (pph) multiplied by operating hours and a normal period of desorption assignec. There may be a limitation on the length of time that certain solvents should sit in a carton bed, considering the reactions that may occur.

\subsection{Host Site Candidates}

Forty-five companies were contacted directly as part of the search for industrial host sites. Thity of these sites were selected by screening the applications data base for the selection criteria defined in the previous section. The balance either initiated the contact themselves or were selected based on newspaper accounts of large VOC emitters. Table 2-3 summarizes the responses received according to the representative process groups and provides some statistical information on the contacts made.

Table 2-3. Summary of Companies Screened as Host Site Candidates

\begin{tabular}{|c|c|c|c|c|c|c|c|c|}
\hline & $\begin{array}{l}\text { Photographlc } \\
\text { Equipment and } \\
\text { Supplies }\end{array}$ & Printing & $\begin{array}{l}\text { Paper and } \\
\text { Fabric } \\
\text { Coating }\end{array}$ & Chemicals & Electronics & $\begin{array}{c}\text { Matal } \\
\text { Coating and } \\
\text { Cleaning }\end{array}$ & Others & Total \\
\hline Sites Contacted & 2 & 10 & 7 & 5 & 3 & 9 & 9 & 45 \\
\hline Very Interestod & & 1 & 2 & & 1 & 2 & & 6 \\
\hline Interestod & 1 & 4 & 2 & & 2 & 3 & 1 & 13 \\
\hline Not Interested & 1 & 5 & 3 & 5 & & 4 & 8 & 26 \\
\hline Using Adsorption & & 1 & 1 & & 2 & 1 & & 5 \\
\hline Using Condensation & 1 & & 1 & & & & & 2 \\
\hline Using Incineration & & 4 & 3 & & & & & 7 \\
\hline Eliminating Organic Solvents & & 1 & & & & 1 & & 2 \\
\hline Flant Closing & & & 1 & 1 & & & & 2 \\
\hline Has Current Need & 1 & 3 & 3 & & 4 & 1 & & 12 \\
\hline
\end{tabular}


Following an initial phone call to obtain the name and address of the appropriate company representative, a letter describing the project and the solvent recovery heat purnp system was sent to 45 sites. Follow-up phone calls were made to gage the level of interest and obtain preliminary application intormation. Nineteen companies responded positively and openly discussed solvents used, emission levels, current control technologies, regulatory issues, and related topics. This high level of response to "cold phone contacts" indicates the priority that many of these companies are putting on VOC emissions. In large companies, several people will be dedicated to this area, and, even in small companies, specific individuals have been given responsibility for air quality issues.

The "not interested" category undoubtedly includes a considerable number of compa. nies who are dealing with the same emission issues as those who were interested but want to avoid public discussion of them. The following cases are representative of the contacts mado and serve to illustrate important issues highlighted by the study.

Low Concentration Emlssions. A number of sites were searching for an economical control technology for VOC emissions in concentrations below $100 \mathrm{ppm}$. These include streams from parts cleaning booths and room exhaust. While low in concentration, these sources often represent significant releases in terms of pounds per year and are currently receiving close scrutiny by government regulations. While carbon adsorption can clean up these streams, the cost is currently prohibitive in most cases.

Incineration. Several companies who were currently incinerating were interested in recovery technologies. Comments from these sources indicated that they recognized that incineration was not a long-term solution to air quality. Secondly, two users of catalytic oxidation were having problems with poisoning of the catalyst.

Solvent Substitutes. Water-based inks and cleaning agents are often cited as substitutes that may eliminate organic solvents in many processes. In fact, one printing company contacted had switched to water-based inks, and, in another case, a major radiator manufacturer was phasing out all organic solvents in favor of water-based cleaning processes. However, based on comments by these and other sites, the substitutes are expensive and can affect product quality. One printer of cereal boxes stated that the duller colors associated with water-based inks were not acceptable. The investment in new equipment to deliver the water-based inks is also : ignificant. This is even more true for the substitution of water-based cleaning agents, where, according to the radiator manufacturer, the cost in new equipment would be prohibitive for the small-or mediumsize manufacturing company.

Carbon Adsorption with Steam Desorption. The concept of inert gas desorption was very appealing to a number of carbon bed users, since it would eliminate the necessity of distilling the solvent. One company who was recovering R-113 by steam desorption was also interested in eliminating the contamination of the Freon by water, which can form acids.

Regulations. While a number of sites were feeling increasing concern about future regulation, most made it clear that little money would be spent to reduce current emissions until they were regulated to do so. 
Letters of intent were executed with three sites interested in the initial field tests. Most viewed this as a way to become familiar with a technology that might be needed in the future. The short list of host site candidates selected for DOE approval is presented in Tabio 2-4.

Table 2-4. Host Site Candidales

\begin{tabular}{|c|c|c|c|c|c|}
\hline Business & Solvents & $\begin{array}{l}\text { Emleslone } \\
\text { (Ib/yr) }\end{array}$ & $\begin{array}{l}\text { SLA Flow } \\
\text { (cfm) }\end{array}$ & $\begin{array}{l}\text { Approximate } \\
\text { Concentration } \\
\text { (ppmv) }\end{array}$ & $\begin{array}{l}\text { Uperating } \\
\text { Hours } \\
\text { Per Year }\end{array}$ \\
\hline Radiator Manufacturer & $\begin{array}{l}\text { VM\&P Naptha } \\
\text { TF R-113 }\end{array}$ & $\begin{array}{r}284,000 \\
56,000^{*}\end{array}$ & $\begin{array}{r}16,000 \\
600\end{array}$ & $\begin{array}{r}320 \\
3000\end{array}$ & $\begin{array}{l}4000 \\
4000\end{array}$ \\
\hline Textile Coating & $\begin{array}{l}\text { Mixture (55\% Toluene, 15\% Methyl } \\
\text { Ethyl Ketcone, 20\% Isopropyl Alcohol) }\end{array}$ & $1,200,000$ & 17,000 & 450 & 6000 \\
\hline Alurninum Extrusion Painting & $\begin{array}{l}\text { Mixture (X.ylene, Naptha, Toluene, } \\
\text { Butyl Cartitol) }\end{array}$ & 20,000 & 18,000 & Unknown & 2000 \\
\hline
\end{tabular}

- Currently being recovered by carbon bed steam desorption. Interested in inert gas desorption. 


\subsection{TURBOMACHINE DESIGN BASIS}

The objective of the Phase I design effort was to develop a commercially attractive, advanced heat pump for the recivery of industrial VOC solvents. To this end, MTI's technical approach was to improve upon existing Brayton-cycle solvent recovery technology via the implementation of a unique turbomachine design that offered significant advantages over previous hardware implementations of the Brayton cycle. These advantages include superior energy efficiency; installation flexibility (low weight, small size, and variable capacity); and lower installation, operating, and maintenance costs.

The unique turbomachine design developed by MTI features a high-speed electric motor, Brayton-cycle compressor and turbine on a common shaft supported by gas bearings. This single rotor machine reduces production costs by eliminating additional compressor stages, gearboxes, and oil lubrication systems. The use of gas bearings provides increased reliability with lower operating costs due to the reduced parasitic losses and maintenance requirements.

The advanced Brayton-cycle system incorporating the integrated turbocompressor is shown schematically in Figure 3-1. As shown, the SLA mixture from the process is first precooled to reduce compressor work. After exiting the compressor, the SLA mixture is sequentially cooled as it passes through a cooler, regenerator, and VOC condenser,

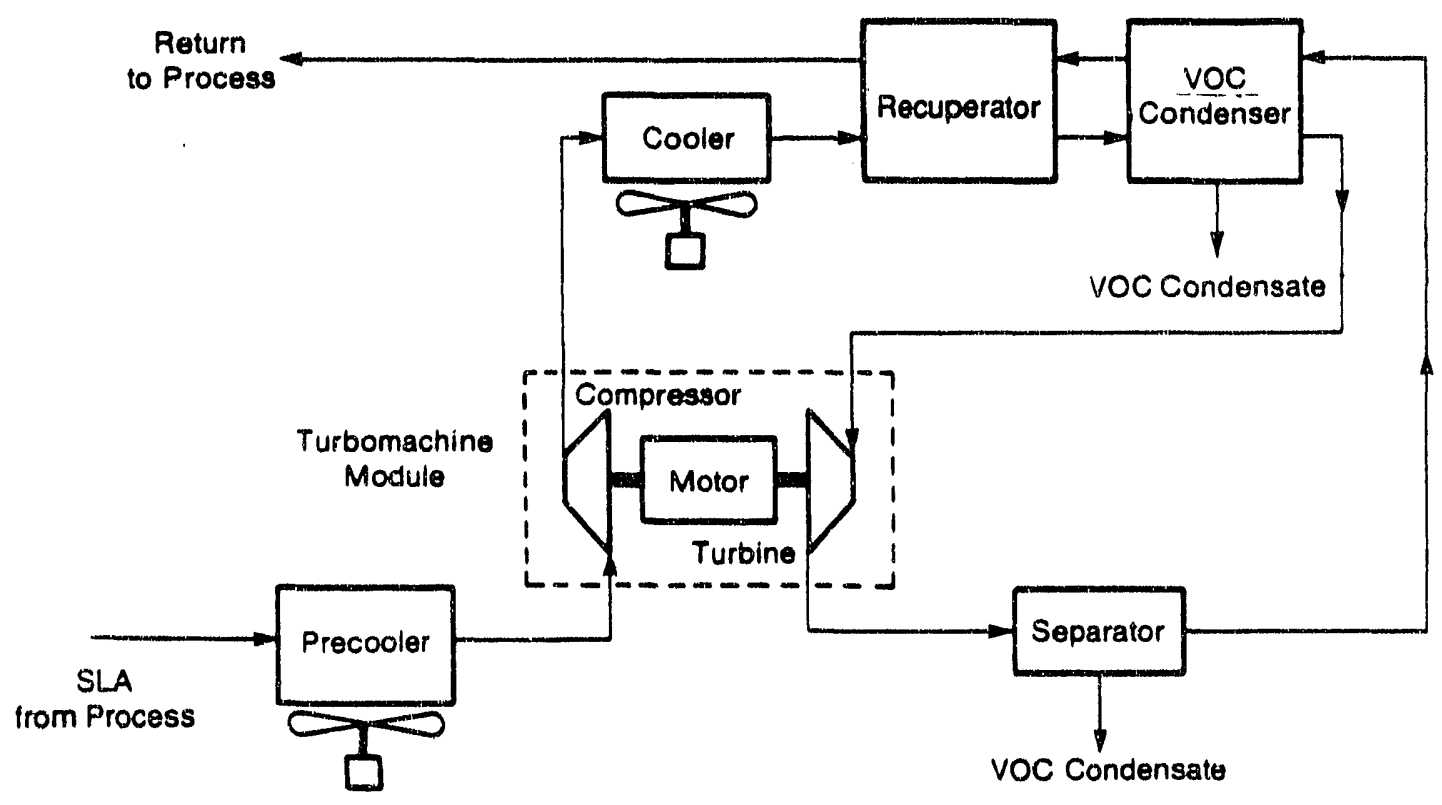

VOC $=$ Volatile Organic Compounds

$S L A=$ Solvent Laden Air

881283

Figure 3-1. Baseline Solvent Recovery Heat Pump Schematic 
such that the temperature drops below the dew point required to condense the solvent. The gases, which are still at elevated pressure, are then expanded through the turbine. This generates power to drive the compressor impeller, which is mounted on the same shaft. The expansion process lowers the temperature further, causing further condensation of the solvents. The condensed solvents are separated from the gas stream after exiting the turbine. The solvent-lean air is returned to the process through the regenerator, where a portion of its original heat content is restored. L.ocated between the turbine and the compressor, the motor provides the balance of the power required to drive the compressor.

Because the intent of the program was the near-term "productization" or commercialization of this equipment, the strategy was to develop the turbomachine using components of existing design and in production for other markets. This approach eliminates the significant development risk and cost that would otherwise have been spread over the relatively small number of units initially produced. Using this strategy, the turbomachine design procedure required the early establishment of the capabilities and limitations of existing key components, including compressors, turbines, and high-speed motors. It was also necessary to establish a model that could predict system performance using the performance characteristics of available component options. These tools were then used to establish an optimized turbomachine design that provided maximized performance and flexibility when combined with the balance of plant equipment for application to site-specific solvent recovery.

Figure 3-2 presents a flow chart depicting the relationships between the tasks of the Phase I design effort. As shown, the focal point was the establishment of the systern model that was used initially to evaluate component requirements. As the program progressed, this model was continually upgraded to reflect the performance of the system with the selection of specific components. This, in turn, allowed further refinement of the model and evaluation of system pertormance on applications. The system design guide, which supplied system definition and component specifications, was heavily dependent upon the use of this model.

Developed from the model output, Figure 3-3 shows the relationship between the optimum turbomachine speed and flow for a variety of system pressure ratios (PR). Because the temperature reached at the turbine outlet is dependent upon pressure ratio, the design requirements for a specific application define both the pressure ratio as well as system flow. These two criteria then established the required motor speed and horsepower based on optimal aero performance. Within this application envelope, the design basis for the turbomachine was most heavily influenced by the available performance in commercial high-speed motors. A variety of motor types were initially considered as candidates for iritegration with the existing aero components. The evaluation covered the complete envelope (50 to $400 \mathrm{hp}$ ) shown in Figure 3-3; however, the effort was focused on rnotors between 75 and $150 \mathrm{hp}$. This range was chosen because it was most compatible with available aerodynamic components.

The objective of the motor performance evaluation was to establish the relationship between performance, commercial availability, and cost for use in the optimization of the turbomachine design. To assist in this evaluation, consultants were used to extend the scope of the review beyond areas where MTI had design experience and expertise. The results of the motor evaluation were reported to DOE in MTI Report 89TR11 (Task 2.1, letter report). 


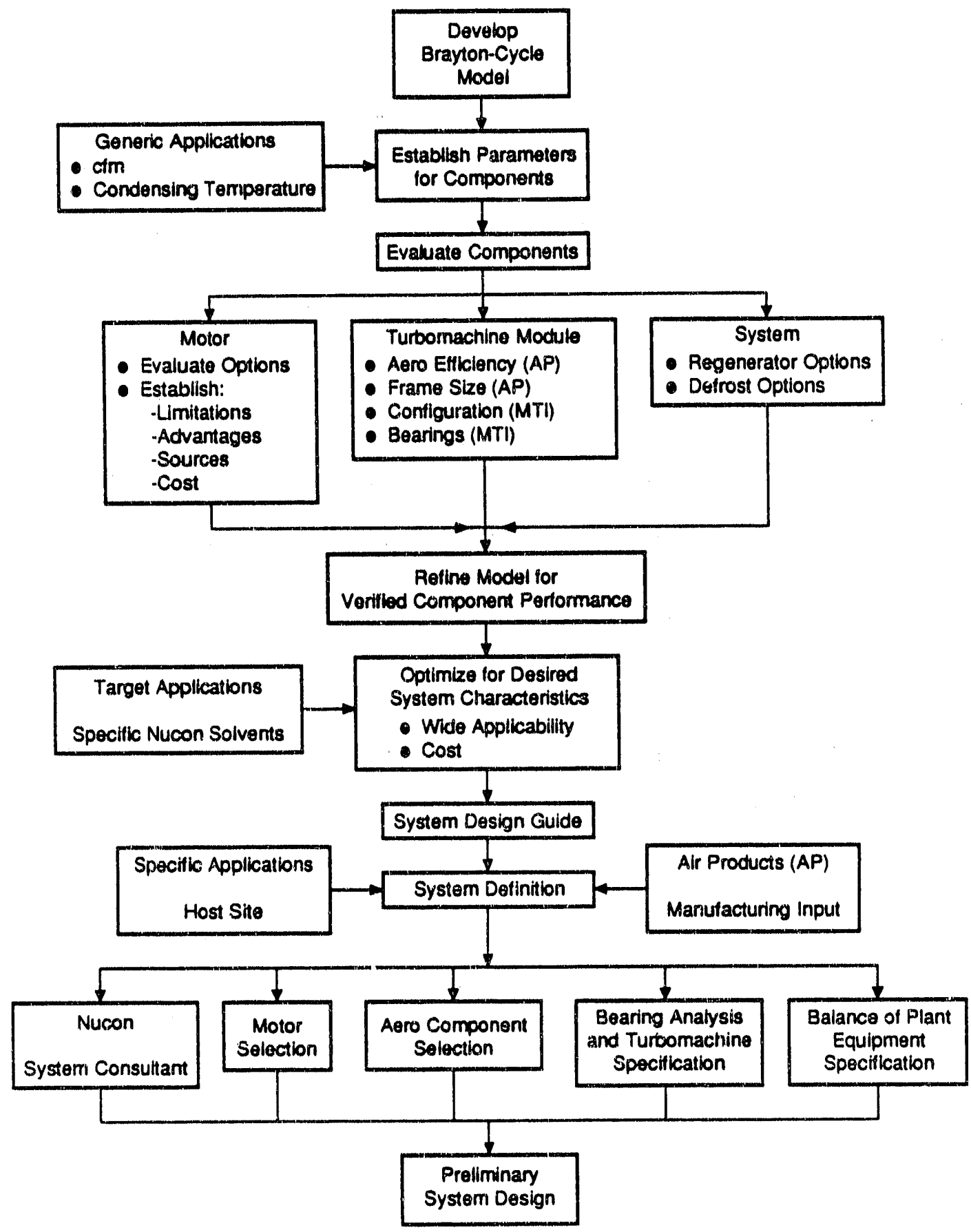

$891749(N)$

Figure 3-2. Relationship Between Tasks of Phase I Design Effort 


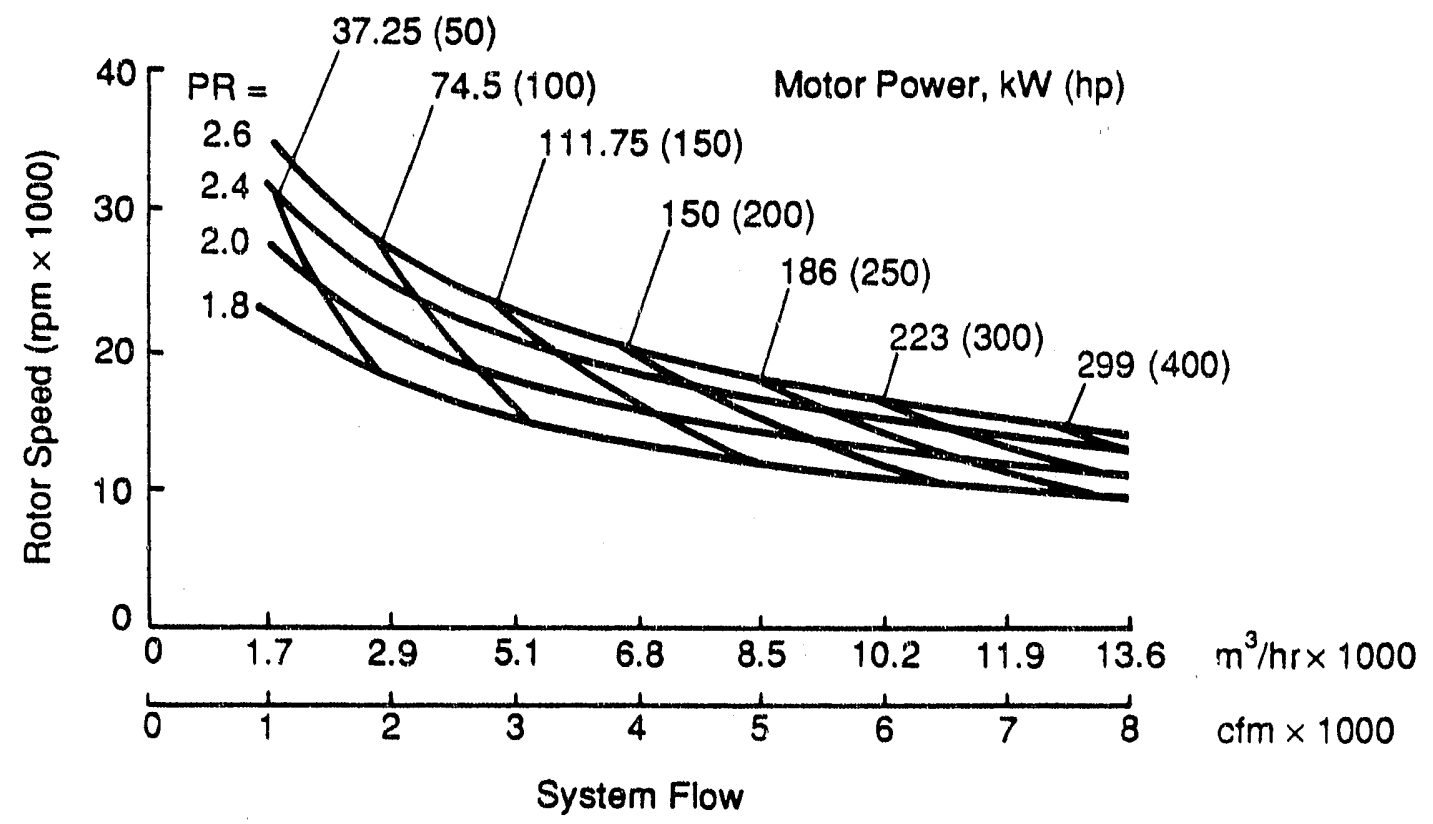

891800

Figure 3-3. Relationship Between Turbomachine Speed and Flow for Various System Pressure Ratios

The evaluation considered permanent magnet, synchronous, homopolar inductor, round rotor synchronous, and squirrel cage induction motor types. The report concluded that the squirrel cage induction motor offered the best capability of achieving the desired performance with an existing commercial offering. Also, in the event that enhanced performance was required, this motor type could achieve higher performance levels with minimum modification. The report further concluded that although the theoretical penformance of alternative motor types also met the requirements, their development cost far exceeded those of the squirrel cage induction motor.

The sizing of the Brayton-cycle turbomachine was established by overlaying the perfor. mance of existing Air Products and Chemicals Incorporated (AP) compressor and turbine designs with the performance of a commercially available squirrel cage induction motor. It was found that a good performance match existed between the motor and existing aero hardware at system flows ranging downward from $2600 \mathrm{cfm}$ and compressor pressure ratios of 2.5 and below. Higher flows and pressure ratios would require scaleup of the aero hardware or implementation of a more costly, nonstandard, solidrotor design rather than the "off-the-shelf" laminated induction rotor.

The selection of the design flow rate for the Brayton-cycle turbomachine was also influenced by the results of the NYS application survey. As described in Section 2.0, this survey showed that the predorninance of the solvent recovery applications in NYS existed at low concentrations of VOC solvents and that these applications were not economically handled by Brayton-cycle technology without the use of a concentrating carbon bed adsorber. The design basis for the turbomachine developed under this 
project was established based on the fact that $2500 \mathrm{cfm}$ was the largest flow rate achievable with existing aero components combined with available motors. This flow rate was determined to be compatible with $80 \%$ of NYS application when combined with solvent concentrating adsorbers. The normal operational envelope of the Brayton-cycle turbomachine was then defined as shown in Table 3-1.

Table 3-1. Brayton-Cycle Turbomachine Operational Envelope

\begin{tabular}{|l|l|}
\hline Compressor Inlet Temperature & +90 to $+100^{\circ} \mathrm{F}$ \\
Turbine Inlet Temperature & +30 to $-60^{\circ} \mathrm{F}$ \\
Compressor Pressure Ratio & 2.1 to 2.4 \\
Operational Speed & $19,0001021,000 \mathrm{rpm}$ \\
Required Motor Horsepower & $10010140 \mathrm{hp}$ \\
Solvent Condensation (ir Turbine) & 0 to $3 \%$ (by Weight) \\
\hline
\end{tabular}




\subsection{PRELIMINARY TURBOMACHINE DESIGN}

This section describes the mechanical configuration, preliminary layout, and performance of the Brayton-cycle turbomachine. A detalled discussion of the gas bearing system design is also included.

\subsection{Mechanical Configuration}

Analysis showed that the use of available two-pole squirrel cage induction motor construction in the double-ended Brayton turbomachine tended to produce a flexible shaft rotor with the third critical (bending) speed near the desired operating point. The reason for this machinery rotordynamics problem was that the standard laminated rotor construction did not contribute significantly to the stiffness of the shaft.

The means available to increase the third critical speed of the operating range included:

- Reduce the weight

- Reduce the shaft length

- Increase the shaft diameter.

Corrosion resistance and material compatibility with a wide range of solvents at low cost was a design requirement. Therefore, it was determined that the machine design should include the heavier stainless steel impellers (more costly titanium and less corrosion resistant, less costly aluminum were considered as special-case alternatives). The design was therefore adjusted to achieve conservative rotordynamics using minimum shaft length and maximurn shaft diameter. This resulted in the selection of a four-pole motor design. At the same speed, the four-pole design requires twice the input frequency of a two-pole motor and tends to incur high stator iron-core losses. However, because of its superior flux utilization, the four-pole motor can accommodate a larger diameter shaft at the same power and speed rating.

Figure 4-1 is a critical speed map of the final rotor configuration with stainless steel impellers. As shown, the final design obtained a conservative $30 \%$ margin between the normal operating speed (approximately $20,000 \mathrm{~mm}$ ) and the third critical (bending) speed of $28,000 \mathrm{~mm}$. The shaft diameter required to achieve this margin was 3 in., with minimized shaft length allowances for seals, bearings, and active motor rotor length.

Although the relationship of operational speed to the first bending critical is primarily a function of rotor stiffness and is essentially constant, the relationship of operating speed to the first and second critical speeds (rigid body criticals) is primarily a function of bearing stiffness and thus a function of bearing type. For this reason, a compliant foil gaslubricated bearing system was selected. Ball and rolling element bearings have typical stiffnesses in the 1 to 3 million range. As shown on Figure 4-1, this would have posed potential problems with the first and second critical speeds. Also, with the 3 -in. shaft diameter required to achieve the third critical speed margin at the 20,000-rpm operating speed, rolling element bearing DN values exceeded 1.7 million, indicating a poor life expectancy with this bearing type. 


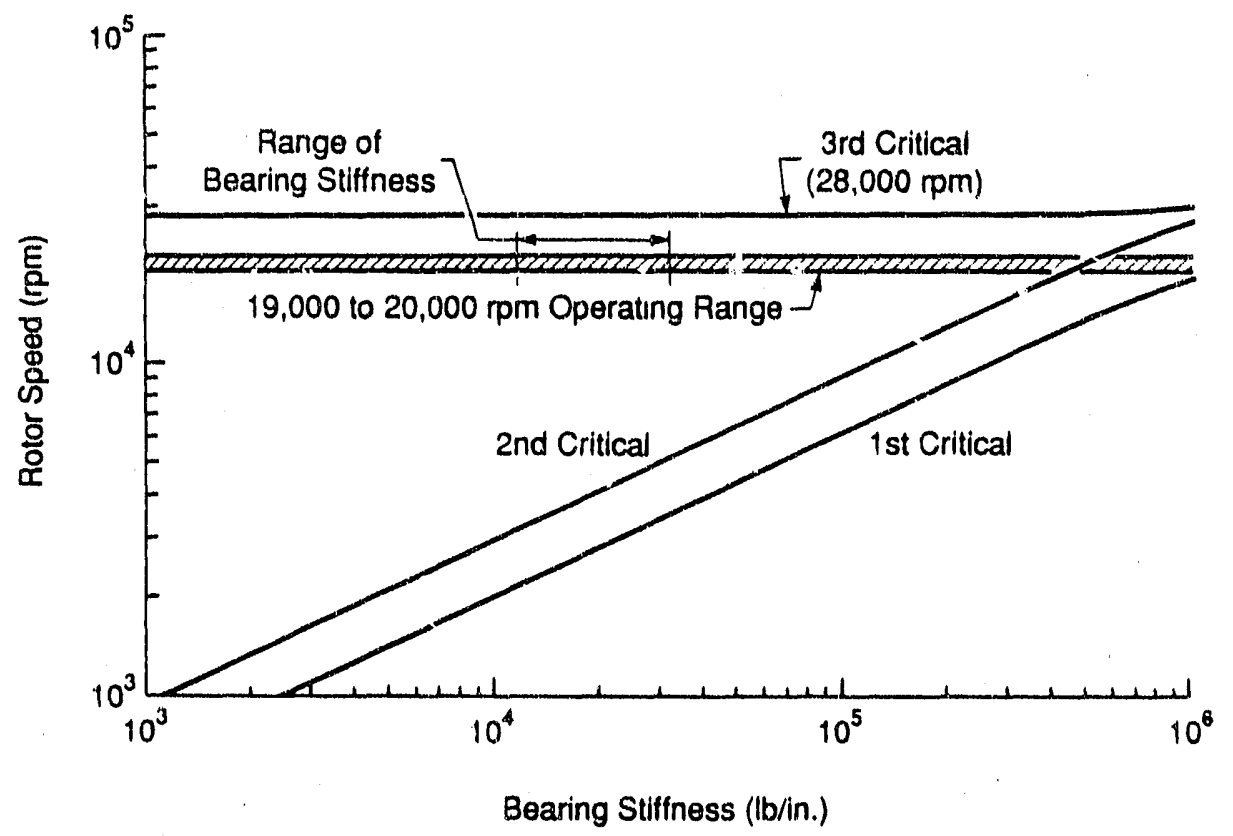

891823

Figure 4-1. Turbomachine Critical Spe日d Map

Oil-lubricated fluid-film bearings were evaluated and found to have a severe shortcoming in terms of power consumption. Because of the large shaft diameter, oil bearing losses would have added $27 \mathrm{~kW}$ to the motor requirement, which would otherwise require a $82-\mathrm{kW}$ drive for aerodynamic power consumption and other mechanical losses. Other shortcomings include more complex seal and oil and loop configurations.

\subsection{Preliminary Layout}

A cross-sectional view of the turbomachine assembly developed during Phase $I$ is presented in Figure 4-2. The machine is designed for vertical rotor operation with the turbine on the bottom. This design facilitates drainage of condensing solvent and allows the rotor weight to be offset by the upward aerodynamic forces developed by the compressor and turbine impellers.

The turbomachine design is based on an AP ETAC-9 "Compander," a single spindle, 9 -in. diameter turbine impeller driving a 13-in. diameter compressor. The compressor and turbine impellers are machined from one-piece castings. The impellers are attached to the high-speed rotor by a preloaded tie bolt and located relative to the shaft by axial and radial pilot surfaces. The impellers are first balanced as components, then trim balanced upon final assembly of the high-speed rotor.

For the solvent recovery application, machining of the "urbine impeller casting will be adjusted to provide an optimized flow cut for the design pressure ratio and flow. Combined with field-adjustable variable area nozzles (VANs), this flow cut achieves high turbine efficiency over the machine's anticipated operating range. With the exception of the turkine shroud and diffuser, which are modified to match the turbine impeller, the 


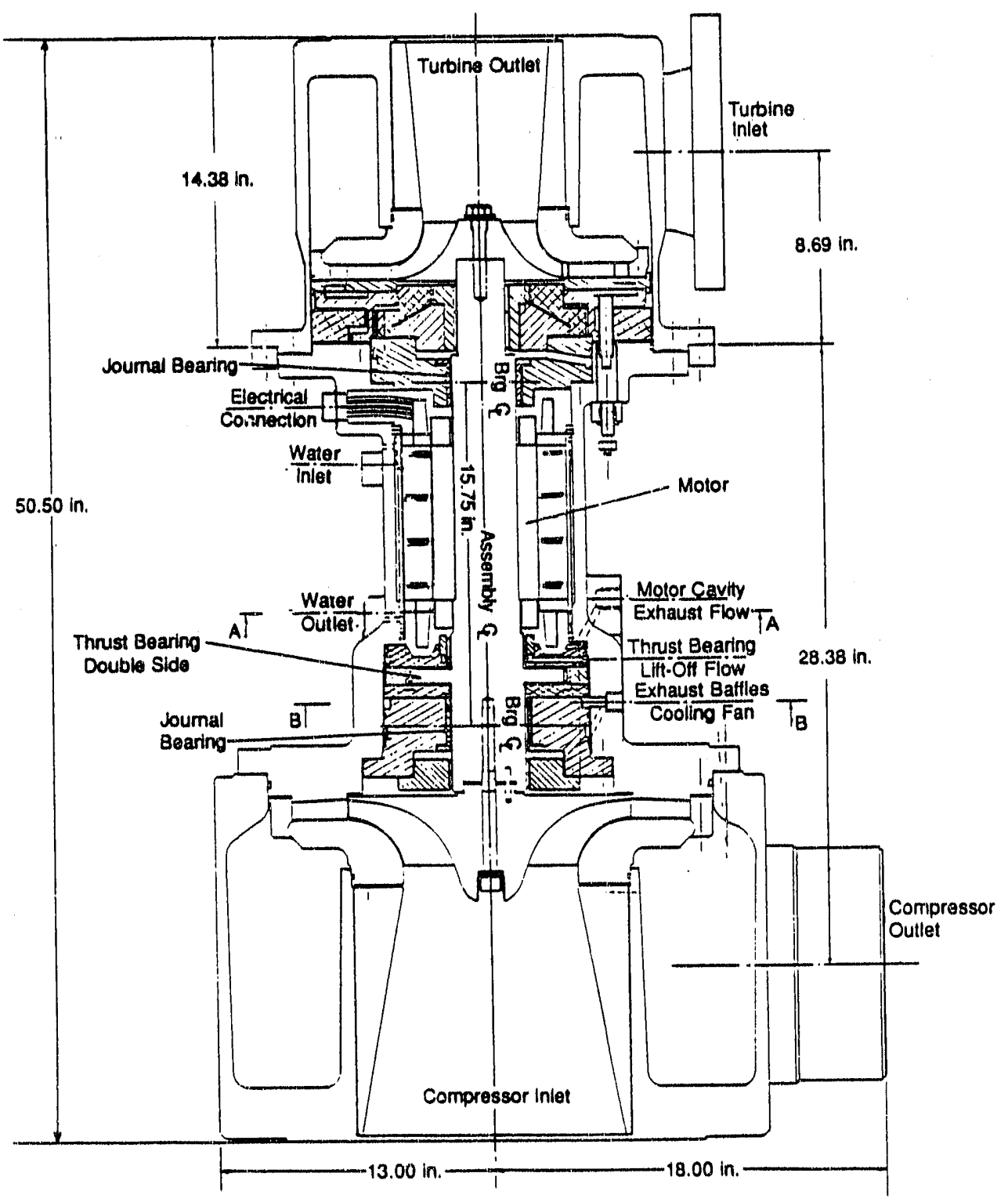

90157

Figure 4-2. Cross Section of Preliminary Layout of Brayton-Cycle Turbomachine 
balance of the aerodynamic components are anticipated to be used with little modification from the ETAC-9 design. This use of previously designed, manufactured, and performance-verified components benefited the turbomachine design effort, allowing a significant reduction in the efforts associated with stress and thermal analyses, as well as blade loading, vibration, and aerodynamic performance. Future benefits can also be expected in manufacturing due to the use of an existing design.

The compressor and turbine are separated from the bearing/motor cavity by noncontacting labyrinth seals. The motor cavity :s continually purged with dry air at low pressure. The flow path for the purged air allows the air to both purge and cool the gas bearings prior to exhausting to atmosphere in the labyrinth seals. On the compressor end, the seal consists of a double labyrinth seal with common intermediate vent for both motor and compressor ends. This vent flow is returned to the compressor inlet. On the turbine end, the labyrinth sealing arrangement consists of three labyrinth sections. In the first section, a buffer gas from the turbine inlet is heated and used to prevent icing of the turbine and seal (see Figure 4-3). In the second section, the heated gas enters the manifold between the turbine and seal and prevents solvents from entering. In the third section, on the bearing side of the buffer manifold, the seal arrangement is identical to that used on the compressor end. A double labyrinth seal with intermediate vent prevents solvent-contaminated air from entering the bearing/motor cavity and also provides an exhaust point for the low-pressure bearing/motor purge flow.

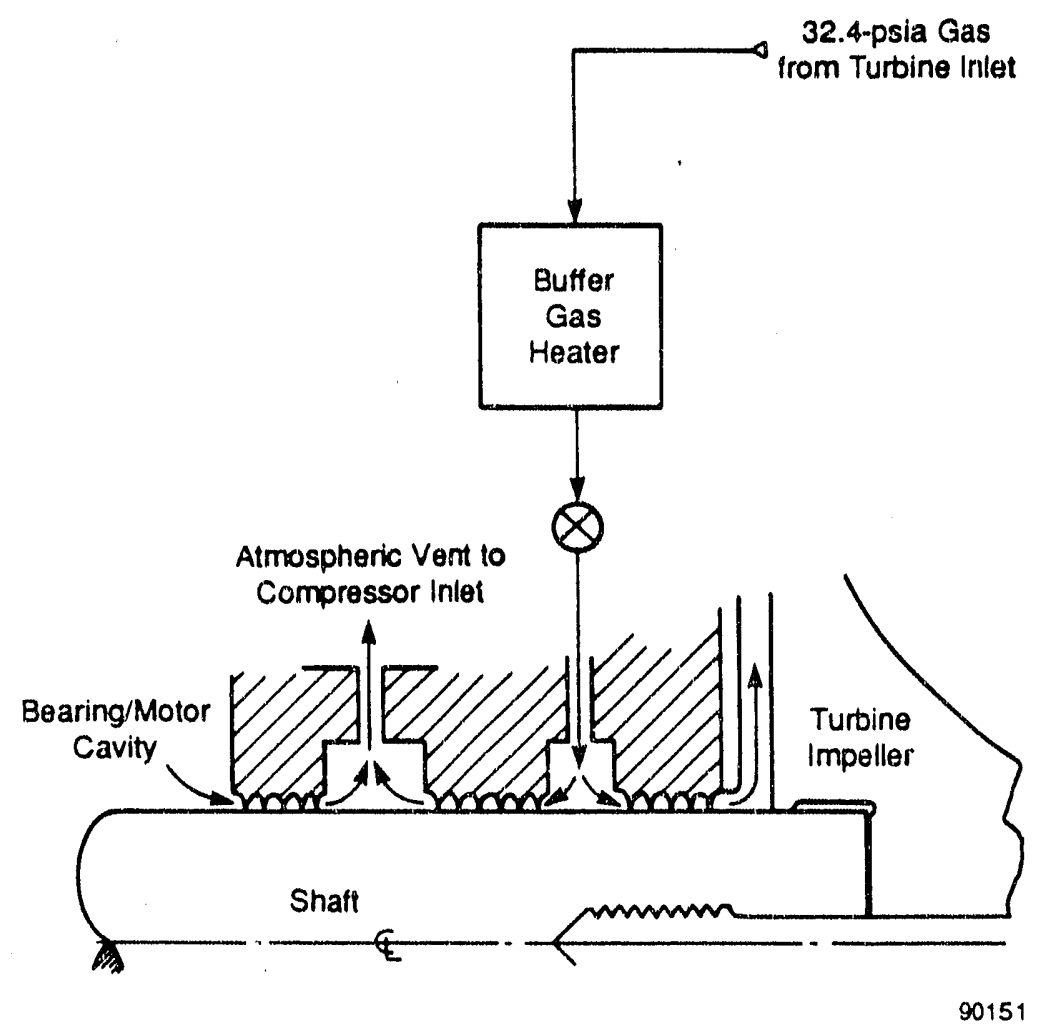

Figure 4-3. Turbine End Labyrinth Seal Arrangement 
The journal bearings are located directly inboard of the labyrinth seals and the doubleacting thrust bearing assembly is located at the compressor end (top ond) of the rotor. The thrust bearing has been designed for aerostatic thrust assist on rotor start and stop, which will eliminate wear in the absence of the aerodynamic film created during low-speed intor rotation. The design and operation of the gas bearing system is described in detail in Section 4.4.

The high-speed, squirrel cage induction motor is straddle mounted between the journal bearings. The selected motor is a commercially available, "partial motor" set consisting of two components: an electromagnetic stator and a laminated squirrel cage rotor. Motors of this type are frequently called shell-type motors and are manufactured for OEM applications such as machine tools, spindles, boring machines, routers, grinders, pumps, and compressors. The motor consists of an 8-in. diameter stator shell with special low loss, high silicon, electrical steel laminations. These thin laminations reduce the stator iron losses, which would otherwise be high at the 700-Hz input frequency. The stator shell contains a helical passage lor cooling water flow. Water cooling of the stator is necessary because of the high power density of the motor. This motor is approximately the same physical size as a 1750-rpm motor rated at $6 \mathrm{hp}$. Pertinent design parameters for the motor are:

- Motor type: Four-pole, squirrel cage induction

- Motor classitication: NEMA B design

- Starting torque: $120 \%$ full load

- Cooling: 13-gpm water at $100^{\circ} \mathrm{F}$ inlet

- Electrical: $460 \mathrm{~V}, 3$ phase, $700 \mathrm{~Hz}$.

The motor rotor is a precision cast, laminated design with a 3-in. diameter bore. The rotor is attached to the shatt via an interference fit. In the current design, it is the mechanical integrity of the laminated rotor that limits turbomachine speed, pressure ratio, and flow. Although analysis indicates that the laminated rotor design will not unduly limit the turtomachine application, all aspects of the current turbomachine design (i.e., rotordynamics, bearing, motor stator, and aero componerits) would remain unchanged if it were desirable to increase performance. This could be achieved through the use of a more experisive solid rotor. Such designs exist in the frame size required and could provide an approximate $25 \%$ increase in speed, flow, and pressure ratio at the expense of an increase in manufacturing cost.

\subsection{Turbomachine Performance}

The Brayton-cycle turbornachine performance is dependent upon aerodynamic component efficiency and motor efficiency, as well as bearing, windage, and other parasitic losses. A system flow of $22.00 \mathrm{acfm}$ was selected as a nominal design basis. The design compressor pressure ratio of 2.25:1 and the design turbine pressure ratio of 2:1 allow for a $10 \%$ system pressure loss. Because of the wide variety of solvent recovery applications anticipated, the preliminary design phase evaluated turbomachinery operation over a wide performance range. Expansion efticiency most directly impacts Brayton-cycle refrigeration pertormance because higher expansion elficiency not only returns more power to the shaft but also provides lower exhaust temperatures by removing more energy from the expanding gas. The expected performance of the 
turbine, expressed in terms of air equivalent parameters, is presented in Figure 4-4. Estimates show that less than a $2 \%$ variation in the design's $82 \%$ expansion efficiency over a $\pm 15 \%$ range of turbine mass flow can be expected because of turbomachine's ability to control both speed and VAN area.

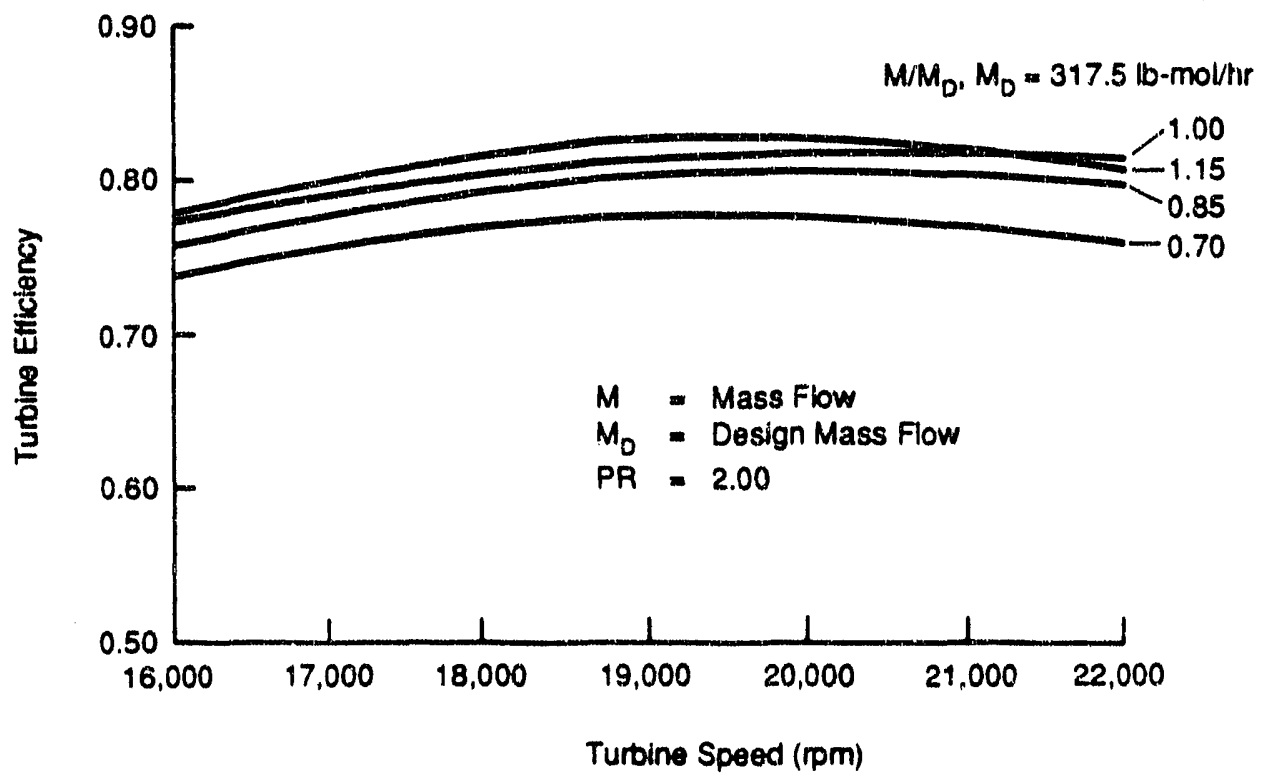

90158

Figure 4-4. Turbine Efficioncy versus rpm

The compressor is designed for high efficiency at low specific speed and is ideally matched to the speed requirements and limitations of the turbine and motor, respectively. (The compressor is a 13-in. open centrifugal impeller with radial blading and a vaneless diffuser.) The expected performance of the compressor is shown in Figure 4-5. At the design flow of $317 \mathrm{lb}$-molhr and a pressure ratio of 2.3 , the compressor elficiency is $82 \%$. In normal operation, the compressor speed is controlled by motor trequency while compressor flow and head are trimmed by turbine VAN adjustment. With these adjustments, high efficiency can be maintained with conservative surge margin on the compressor.

The high-speed motor and gas bearing system are integral components of the turbomachine and contribute to its periormance. The motor must be capable of delivering the differential power required to drive the compressor and overcome mechanical losses when combined with the power developed by the turbine. As discussed in Section 4.4, tha use of gas bearings minimizes the parasinic bearing losses. For the purposes of developing the motor-required horsepower, gas bearing losses were taken at $1.5 \mathrm{hp}$ at a design maximum speed of $21,000 \mathrm{~mm}$. Therefore, rotor windage losses became the predominant parasitic loss and were calculated to be $5.6 \mathrm{hp}$ at this nominal design speed. 


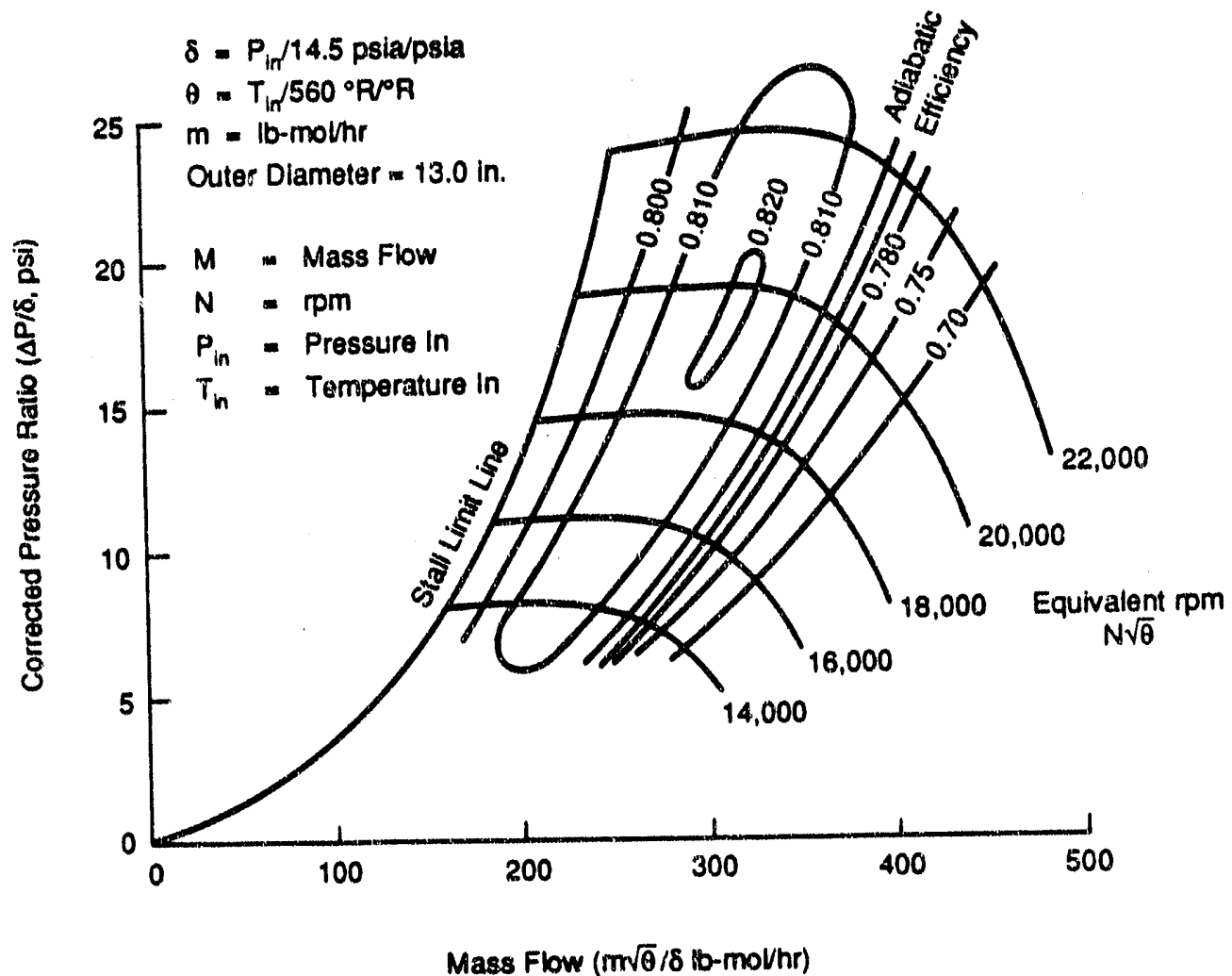

90161

Figure 4-5. Compressor Performance Map

The squirrt! ca'je induction motor is essentially a constant torque machine if a constant volts-to-frequency ratio is maintained as speed is increased. At constant torque, horsepower increases in direct proportion to rotor $\mathrm{pm}$. The limits of the machine are reached when either the rotor reaches maximum allowable stress (speed) or the motor heat rejection limits are reached and maximum temperature rise occurs. For the watercooled stator housing with Class $\mathrm{H}$ insulation at the laminated rotor speed of 21,000 $\mathrm{rm}$, the molor is rated at $140 \mathrm{hp}$. As discussed earlier, higher speeds and, consequently, higher power levels are achievable through the use of a solid rotor of the same physical dimensions. The solid rotor simultarieously raises the rotor critical speed, allowing higher rotational speeds and motor power levels.

Through adjustment of motor speed and turine VAN area, the performance of the turbomachine can be matched to the solvent recovery application requirements providing the desired state points and flows. Turbomachine performance at the nominial system design basis of $317 \mathrm{lb}-\mathrm{mol} / \mathrm{hr}(2200 \mathrm{acim})$ and a compressor pressure ratio of 2.25:1 is shown in Table 4-1. Full utilization of rated motor performance could be achieved at $370 \mathrm{lb}$-mol/hr flow $(2600 \mathrm{cfm})$ and a compressor pressure ratio of 2.5 . At this point the motor would be providing $140 \mathrm{hp}$ at $21,000 \mathrm{~mm}$. 
Table 4-1. Performance at Nominal Design Conditions

Design Conditions and Aorodynamic Performance

\begin{tabular}{|c|c|c|}
\hline Dealgn Conditlon. & Comproseor & Turbine \\
\hline Pressure In $\left(P_{\ln }\right.$, psia $)$ & 14.5 & 30.125 \\
\hline Temperature $\ln \left(T_{\ln }{ }^{\circ} \mathrm{F}\right)$ & +100 & +0 \\
\hline Pressure Out $\left(P_{\text {out }}\right.$, psia $)$ & 32.6 & 16.4 \\
\hline Temperature Out $\left(T_{\text {out }}{ }^{\circ} \mathrm{F}\right)$ & +277 & -60.47 \\
\hline Flow (lb-moimr) & 317.5 & 317.5 \\
\hline Power (hp) & 154.4 & 52.0 \\
\hline$\eta$ & 82.0 & 82.0 \\
\hline Gas & Air & Air \\
\hline Outer Diameter & 13.0 & 7.65 \\
\hline rpm & 19,650 & - \\
\hline
\end{tabular}

Mechanical Parformance

Bearing Losses $-1.5 \mathrm{hp}$

Motor Rotor Windage $=5.6 \mathrm{hp}$

Net Required Horsepower $=109.5$

Available Horsepower at $19,650 \mathrm{rpm}=131$

Motor Efficiency $=90 \%$ at Full Load

90TR7

\subsection{Gas Bearing System}

This subsection provides a detailed discussion of the gas bearing system design.

\subsubsection{Gas Bearing Theory}

A self-acting or, as commonly known, hydrodynamic type of gas bearing operates in a similar manner to a hydrodynamic oil bearing except that gas provides the fluid support film. With this bearing type, load support is generated from the relative rotation of the rotor and bearing suriaces. As shown in Figure 4-6, this produces a pressure wedge between the converging surfaces of the offset rotor in the journal bearing and from the tapered inlet or ramp region of each pad of the thrust bearing. The effectiveness of the load support is a function of many variables which include bearing size, geometry, clearance, speed, gas viscosity, and ambient pressure. 


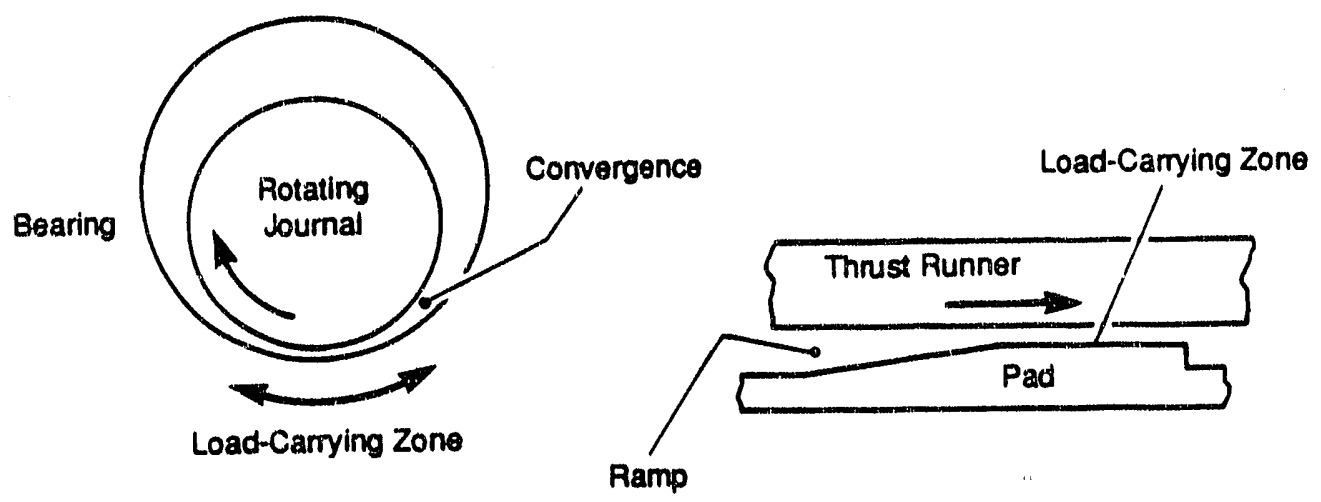

90155

Figure 4-6. Load Support for Joumal and Thrust Bearings

Being self-acting and having no residual oil film to separate the bearing/rotor surfaces, the gas bearing system starts and stops with direct surface-to-surface sliding contact. This necessitates the provision for low friction and wear-resistant surfaces.

Much of the early experience with gas bearings utilized bearings with rigid members and surfaces. These presented some problems or limitations in high performance turbomachinery and led to the development of compliant surface bearings. Compliant bearings, dating from the late $1960 \mathrm{~s}$, utilize thin metal foil materials in their construction and overcame many limitations. The MTI Hydresil'm designs proposed for this application are in this category.

In its simplest form, the Hydresil journal bearing consists of two foil parts mounted in a sleeve: a smooth top foil that provides the bearing surface, and a flexible "bump" or spring foil that provides controlled resilient support to this surface (see Figure 4-7a). The smooth foil operating surface is usually coated for the reasons previously discussed, and micromotions between contacting foils and the foil-to-sleeve surface when the machinery is operating generate Coulomb frictional damping forces beneficial to controlling rotor excitations. It is evident that by varying the pitch of the bumps and the foil thicknesses, the mechanical stiffnesses of the bearings can be selectively designed.

The Hydresil foil thrust bearing shown in Figure 4-7b follows the same basic design principles described above.

\subsubsection{Advantages of Gas Bearings}

In the solvent recovery application, there are significant advantages in the use of gas bearings as compared to oil bearings. Several unique characteristics of the compliant foil gas bearings provide additional benefits. Basic gas bearing advantages include:

- Elimination of the oil system and associated critical seals

- Lower frictional power loss at high speed

- Higher achievable operating speeds and a more compact machine

- Reduced high and low temperature sensitivity

- No long-terrn storage or downtime problems. 

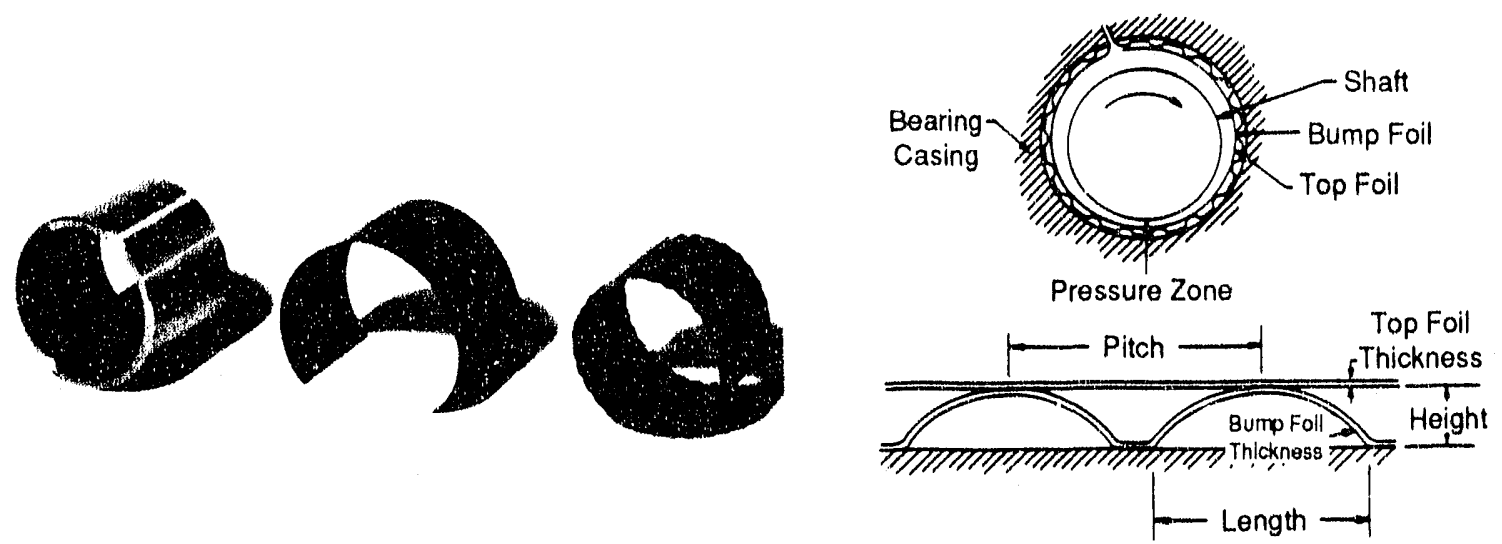

a) Typical Details of Foll Journal Bearing
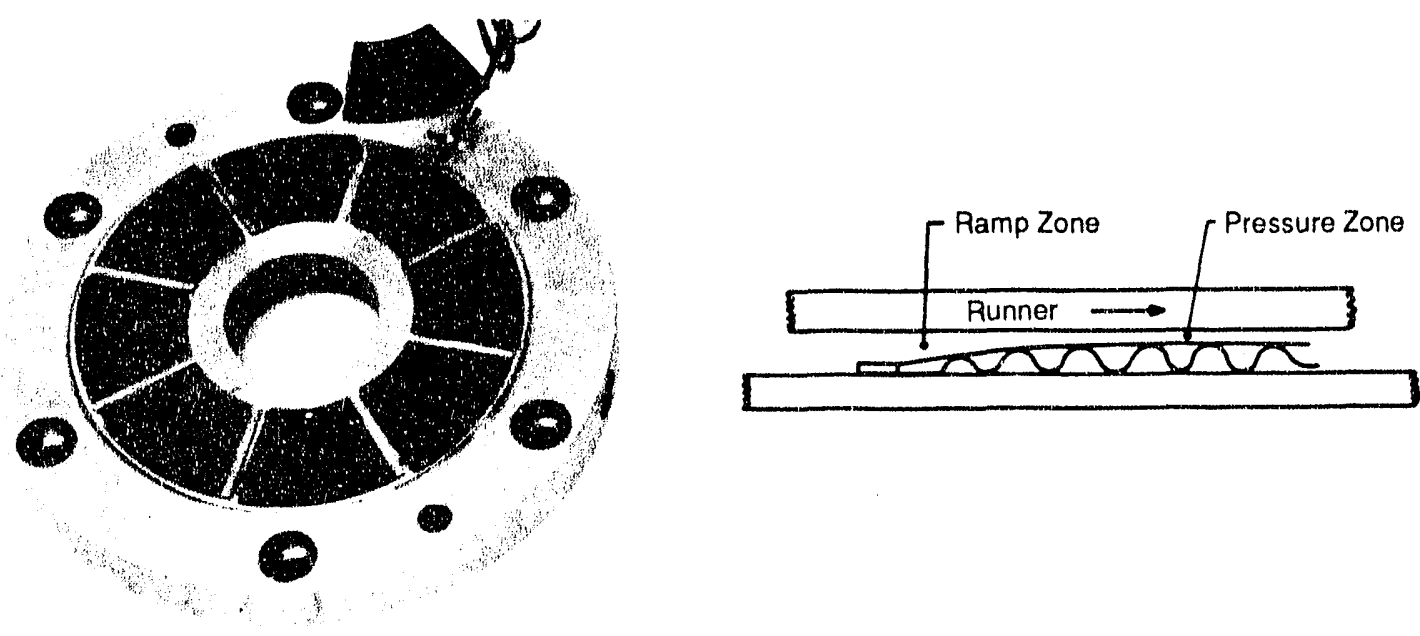

b) Pad Operation of Foll Thrust Bearing

V92.127

Figure 4-7. The MTI Hydres/TM Compliant Foll-Type Air Bearing 
The additional benefits of the compliant foil bearing over the rigid surface gas bearing include:

- Reduced sensitivity to dirt and thermal distortions

- Greater load capacity for a given bearing size

- Greater tolerance to shock loads and misalignment

- Increased high-speed rotor stability margin

- Lower cost in volume manufacturing.

\subsubsection{Design Parameters}

A matrix of interacting variables in the bearing/rotor system have to be addressed in order to reach an optimized, complete design. Several MTI-developed computer codes pertaining to bearing designs, rotordynamics, stability review, and thermal-mechanical analysis are used in this process.

The jurnal bearing size and characteristics are selected to match the high-speed operating loads, start-stop coating loading, a diameter that will ensure adequate rotor stiffness, and a bearing stiffness that will ensure favorable critical speeds. Journal bearing loads normally considered are a vector summation of rotor weight, electrical and aerodynamic side pull, and uribalance and shock or dynamic load (such as on a moving vehicle), as discussed in Section 4.4.4. The interplay between journal bearing characteristics, critical speeds, and rotor stability margin is discussed in Section 4.4.4.

The thrust bearing design is handled in a similar manner with a summation being made of mechanical and aerodynamic thrust loading and start-stop loadings. The bearing is sized to provide the smallest acceptable outside diameter compatible with the loads in order to minimize viscous shear frictional heat and power loss and to achieve thrust nunner accuracy and minimum cost. The stiffness of the thrust bearing is engineered to control rotor float, which affects the sealing efficiency of the aerodynamic blading in the housings, and to favorably position the "bounce" frequency of the bearing/rotor system relative to the speed range. The thrust bearings consist of an opposed pair, since the loading reverses between starting and operating speed.

A thermal-mechanical stress review of the bearing/rotor system provides information on rotor, bearing, and housing dimensional changes and their effects on bearing clearances, alignment, and distortions. This permits an estimate of the quantity of cooling flow required and establishes the best cooling paths or insulation arrangements to minimize these effects.

In arriving at the selected preliminary design, several bearing/rotor configurations were considered. The selected configuration, with the rotor vertical arrangement as shown earlier in Figure 4-2, is discussed in the following subsection in terms of resultant bearing loadings.

\subsubsection{Selection of Bearing Configurations and Load Analysis}

As a result of an iterative review of bearing loadings, rotordynamic, and other machinery requirements, the preliminary bearing size selection was made. One important factor influencing the bearing design was the attractiveness of having a vertical rotor arrangement with the turbine at the lower end as shown earlier in Figure 4-2. This arrangement offered the following advantages: 
- Prevented any solvent liquid residue in the turbine from entering the bearing section

- Provided the ability of opposing the full rotor weight against the aerodynamic thrust, thus reducing the thrust bearing loading or size

- Made it relatively easy to provide a jacking piston and pressure to relieve the rotor weight on the thrust bearing coating during starts and stops.

This vertical rotor arrangement resulted in lightly loaded journal bearings during highspeed operation. While seemingly attractive, at the same time, this also increases the rotor system's sensitivity to excitations. One method for counteracting this is to introduce a side load in the journal bearings by mounting the machine at a small tilt angle. Another machinery design feature used for stability reasons has been to ensure that the rotor center of gravity is beneath the thrust bearing plane to the greatest extent possible.

Because of the rotordynamilc, rotor stiffness, weight distribution, and other fabrication and assembly considerations, the compressor end journal bearing is slightly larger than the turbine end bearing.

Figure 4-8 shows the prelim nary concept arrangement for the compressor end bearing, which is typical for both journal bearings. It will be noted that this is a variation of the configuration shown in Figure 4-7a in that a three-pad design has been selected. This has been done because a multipad design has the inherent ability of minimizing crosscoupling disturbing forces in the gas film and provides a greater stability margin. The multipad bearing can also be made with greater accuracy in these larger sizes. As shown in Figure 4-8, provisions have been made for mounting the journal bearing

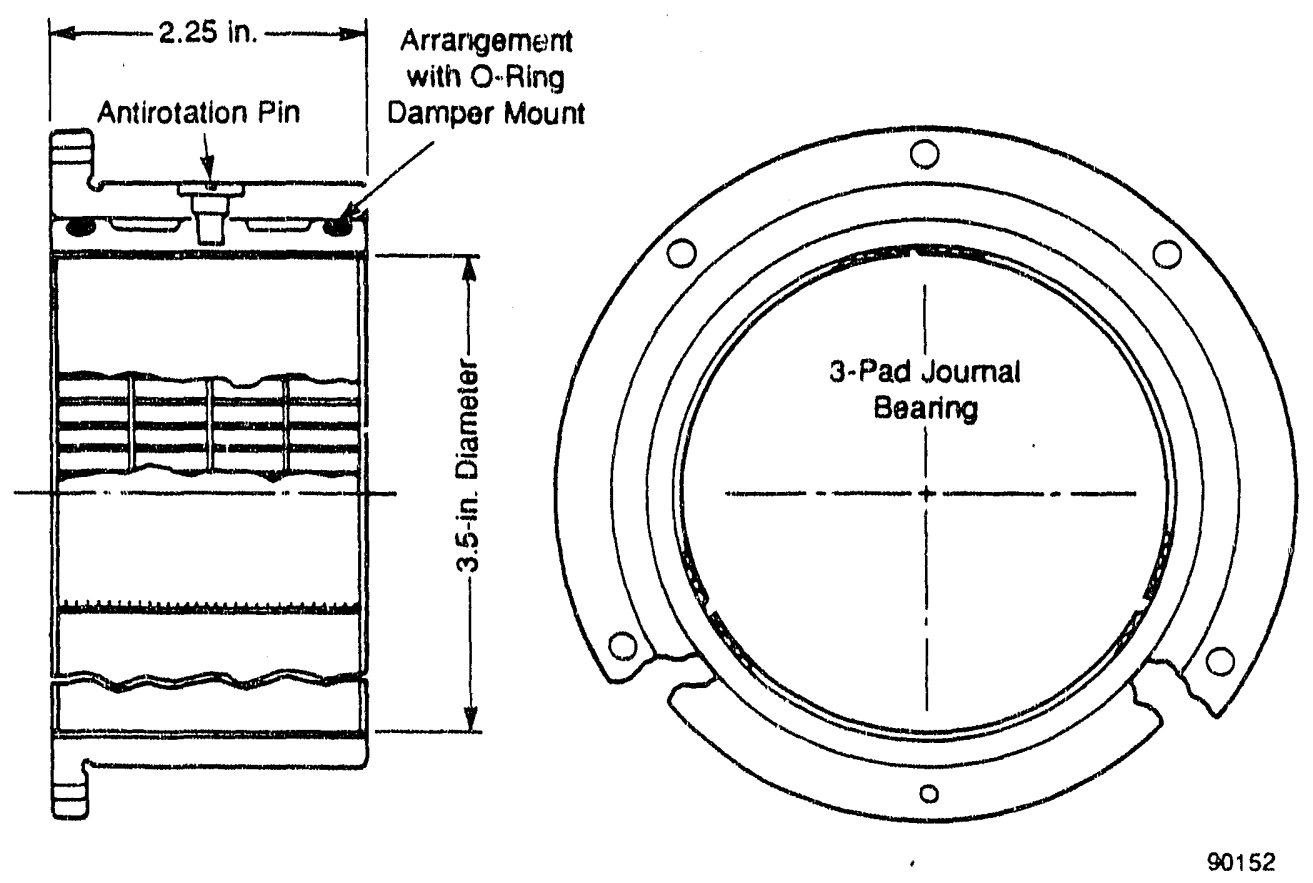

Figure 4-8. Preliminary Concept for Foil Journal Bearing (Compressor End) 
sleeve in static, compliant elastomeric O-rings. This method of mounting can offer an additional source of damping to the bearing/rotor system, increase its ability to handle rotor misalignments, and modulate any external shock loads. The stiffness/damping characteristics of the total bearing and mounting system are also engineered to ensure control of the total rotor motions in the stationary housings.

The thrust bearing, which is the most heavily loaded bearing because of the predominant aerodynamic loading, is sized in accordance with good design practice and experience coupled with limitations on tip speed of the runner and fabrication considerations. The preliminary design shown on Figure 4-9 has 10 similar pads. Figure 4-10 shows the operating gas film thickness as a function of load at design speed and points to the importance of the compliance of the foil parts and the need for accuracy and squareness in housing and rotor parts. To this end, the thrust runner is machined as an integral part of the rotor.

In the final design, the interplay of foil and total bearing stiffness against foil stresses will be evaluated to achieve the optimum design. Because of possible load reversal, the opposed thrust bearing is made in a similar size. Selection of the optimum bearing stiffness is also important in the dynamic sense since, in association with other rotor variables, it controls the bounce frequency and amplitude of the vertical rotor between the opposed thrust bearings.

Table 4-2 summarizes the weight loadings for the journal and thrust bearings during starts and stops and at design speed conditions. Since one method for introducing joumal bearing loading at high speed with a vertical rotor is to provide a small tilt angle, this has been included in the table.

The journal bearing weight loadings for the rotor design at small angles of tilting are good in terms of the proven design practice of using about 2 psi on the foil coatings to give long service life under start-stop conditions. Loads are modest at high speed even with the tilt angle and remain so even when adding representative residue rotor unbalance loads of 1 to $2 \mathrm{lb}$ per bearing.

The thrust bearing weight loading values are high for long coating life under start-stop conditions, but could be accepted for occasional emergency conditions. It is, however, relatively easy to reduce the loading to 2 psi by use of the air-actuated balance piston as is planned. When the system is operating at design speed, the aerodynamic loading (not included in Table 4-2) is dominant and opposes the rotor weight loading.

For example, with the machine at $15^{\circ}$ tilt, the resultant thrust bearing loading becomes:

$$
\text { (350 lb aero }-112 \mathrm{lb} \text { rotor weight) }=238 \mathrm{lb}(10.3 \mathrm{psi})
$$

This is considered to be good design practice, and the bearing should be satisfactory if this was to increase because the balance static pressure was accidentally left on.

\subsubsection{Frictional Power Losses}

The frictional power loss in a fluid-film bearing results from the viscous shearing of the film between the bearing and rotor surfaces. It is a function of several variables including fluid viscosity, bearing size and configuration, clearance, and relative velocities. 


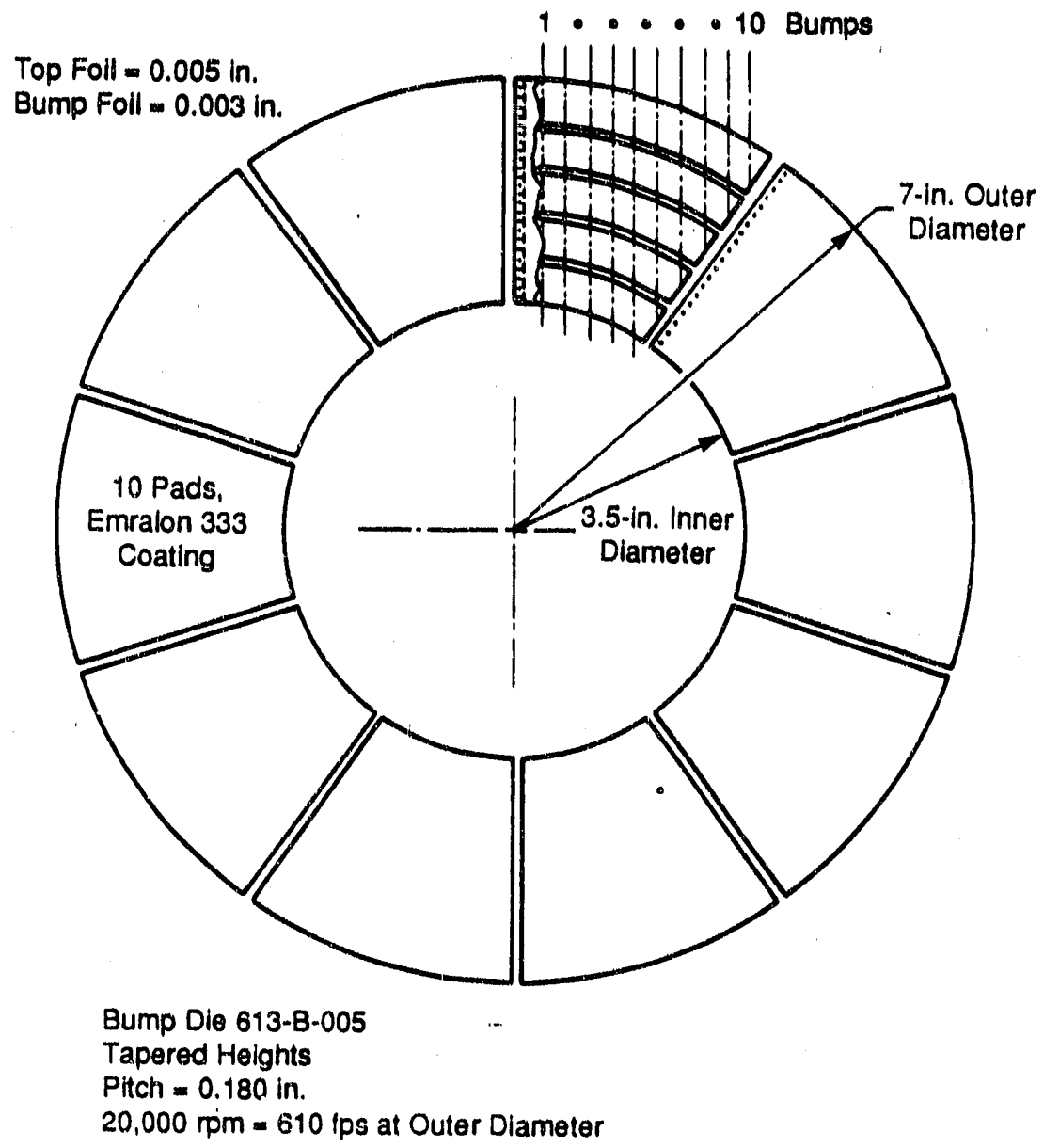

90153

Figure 4-9. Preliminary Concept for Foil Thrust Bearings

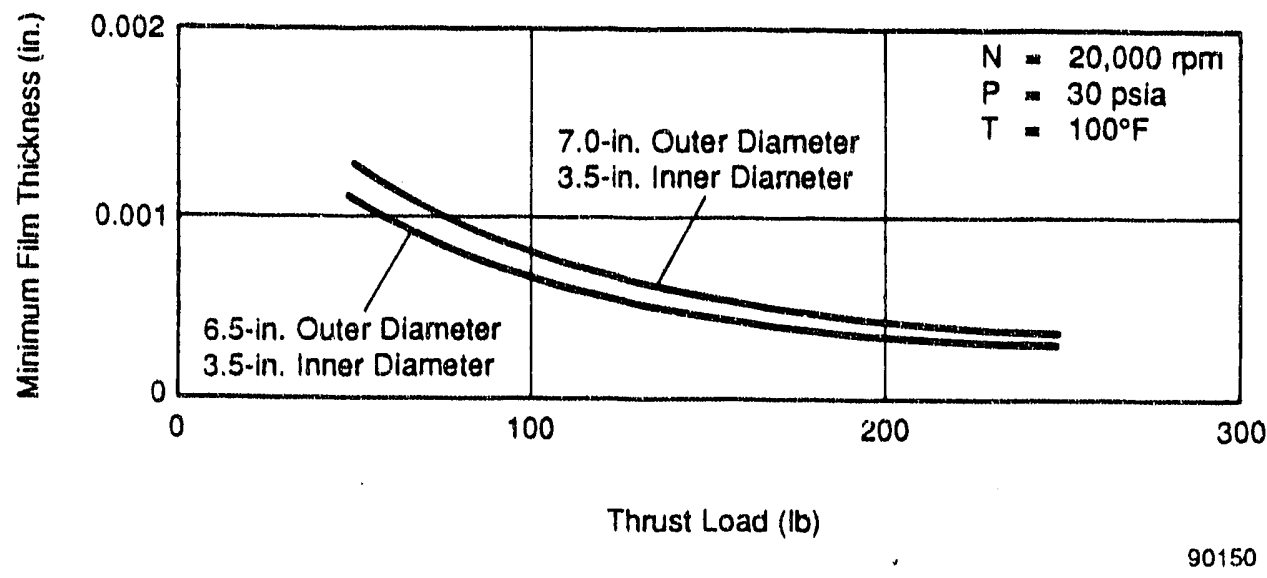

Figure 4-10. Foil Thrust Bearing: Operating Gas Film Thickness as a Function of Load 
Table 4-2. Rotor Weight Loads on Bearings

\begin{tabular}{|l|c|c|c|}
\cline { 2 - 4 } \multicolumn{1}{c|}{} & $\begin{array}{c}\text { Turbine } \\
\text { Journal Bearing }\end{array}$ & $\begin{array}{c}\text { Compressor } \\
\text { Journal Bearing }\end{array}$ & Thrust Bearing \\
\hline Bearing Size'(in.) & $\begin{array}{c}3 \text { Dlameter } x \\
2 \text { Length }\end{array}$ & $\begin{array}{c}3.5 \text { Dlameter } x \\
2.25 \text { Length }\end{array}$ & $\begin{array}{c}7.0 \text { Outer Dlameter } x \\
3.5 \text { Inner Dlameter }\end{array}$ \\
\hline Effective Area (in. ${ }^{2}$ ) & 6 & 7.88 & 23 \\
\hline
\end{tabular}

\begin{tabular}{|c|c|c|c|c|c|c|}
\hline \multirow[b]{3}{*}{ Tilt Angle } & \multicolumn{4}{|c|}{ lowdings } & & \\
\hline & \multicolumn{2}{|c|}{$\begin{array}{l}\text { Turblne } \\
\text { Journal Bearing }\end{array}$} & \multicolumn{2}{|c|}{$\begin{array}{l}\text { Compresesor } \\
\text { Journal Bearing }\end{array}$} & \multicolumn{2}{|c|}{ Thrust Bearing } \\
\hline & Ib & pul & Ib & pol & lb & psi \\
\hline Vertical & 0 & 0 & 0 & 0 & 116 & 5.04 \\
\hline $10^{\circ}$ & 6.2 & 1.03 & 13.9 & 1.76 & 114 & 4.96 \\
\hline $15^{\circ}$ & 9.2 & 1.53 & 20.8 & 2.64 & 112 & 4.87 \\
\hline $20^{\circ}$ & 12.2 & 2.03 & 27.5 & 3.49 & 109 & 4.74 \\
\hline
\end{tabular}

While the gas bearing is larger than an equivalent oil-film bearing of the same load capacity, the significant difference in fluid viscosity results in lower power loss in most cases. The calculated frictional power losses for the two journal bearings and opposed thrust bearings at $20,000 \mathrm{rpm}$ as defined in Section 4.4 .4 are:

\section{Bearing Type}

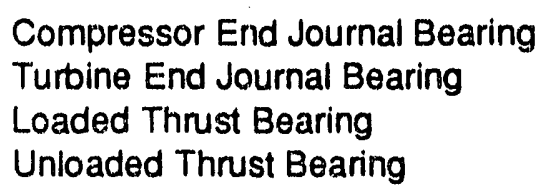

\section{Horsepower}
0.135
0.075
0.710
0.230
1.150

This value is obviously small compared to the motor power. There are additional frictional losses associated with the gas pumping of other rotor components, which will be greater. Since the bearing frictional power is generated directly in the gas film, the cooling air acts to remove it for reasons discussed below.

\subsubsection{Cooling}

The bearing system and motor assembly between the compressor and turbine impellers are supplied with a separately controlled source of clean, dry, pressurized air flow. 
Pressure is maintained at a few psi higher than the system levels adjacent to this zone. The air flow serves several purposes:

- Prevents entry of solvent liquids or gases through the shaft seals into the bearing

- Provides additional cooling to the motor components (the major cooling is from an external water jacket)

- Provides a means of reducing the rotor weight loading on the thrust bearing with a pressure balance piston during the start-stop cycle

- Provides a cooling flow through the foil bearings.

The cooling air flow through the foil bearings removes the self-generated frictional heat to ensure long coating life, balances heat flow from other sources such as the motor to minimize misalignments and distortions within the bearings, removes coating wear debris from the bearings, and prevents entry of any rotor seal debris into the bearings. Representative cooling flows for the bearings for removal of the self-generated frictional heat total $32 \mathrm{scfm}$ for a $100^{\circ} \mathrm{F}$ temperature rise in the bearings. Any additional cooling flow needed to balance other heat sources will be determined in a thermal review during the final design work.

\subsubsection{Coatings}

The operating surfaces of the top foils of the bearings and the matching rotor surfaces are provided with a coating or treatment. These provide low friction and wear resistance during the start-stop sliding contacts between bearings and rotor or during any instantaneous contact occurring at operating speed during a shock-type loading.

These coatings or treatments, in the form of proven, compatible "tribological" pairs, usually consist of a very thin ( 0.0001 to 0.0003 in.) soft coating on the foils and a harder treatiment on the rotor. The rotor treatment increases hardness and reduces the potential of surface damage to the more expensive rotor system.

The required properties of the foil coatings include:

- Low coefficient of friction in sliding

- Easy to apply

- Strong adhesion and compatible with base material

- Impervious to environment

- Minimum generation of wear debris

- Maintain good finish in service for hydrodynamic efficiency.

The required properties of the rotor journal and thrust runner surfaces include:

- Compatibility with the selected bearing surface

- Easy to process or apply

- Hardness with capability for accurate and smooth finishing

- Repairability.

The selection of the tribological pair is very dependent on the specific requirements of the application and is based on MTI baseline data from dedicated friction and wear test rigs and on prior experience. It is estimated that 15,000 to 20,000 start-stop cycles of 
operation will occur before equipment replacernent is performed. Based on the design loading of 2 psi defined in Section 4.4.4, the fvibological pair has been selected and consists of a proprietary MTI polyamide imide-type coating.

\subsubsection{Issues for Final Design}

In the above discussion, some of the issues that must be addressed in the final design phase have been highlighted and the general approach to be followed for many of them defined. Some of the more straightforward issues include:

- Ensuring bearings have satisfactory load performance

- Providing adequate foil coating life

- Minimizing friction power losses

- Ensuring a rotor of required stifiness, high-speed integrity, and accuracy

- Providing optimized bearing cooling flows and paths

- Commonality of bearings for minimum costs

- Controlling bounce frequency and amplitude of rotor on thrust bearings.

Particular attention in the final design will be directed at a complete dynamic review of the journal bearing/rotor system to ensure adequate stability margin against possible excitation sources. These sources can be forces from the aerodynamic flow paths, flow through seals, and self-induced forces from within the gas film of the bearings. Highspeed bearing/rotor systems operating at several multiples of the first rigid body critical speed are particularly prone to excitation of the rotor, where the first or second rigid body critical speed may appear as a subsynchronous frequency motion at operating speed.

As discussed in Section 4.4.4, particular care is required with vertical rotor machines that have lightly loaded journal bearings and, consequently, concentrically operating joumals. Possible ways of providing a stabilizing side load in the bearing include:

- Bearings designed with internal preload

- Tilting the machine to provide a small radial load component

- Providing an electrically or pneumatically induced radial load.

Of these options, the first will be given priority in the design, and, as discussed, the multipad foil bearing with its inherently good stability characteristics will be used.

Damping mechanisms can come from three sources: squeeze action in the bearing gas film, enhanced Coulomb friction generated from interaction between specially treated foil members in the bearings, and from external mountings such as O-rings. All of these features will be addressed when optimizing the design. 


\subsection{PRELIMINARY SYSTEM DESIGN}

This section provides a description of the preliminary design of the solvent recovery heat pump system, including a discussion of the system and equipment alternatives that were considered in the design process.

\subsection{System Alternatives}

The solvent recovery heat pump sysiem is quite flexible and can be utilized in a variety of application contigurations. Because the process recovers solvents via condensation, the dew point temperature of the vapor gas mixture strongly influences the selection of the best system configuration. The dew point temperature of a vapor/gas mixture is primarily a function of the vapor concentrations. Another consideration in establishing the system configuration is the flammability limits of the solvent, expressed as :he LEL, If the concentration of the solvent exceeds $50 \%$ LEL, insurance underwriters insist that an inert carrier gas must be used to convey the mixture.

The system may be designed as an open-loop or closed-loop (recycling the gas back to the application) process. An open-loop configuration must condense at much lower temperatures to minimize the solvent concentration discharged to ambient. In general, closed-loop processes operate with higher solvent concentrations, thereby recovering more solvent for the amount of gas handled. The NYS application survey conducted by MTI showed that the majority of NYS VOC solvent emissions are found in open-loop air streams at low concentrations.

One option that extends the application range and improves the economics of the heat pump at low concentrations is to intertace it to the emission source through a solventconcentrating adsorber. Such a system can be implemented to run on a continuous basis with a molecular sieve as shown in Figure 5-1, or in a batch desorption process such as an activated carbon bed as shown in Figure 5-2. Although there are no hard and 'ast rules with regard to the application of the heat pump with or without a solvent concentrator of a given type, it is possible to make some fairly accurate generalizations based on the concentration levels of solverits in the exhaust process stream.

Direct application of the heat pump for solvent recovery without concentration is most competitive when combined with a continuously operating, closed-cycle solvent evaporation process where the solvent concentrations entering the system are in excess of $5000 \mathrm{ppm}$ typically ( $40 \% \mathrm{LEL}$ ). Rotary absorbers and/or molecular sieves are best suited for concentrating solvents by a factor of 2 to $4: 1$. They may be used in conjunction with both open- and closed-loop application processes. Because of the difficulties of maintaining seals on a rotating continuous media, current designs are probably best suited for nonflammable soivents or for use in conjunction with flammable solvents initially in concentrations of $5 \%$ to $25 \% \mathrm{LEL}$ and then concentrated to a maximum $50 \% \mathrm{LEL}$ value. Fixed-bed adsorbers, typically of the activated carbon type, are best suited to solvent concentrations below $10 \%$ LEL. They are also well suited to applications with intermittent or noncontinuous solvent emissions at much higher levels. 


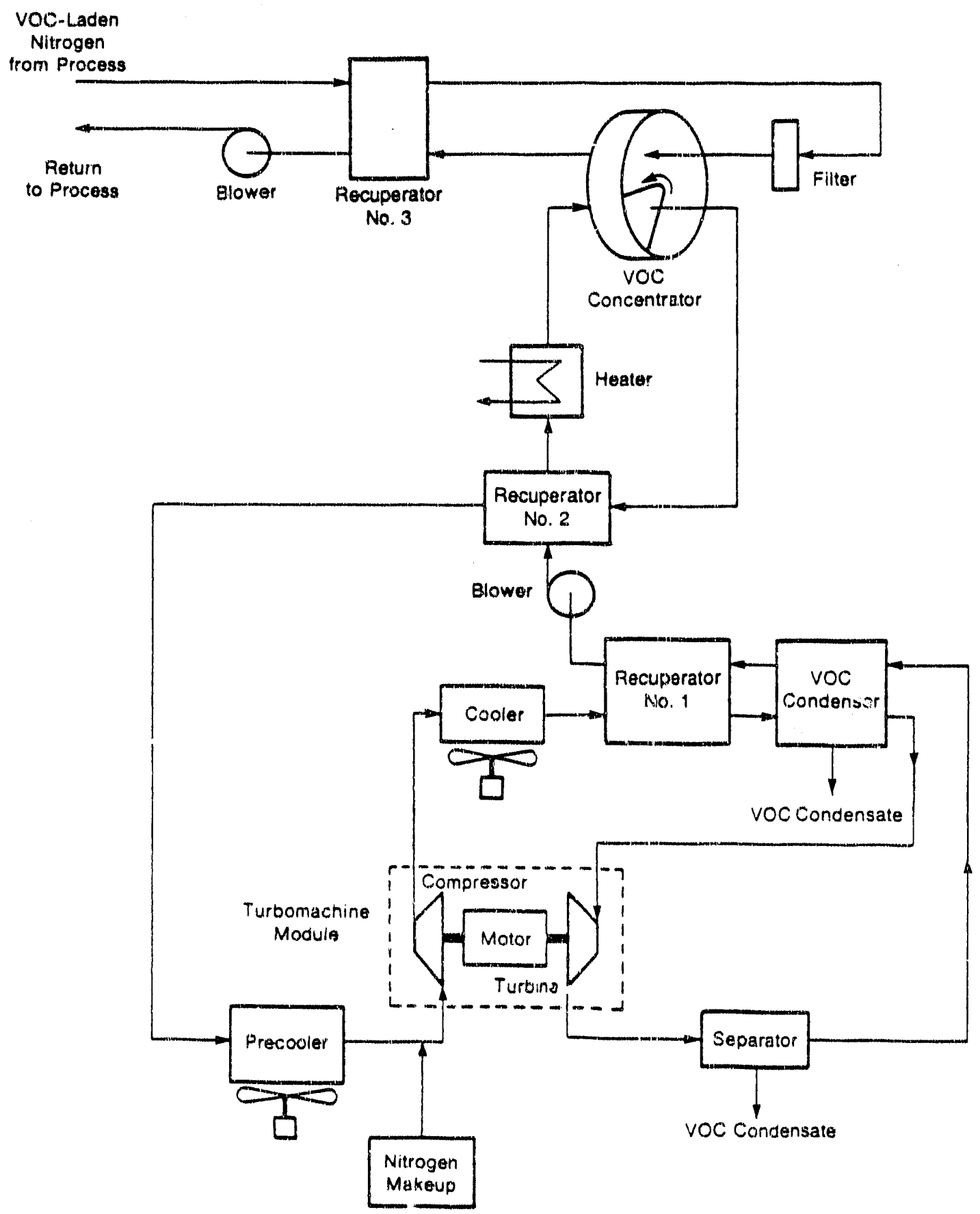

881112

Figure 5-1. Solvent Recoveny Hoat Pump Systom U/sed with Molecular Sieve VOC Sotvent 


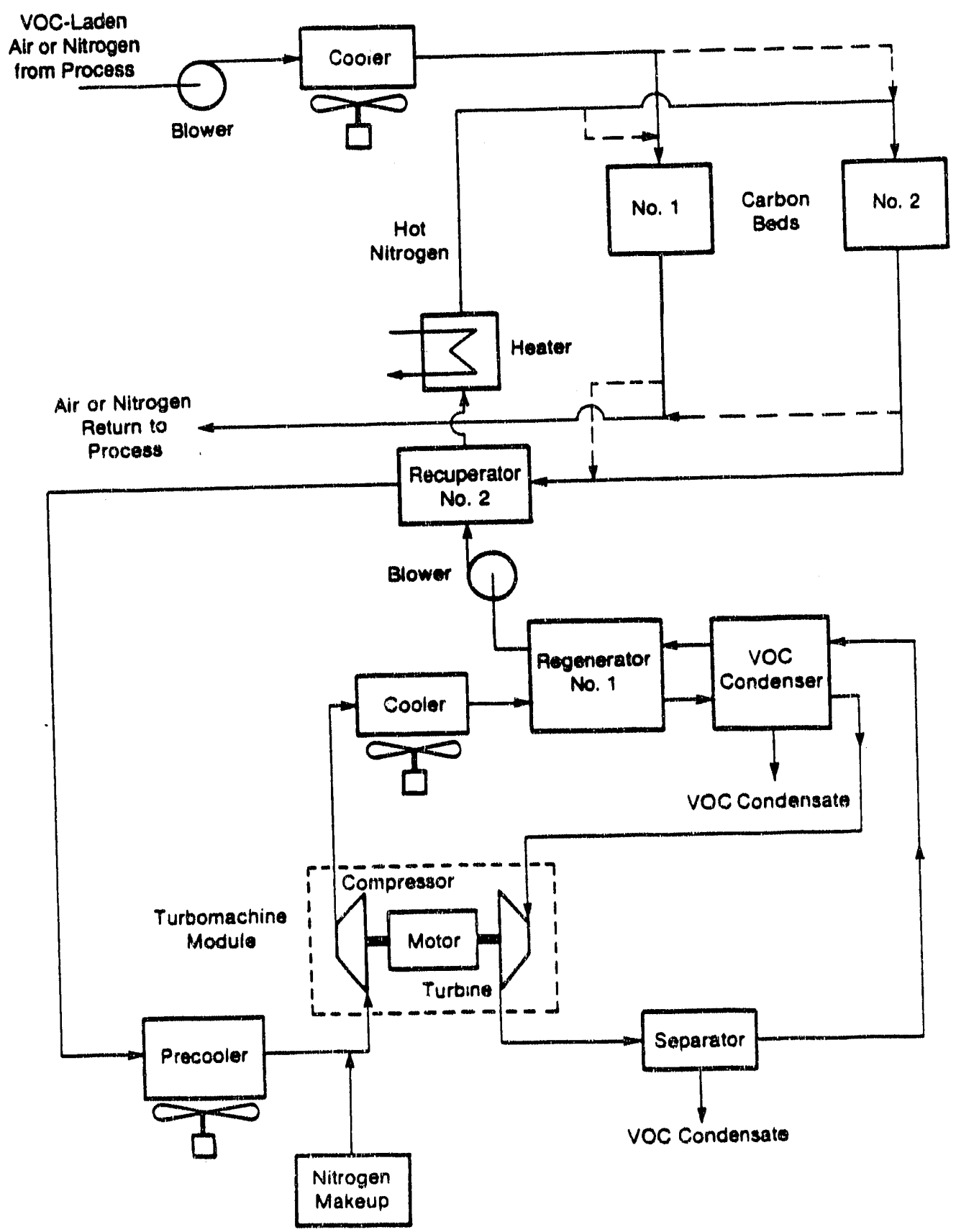

881113

Figure 5-2. Solvent Recovery Heat Purnp System Used for Carbon Bed Desorption 
By appropriate sizing of a batch-type solvent adsorber, the interval between desorption increases such that the solvent recovery system can be shared between many applications. With such a concept, the system becomes "mobile" and is periodically brought to the fixed location of the adsorber for desorption. In general, this concept is applicable for sources emitting less than $4000 \mathrm{lb}$ of solvent per day, either by virtue of low concentrations and high gas volume or intermittent emissions at higher concentrations.

Table 5-1 summarizes the relationship between source emission solvent concentration and the most competitive means of interfacing the solvent recovery heat pump to the source. The solvent recovery heat pump system with its Brayton-cycle turbomachine can be common to each of the applications listed, giving this equipment wide flexibility in application. The system type found to be most compatible with NYS solvent emissions applications was a mobile system for batch desorption. The Phase I preliminary design was therefore based on this application concept.

Table 5-1. Optimized Brayton-Cycle Heat Pump Applications

\begin{tabular}{|l|c|c|c|c|}
\cline { 2 - 5 } \multicolumn{1}{c|}{} & $\begin{array}{c}\text { Stand-Alone } \\
\text { Brayton-Cycle } \\
\text { Heat Pump }\end{array}$ & $\begin{array}{c}\text { Heat Pump with } \\
\text { Continuous } \\
\text { Concentrator }\end{array}$ & $\begin{array}{c}\text { Fixed Heat Pump } \\
\text { for Parallel } \\
\text { Bed Desorptlon }\end{array}$ & $\begin{array}{c}\text { Mobile Heat Pump } \\
\text { for Infrequent } \\
\text { Bed Desiorption }\end{array}$ \\
\hline Best Application Type & Closed Loop & $\begin{array}{c}\text { Closed or } \\
\text { Open Loop }\end{array}$ & Open Loop & Open Loop \\
\hline VOC Emissions (Ib/day) & $>2000$ & $>2000$ & $>1000$ & $<2000$ \\
\hline Emission Source Operation & Continuous & Continuous & $\begin{array}{c}\text { Continuous or } \\
\text { Intermittent }\end{array}$ & $\begin{array}{c}\text { Continuous or } \\
\text { Intermittent }\end{array}$ \\
\hline VOC Concentration Level (ppmV) & $>5000$ & 1000 to 5000 & $<1500$ & $<1000$ \\
\hline
\end{tabular}

90TR7

\subsection{Heat Pump Alternatives}

Closed-loop solvent recovery, whether a direct process-connected type or the type involving a solvent concentrator, requires a supply of heat to vaporize the solvent and, simultaneously, a supply of refrigeration for solvent condensation and recovery. The extent to which the heat pump alternatives meet this requirement is discussed below. During the Phase I effort, several heat pump equipment configurations were evaluated for closed-loop operation. The final system design was the result of trade-off analysis and competitive comparison of heat pump options. Two important heat pump configuration comparisons were:

- Electric versus thermal engine-driven systems

- Brayton-cycle versus combined Brayton-Rankine cycle (multiple level) refrigeration systems. 
The following subsections describe this evaluation and the resulting selection of an engine-driven/combined Brayton-Rankine cycle system as the preferred configuration for closed-loop solvent recovery.

\subsubsection{Electric versus Thermal Engine-Driven Systems}

Figure 5-3 shows a comparison between energy balances for Brayton-cycle solvent recovery systems powered by electric energy and thermal engine-driven systems. For both cases, it is assumed that the application requires 804,000 Btu for desorbing the concentrator (volatilization of the solvents) and a simultaneous 114,000 Btu of refrigeration for condensing the solvents. Because the thermal engine-driven system provides for cogenerated use of the rejected engine exhaust and water jacket heat, this system shows a $40 \%$ advantage in fuel consumption. In a closed-loop oven operating continuously, this advantage represents a significant operating cost differential. When applied to a closed-loop batch desorption process, the engine-driven system provides an additional advantage by eliminating the electrical demand charge associated with the intermittent use of a high horsepower electric motor. The cost of a commercially available . $150-\mathrm{kVA}$ electronic power converter to drive the high-speed motor is $\$ 26,000$ for small quantities.

Because most of industrial solvents are combustible, it is usually necessary to provide an inert carrier gas for their transport if the concentration is expected to reach levels of $50 \%$ LEL. In the case where an inert gas is required, the engine-driven system can provide this carrier gas from the engine exhaust. The use of the engine exhaust for system inerting eliminates the need for a separate and costly inert gas generating subsystem.

\subsubsection{Multiple-Level versus Singlo-Level Refrigeration Systems}

In a typical solvent recovery application, the desired turbine exhaust temperature might be $-100^{\circ} \mathrm{F}$. The cooling of the solvent-laden gas to this temperature is achieved with a combination of refrigeration (gas expansion) and recuperative heat transfer. Only the sensible portion of the thermal duty can be handled by the recuperation of heat with the returning, cold carrier gas. The additional heat load associated with the condensing vapors must be handled by active refrigeration because the returning dry carrier gas has inadequate heat capacity.

In the Brayton refrigeration cycle, the amount of temperature drop across the turbine is dependent upon the pressure ratio developed by the compressor. As the solvent or water vapor latent heat load increases, there is a proportional increase in the Braytoncycle work required to handle this refrigeration load and maintain the same exhaust dew point temperature. Figure 5-4 shows the relationship between increasing inlet concentration of methylene chloride solvent and the pressure ratio (compressor power) required to achieve outlet solvent concentrations of $700 \mathrm{ppm}$ and $3000 \mathrm{ppmv}$. Also shown in Figure 5-4 is the impact of water vapor on required pressure ratio and resulting motor horsepower.

Refrigeration-cycle thermodynamic analysis shows that the power required to produce a unit of refrigeration (capacity) is proportional to the temperature difference between the available heat sink and the source to be cooled. That is, the lower the minimum cycle 


\section{Thermal Engine-Driven} System

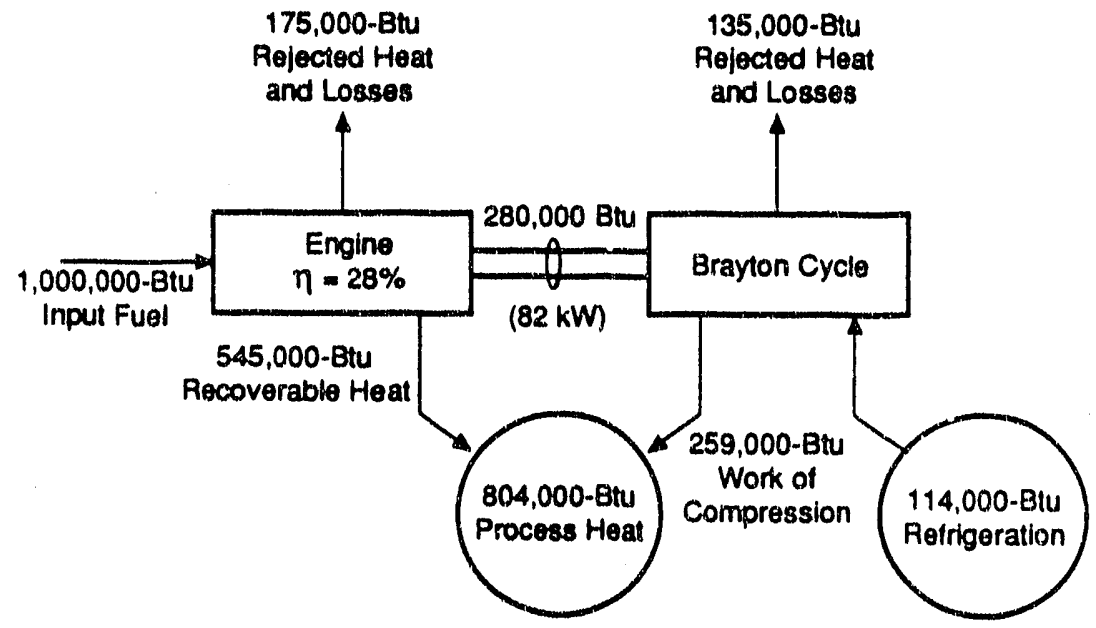

Electric System

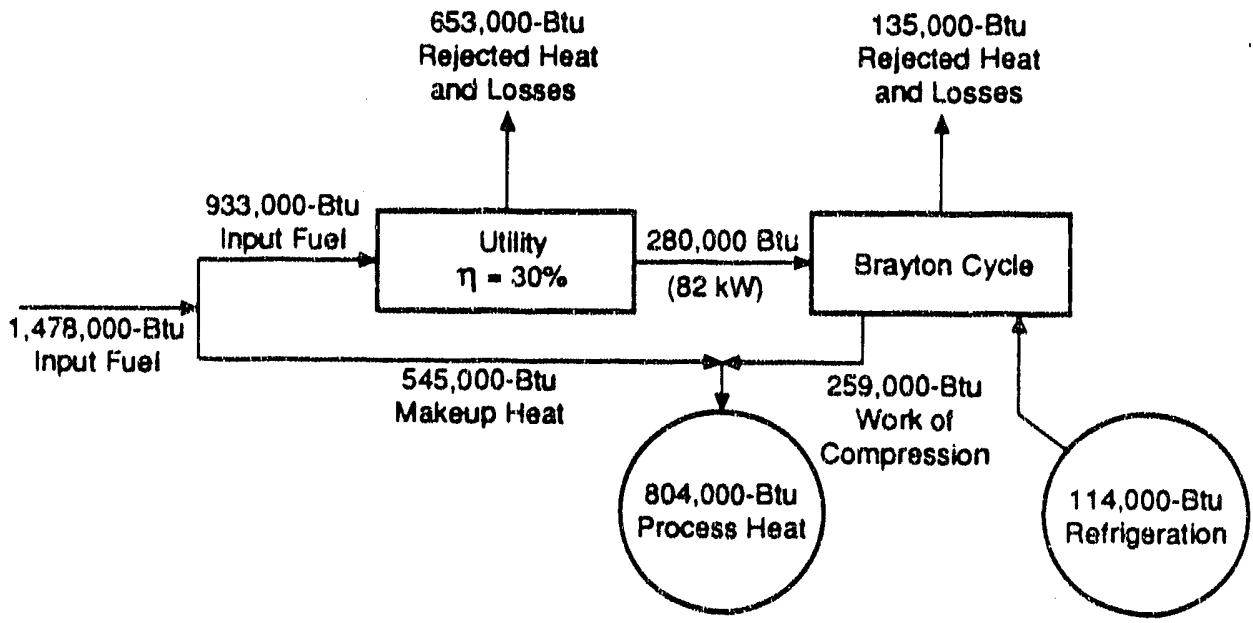

$891740(N)$

Figure 5-3. Comparison of Electric versus Thermal Engine-Driven Systems 


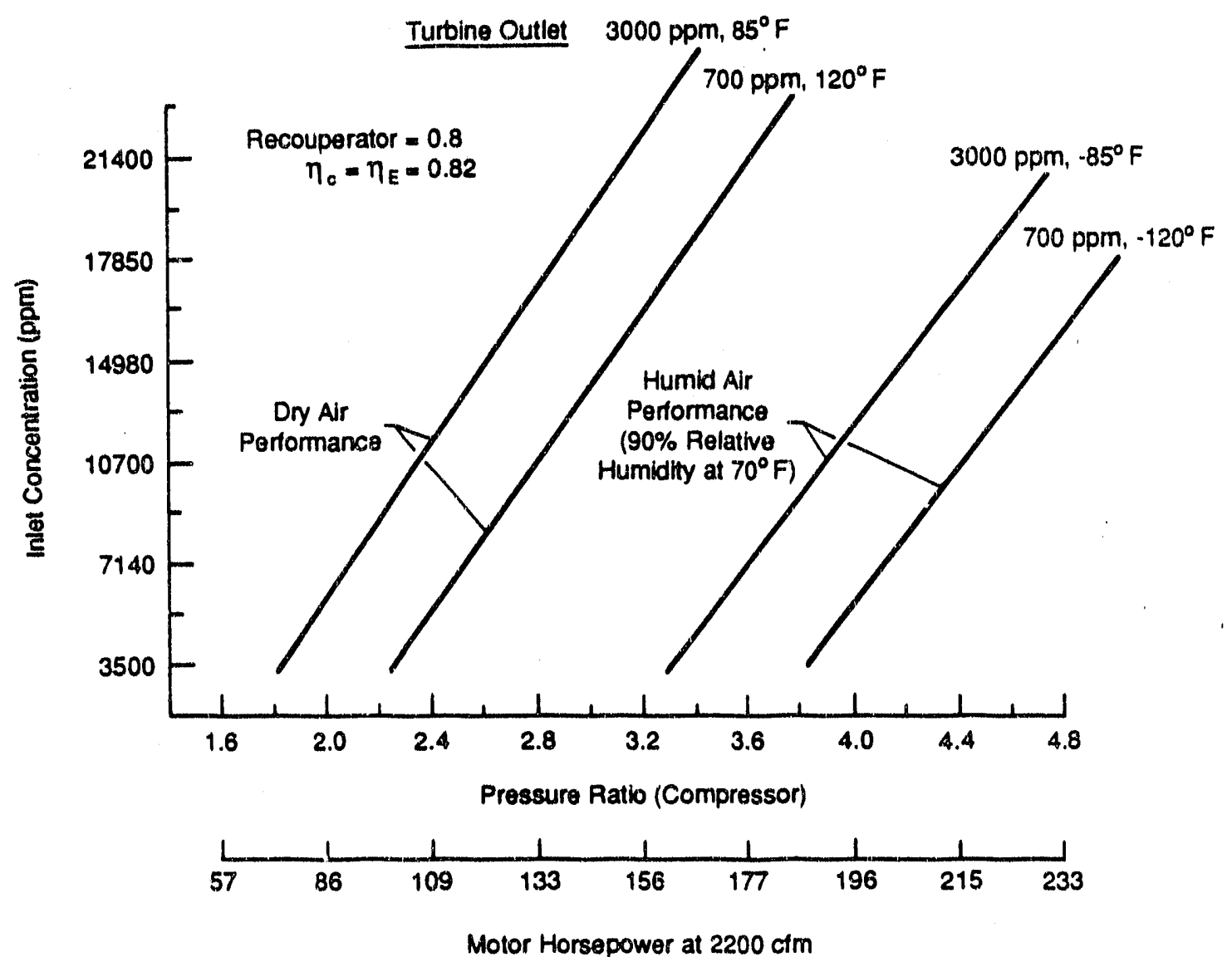

90160

Figure 5-4. Brayton-Cycle Pressure Ratio versus Inlet Concentration of Methylene Chloride Solvent

temperature, the higher the power requirements per unit of refrigeration capacity. There are differences between the power requirements of the Brayton cycle and conventional reverse Rankine refrigeration both in terms of sensitivity to cycle temperature difference and actual power requirements. Figure 5-5 shows the relative power requirements per unit of refrigeration capacity for both reverse Brayton (air cycle) and reverse Rankine refrigeration as a function of minimum temperature achieved. From Figure 5-5, it can be seen that although reverse Rankine refrigeration has only a $30 \%$ advantage over Brayton refrigeration in power consumption at a temperature of $-100^{\circ} \mathrm{F}$, the advantage in reverse Rankine refrigeration at a temperature of $20^{\circ} \mathrm{F}$ is nearly $400 \%$.

This significant efficiency advantage with reverse Rankine refrigeration can have a major favorable impact on the performance of a solvent recovery heat pump system when that system is applied to exhaust streams having high concentrations of VOC solvents or water vapor. The reason is because the refrigeration load associated with high concentrations of solvents occurs at high dew point temperatures. Of course, the refrigeration load associated with condensing water vapor occurs almost completely at dew points above $32^{\circ} \mathrm{F}$. By taking advantage of the fact that this refrigeration load exists at higher 


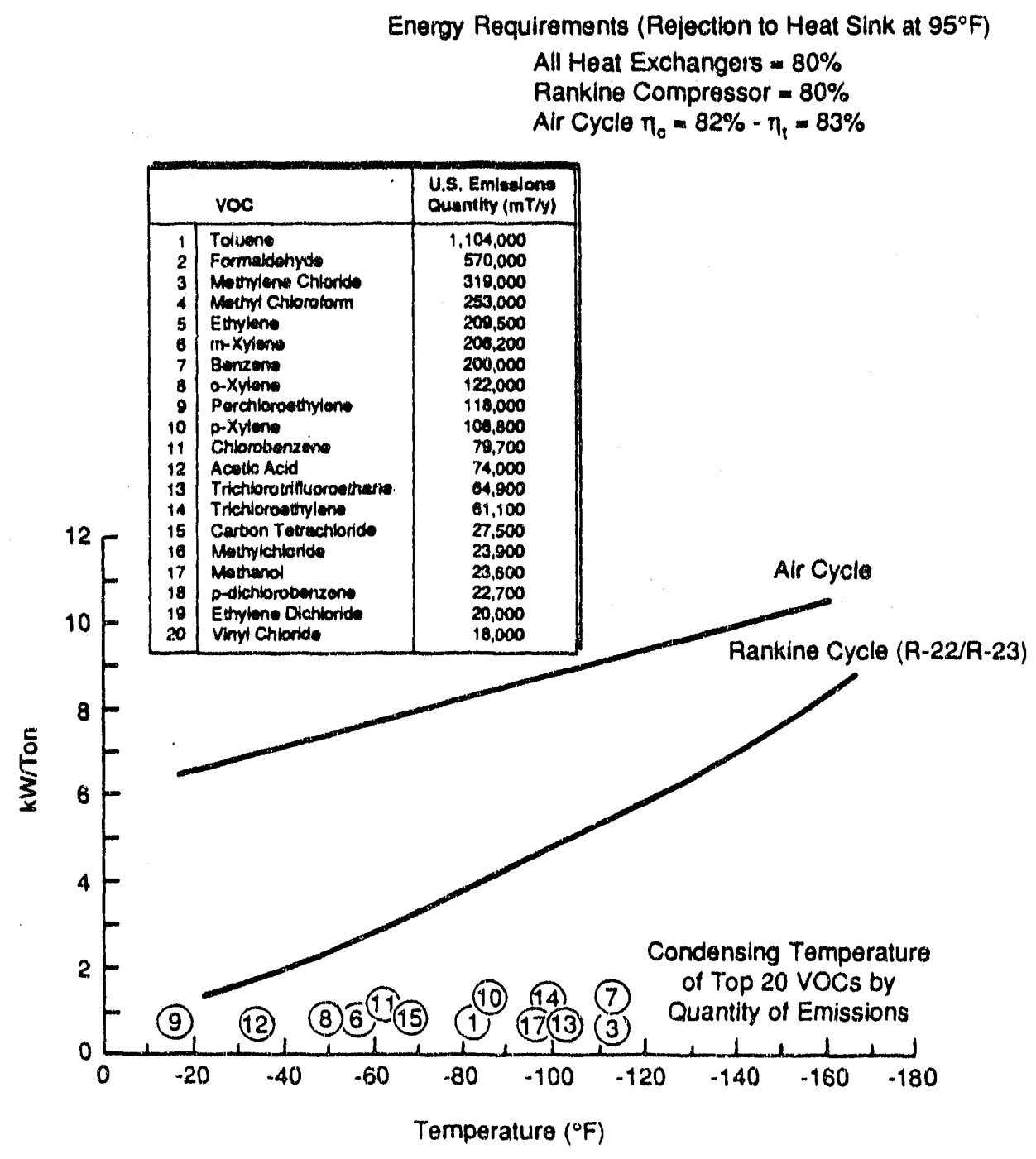

90168

Figure 5-5. Comparison of Refrigeration Cycle

temperatures and using reverse Rankine refrigeration to handle this refrigeration load at the elevated temperature, a significant system energy advantage can be achieved. For example, in an exhaust stream, with a $40 \%$ LEL solvent concentration and a $70 \%$ relative humidity $\left(70^{\circ} \mathrm{F}\right.$ dry bulb), roughly $50 \%$ of the refrigeration load occurs at temperatures above $-20^{\circ} \mathrm{F}$. In this case, the use of an intermediate temperature reverse Rankine refrigeration system to handle this toad with a $-30^{\circ} \mathrm{F}$ evaporator temperature provides nearly a $40 \%$ reduction in required system energy usage over the alternative of handling all of the refrigeration bad at $-100^{\circ} \mathrm{F}$ with Brayton refrigeration. 


\subsection{Process Flow Diagram}

A process flow schematic of the solvent recovery heat pump system is shown in Figure 5-6. Solvent-laden air is cooled to $100^{\circ} \mathrm{F}$ in a heat exchanger $(H \times 1)$ prior to entering the Brayton compressor. Typically, a mixture of solvent vapors and water is present. The baseline process inlet conditions are taken as 2200 -cfm flow, which consists of $9372 \mathrm{lb} / \mathrm{hr}$ air, $138 \mathrm{lb} / \mathrm{hr}$ methylene chloride, and $100 \mathrm{lb} / \mathrm{hr}$ water vapor. Operating at $19,600 \mathrm{~mm}$, the turbomachine compresses the mixture to $33.4 \mathrm{psia}$ and a temperature of $275^{\circ} \mathrm{F}$. A high-temperature recuperative heat exchanger (HX2) cools the compressed gas to $100^{\circ} \mathrm{F}$, using the solvent lean gas returning from the cold solvent condensation process. The lean gas is heated to $220^{\circ} \mathrm{F}$ in heat exchanger $\mathrm{H} \times 2$ prior to returning to the process for additional solvent vaporization.

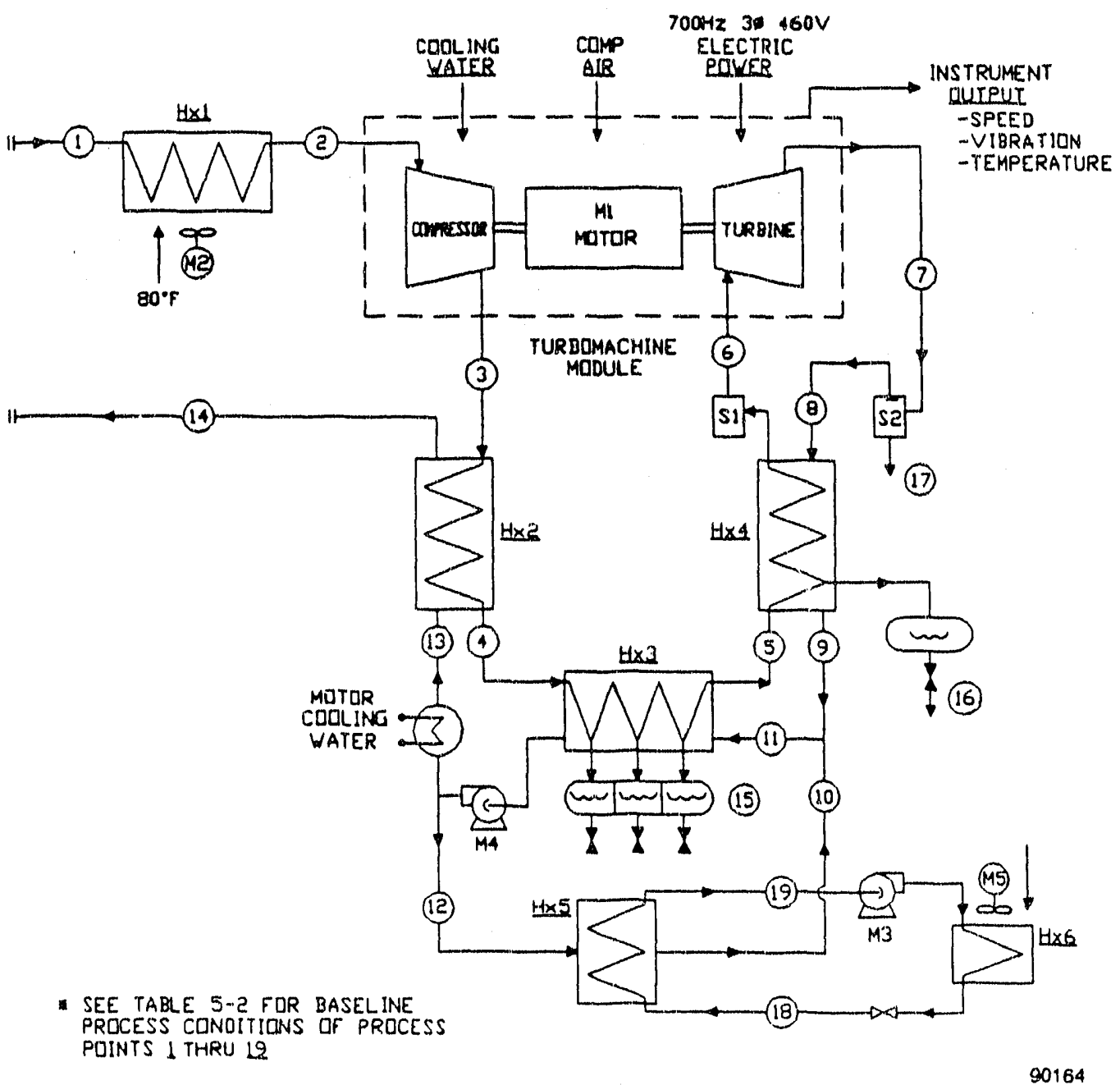

Figure 5-6. Process Flow Schematic of Solvent Recovery Heat Pump System 
In the intermediate temperature heat exchanger ( $H \times 3)$, the solvent-laden compressed gas is cooled to $15^{\circ} \mathrm{F}$, removing via condensation and frosting the majority of the water vapor present (see section 5.6.3 for a discussion of water vapor and frost). To handle the large latent loads associated with water vapor in normal ambient relative humidities, both reverse Rankine refrigeration combined with cold $\left(-20^{\circ} \mathrm{F}\right)$ solvent lean gas returning from a low-temperature heat exchanger $(H \times 4)$ are employed. As shown, the reverse Rankine system is incorporated in a recirculation side stream of the returning solvent lean gas, typically cooling the dry gas from $40^{\circ} \mathrm{F}$ to $-15^{\circ} \mathrm{F}$. Although the fixed surface evaporative coil operates at $-20^{\circ} \mathrm{F}$, no frosting occurs because the gas has a dew point of $-110^{\circ} \mathrm{F}$, having previously completed the expansion process.

The low-temperature heat exchanger (HX4) cools the compressed solvent-laden gas from -15 to $-60^{\circ} \mathrm{F}$, utilizing the $-110^{\circ} \mathrm{F}$ gas exiting the Brayton-cycle turbine. Solvent is condensed on the compressed gas side of heat exchanger $\mathrm{HX}_{4}$ as well as in the expansion process. Solvent separator $S 1$ is designed to prevent expander erosion by eliminating droplets larger than 5 micron from entering the turbine. Solvent separator S2, a cyclone separator and coalescing filter, collects the condensed solvent vapor from the turbine exhaust.

Table 5-2 shows the baseline process conditions of pressure, temperature, and vapor concentration at the 19 process points shown in the process flow schematic of Figure 5-6. In this baseline case, the 2200-cfm system recovers methylene chloride at $95 \%$ efficiency and simultaneously separates water vapor. For this case, water vapor was assumed to enter the system at the rate of $100 \mathrm{lb} / \mathrm{hr}$. (This is the equivalent of $90 \%$ relative humidity at a room temperature of $70^{\circ} \mathrm{F}$.) At these solvent and water vapor loading conditions and a system pressure ratio of 2.3, a turbine outlet temperature of $-108^{\circ} \mathrm{F}$ is achieved.

\subsection{System Simulation Model}

A computer model simulating system performance was instrumental in establishing the Phase I system design. The model was continuously updated to reflect refinements in process and equipment. The end result was a model that could be used to predict baseline system performance on seven common industrial solvents: toluene, acetone, methanol, methyl ethyl ketone, methylene chloride, perchloroethylene, and trichloroethylene. Characteristics of these seven solvents were included in the program data base. The model was also capable of assessing the sensitivity of system performance to various options in component selection and specification.

Figure 5-7 shows a simple schematic of the combined Brayton-Rankine solvent recovery heat pump process modei. A mathematical model included the algorithms for calculation of compressor, turbine, and motor pertorrnance based on shaft speed and process conditions. In addition to the turbomachine speed, the other model input variables included:

- $\mathrm{PR}_{\mathrm{C}}=$ compressor pressure ratio

- $T_{A}=$ amblent temperature for heat rejection

- $T_{5}=$ temperature of reverse Rankine evaporator

- $T_{2}=$ compressor inlet temperature 
Table 5-2. Baseline Process Conditions

\begin{tabular}{|c|c|c|c|c|c|}
\hline \multirow[b]{2}{*}{$\begin{array}{c}\text { Proceses } \\
\text { Point }\end{array}$} & \multicolumn{3}{|c|}{ Fluld Allocation } & \multirow[b]{2}{*}{$\begin{array}{l}\text { Preseure } \\
\text { (psla) }\end{array}$} & \multirow[b]{2}{*}{$\begin{array}{c}\text { Temperature } \\
\left.\text { ( }{ }^{\circ} \mathrm{F}\right)\end{array}$} \\
\hline & $\begin{array}{c}\text { Alr } \\
(\mathbf{l b} / \mathbf{h r})\end{array}$ & $\begin{array}{c}\text { Solvent } \\
\text { (lb/hr) }\end{array}$ & $\begin{array}{l}\text { Water } \\
\text { (lb/hr) }\end{array}$ & & \\
\hline $\begin{array}{r}1 \\
2 \\
3 \\
4 \\
5 \\
6 \\
7 \\
8 \\
9 \\
10 \\
11 \\
12 \\
13 \\
14 \\
15 \\
16 \\
17\end{array}$ & $\begin{array}{r}9,372 \\
9,372 \\
9,372 \\
9,372 \\
9,372 \\
9,372 \\
9,372 \\
9,372 \\
9,372 \\
13,021 \\
22,393 \\
22,393 \\
9,372 \\
9,372 \\
- \\
- \\
-\end{array}$ & $\begin{array}{r}138.0 \\
138.0 \\
138.0 \\
138.0 \\
138.0 \\
- \\
\overline{-} \\
4.9 \\
4.9 \\
6.8 \\
11.7 \\
11.7 \\
4.9 \\
4.9 \\
-\overline{4} \\
42.4 \\
90.7\end{array}$ & $\begin{array}{r}100 \\
100 \\
100 \\
100 \\
5.5 \\
0.08 \\
0 \\
0 \\
0 \\
0 \\
0 \\
0 \\
0 \\
0 \\
94.5 \\
5.4 \\
-\end{array}$ & $\begin{array}{r}14.7 \\
14.5 \\
33.35 \\
33.15 \\
32.65 \\
31.65 \\
16.4 \\
15.4 \\
15.1 \\
15.1 \\
15.1 \\
14.8 \\
15.0 \\
14.7 \\
32 \\
32 \\
16.4\end{array}$ & $\begin{array}{r}+150 \\
+95 \\
+275 \\
+100 \\
+15 \\
-60 \\
-107 \\
-107 \\
-20 \\
-10 \\
-14 \\
+40 \\
+40 \\
+222 \\
-75 \\
-60 \\
-107\end{array}$ \\
\hline $\begin{array}{l}\text { Procases } \\
\text { Point }\end{array}$ & \multicolumn{3}{|c|}{$\begin{array}{l}\text { Flow } \\
\text { (lb/hr) }\end{array}$} & $\begin{array}{c}\text { Presesure } \\
\text { (psi) }\end{array}$ & $\begin{array}{c}\text { Temperature } \\
\left({ }^{\circ} \mathrm{F}\right)\end{array}$ \\
\hline $\begin{array}{l}18 \\
19\end{array}$ & \multicolumn{3}{|c|}{$\begin{array}{l}2650 \\
2650\end{array}$} & $\begin{array}{r}270.2 \\
19.7\end{array}$ & $\begin{array}{r}+115 \\
-30\end{array}$ \\
\hline
\end{tabular}

- SLA stream characteristics:

- Flow rate, $\mathrm{lb} / \mathrm{hr}$

- Temperature, ${ }^{\circ} \mathrm{F}$

- Inlet water vapor, grains/lb dry air

- Inlet solvent composition and concentration ppmv.

The computer model calculated the turbomachine performance parameters of motor horsepower and component efficiencies as well as system temperatures, pressures, and vapor concentrations at the nine process points indicated in the Figure 5-7. At the completion of the Phase I effort, the capability of the model was limited to single component solvent streams with and without water vapor under steady-state conditions. The data presented in Table 5-2 are representative of the output available from the model. 


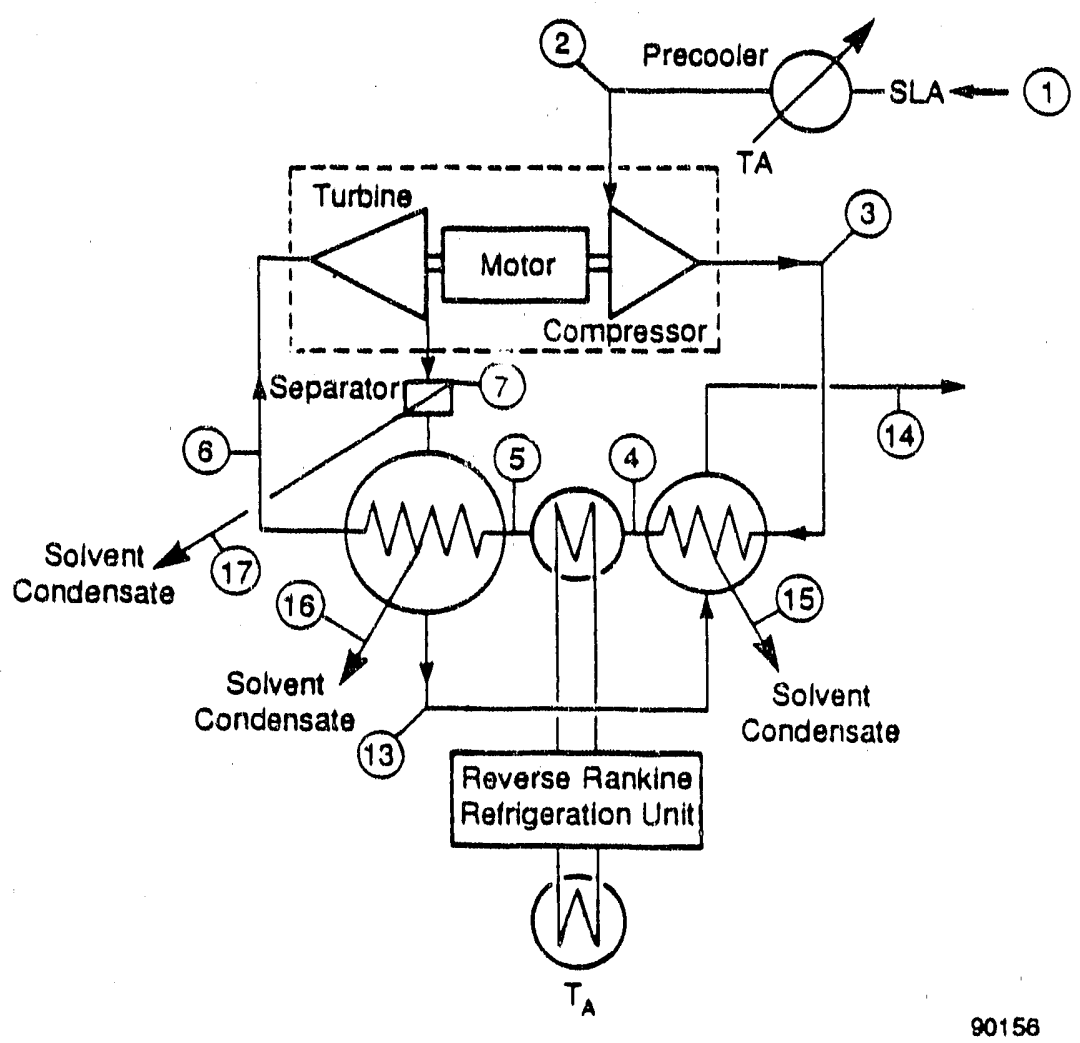

Figure 5-7. Schematic of Combined Brayton-Rankine Process Model

\subsubsection{Performance}

Using the system model, the heat pump performance in the direct process-connected arrangement was estimated for seven common industrial solvents. It was found that both application-specific factors and equipment operational parameters influence system recovery efficiency, i.e., percent of inlet solvent recovered. The primary application factors involved are solvent vapor pressure, solvent concentration, and amount of water vapor present. Equipment-specific factors include turbomachine speed (pressure ratio) and reverse Rankine refrigeration system loading.

Figures 5-8 through 5-14 present the calculated system performance for the seven industrial solvents used in the system model. These performance curves show the percent of solvent recovered as a function of the concentration of solvent entering the system. The impact of water vapor on system periormance is also indicated. A turbomachine operational speed of $19,600 \mathrm{rpm}$ and a reverse Rankine refrigeration load of 7 tons were used in the calculation of performance shown in these figures. Variations in these operational set points would, of course, produce different system performance. 


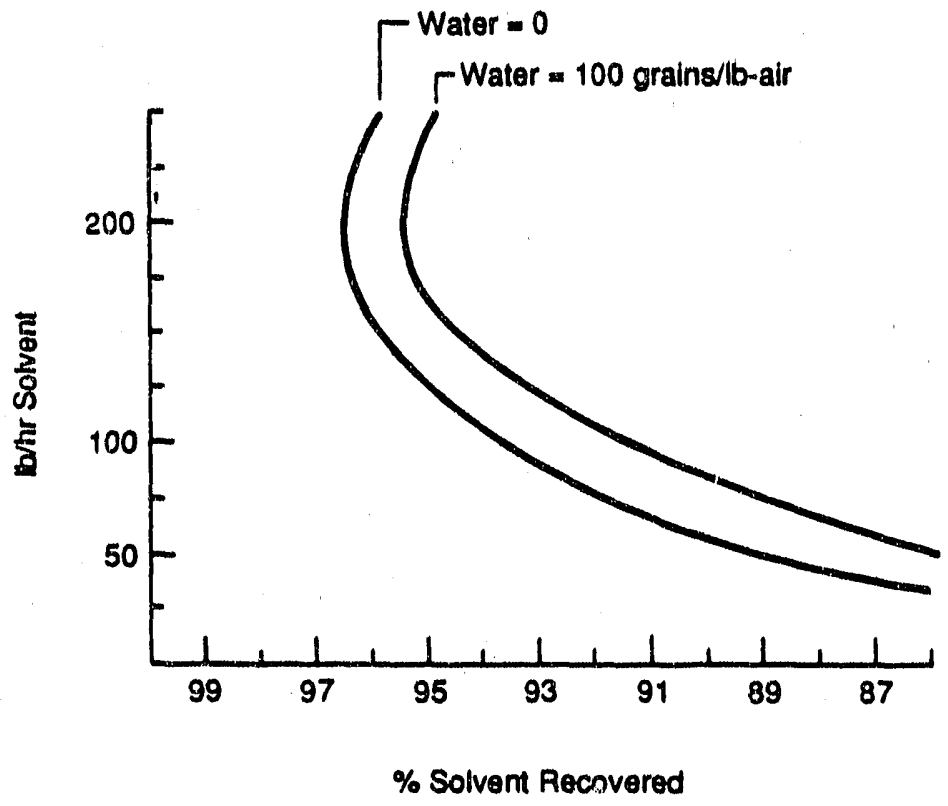

Figure 5-8. System Perfomance for Methylone Chloride (2200-cfm System)

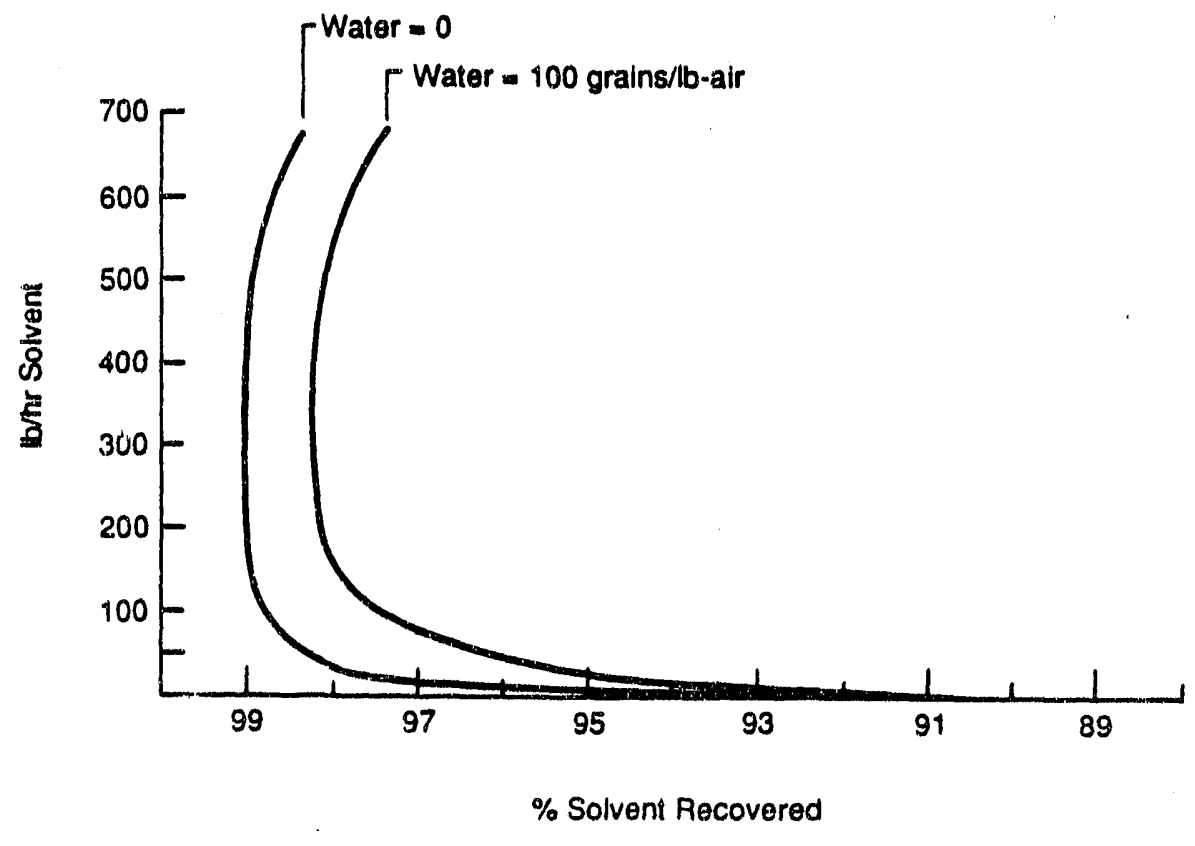

Figure 5-9. System Performance for Toluene (2200-cfm System) 
Mechanical Technology Iric.

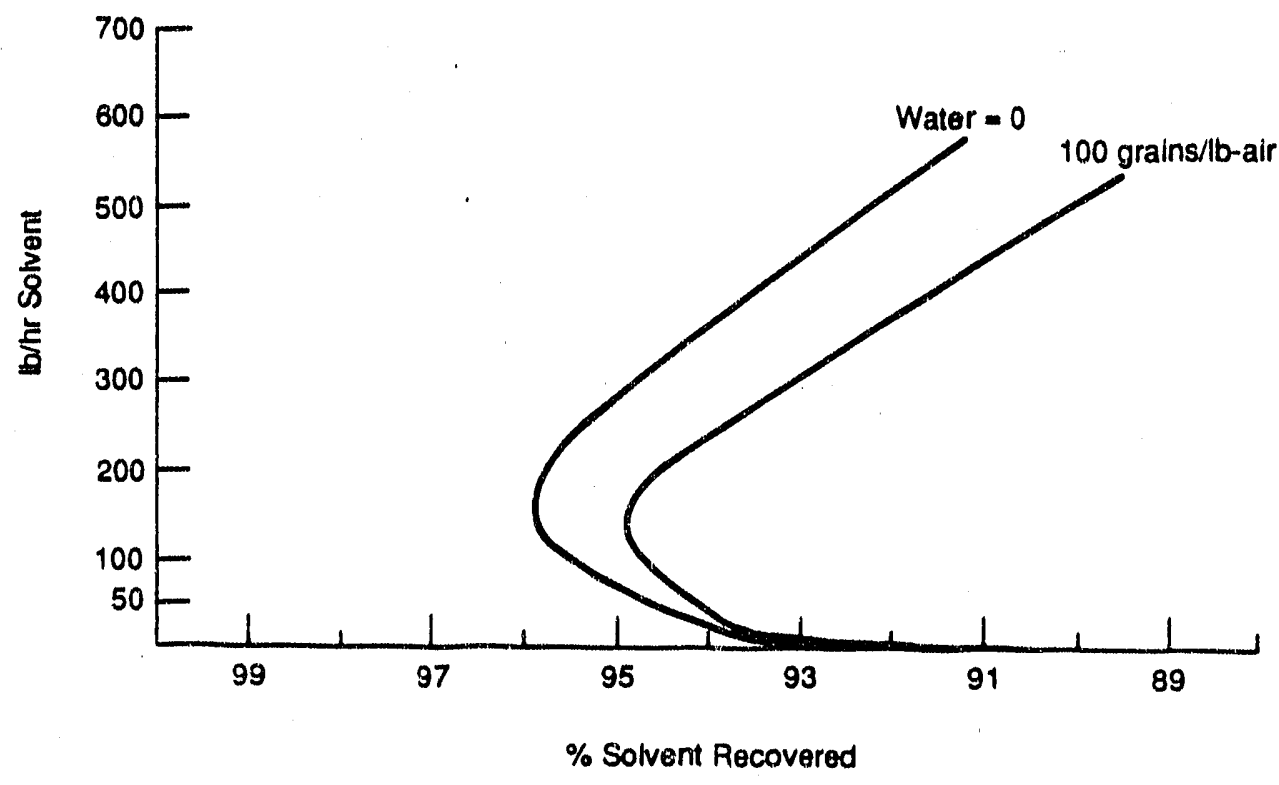

Figure 5-10. System Pertormance for Acetone (22.00-cfm System)

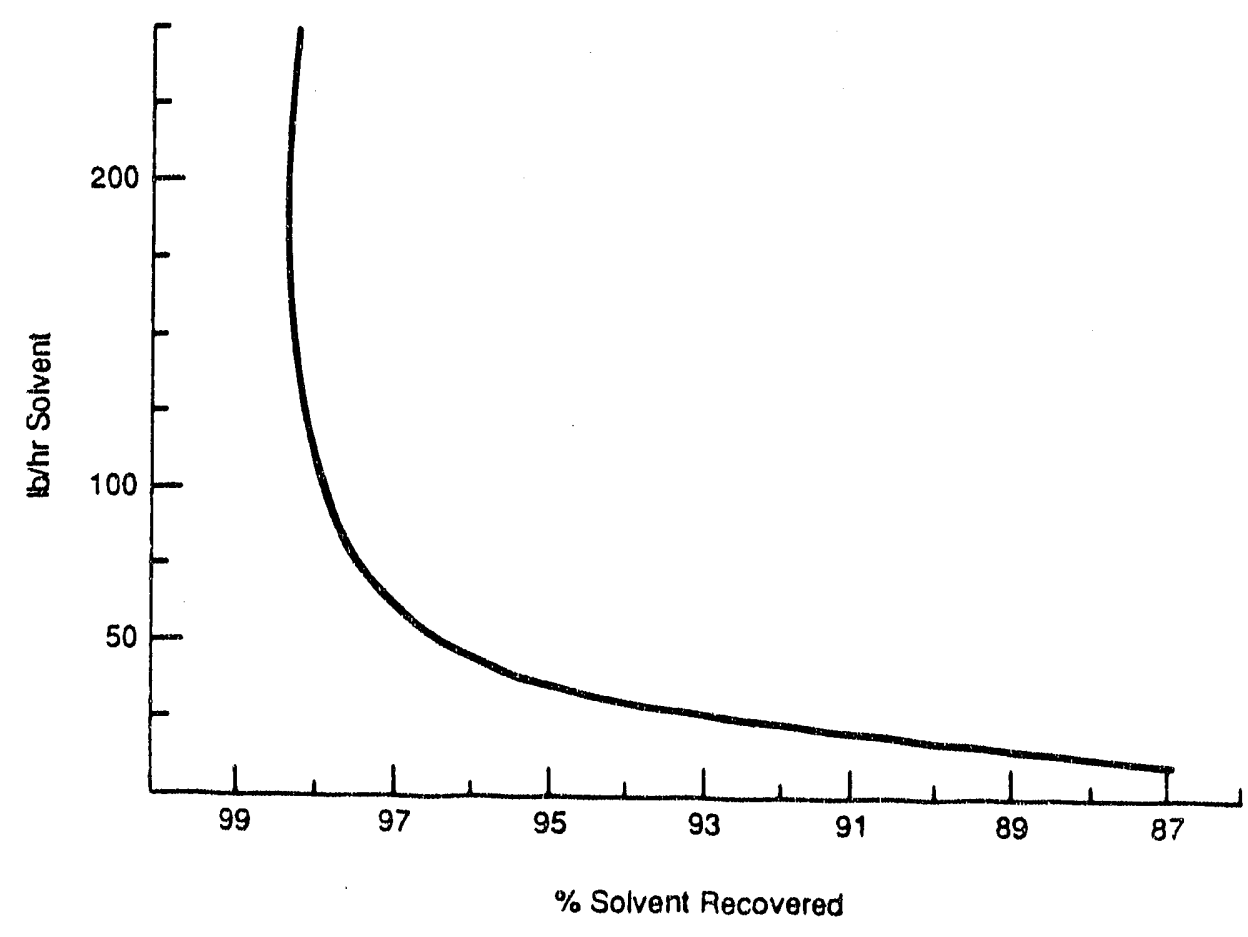

Figure 5-11. System Performance for Tetrahydrofuran (2200-cfm System) 


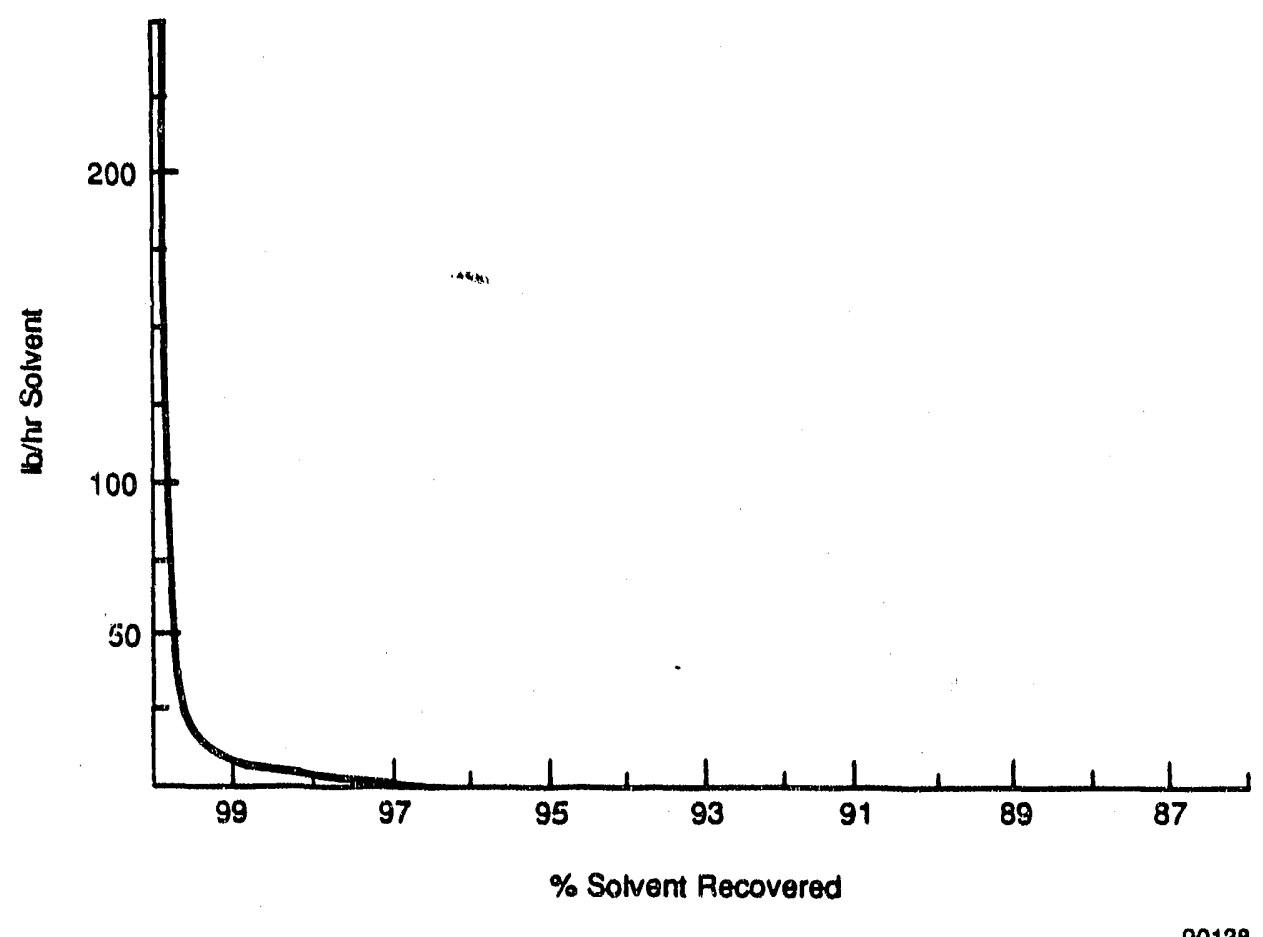

Figure 5-12. System Performance for Trichloroethylene (2200-cfm System)

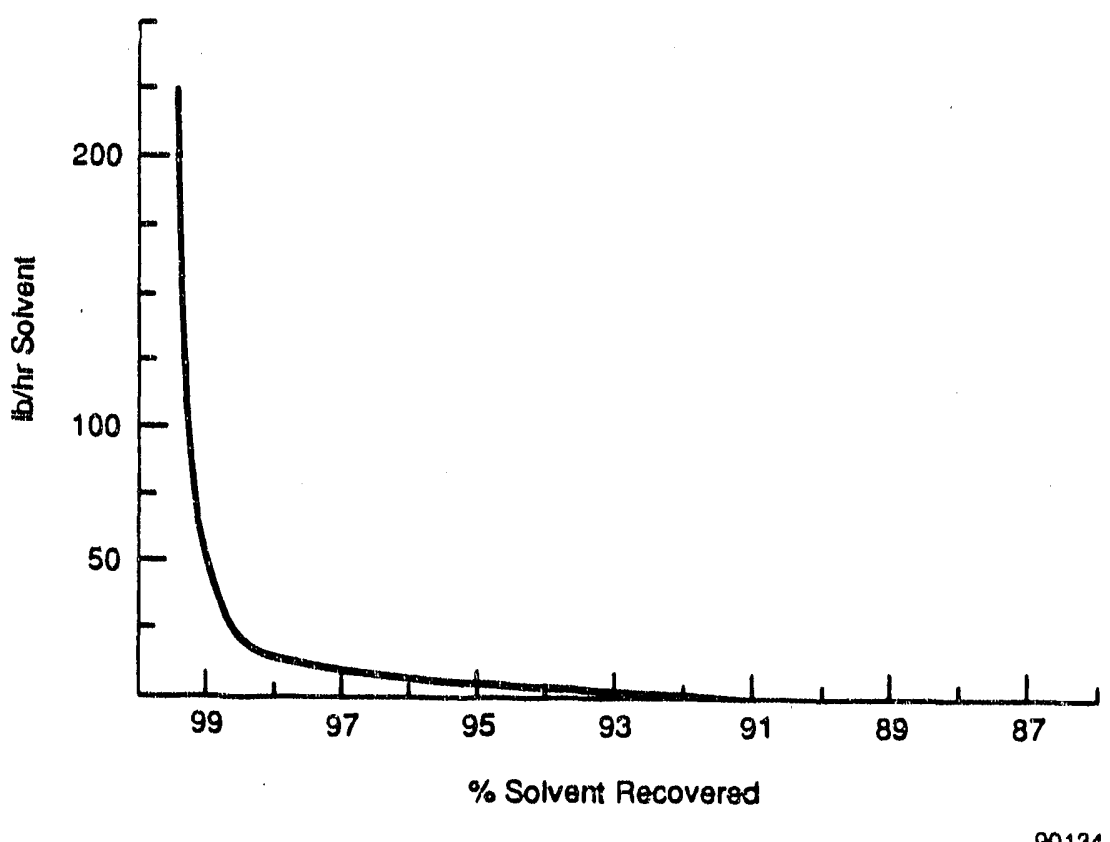

Figure 5-13. System Performance for Perchloroethylene (2200-cfm System) 


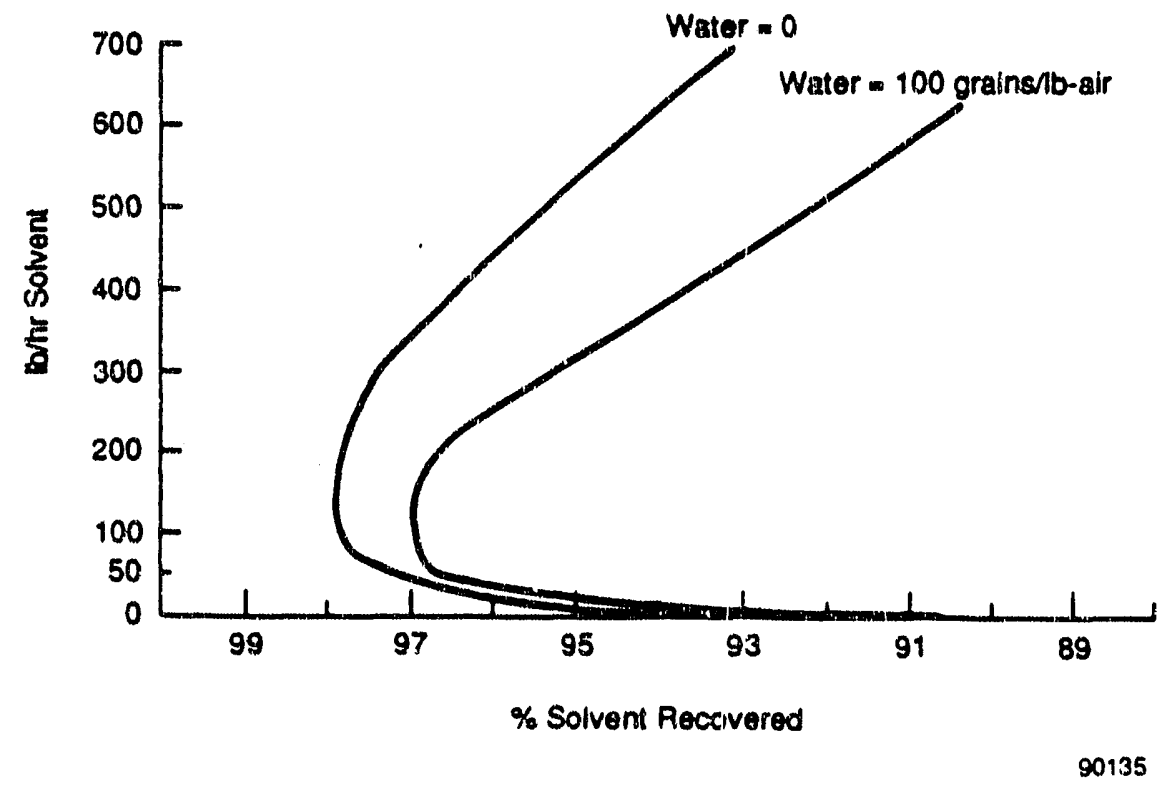

Figure 5-14. System Pe troma.7ce for Methyl Ethyl Kotono

\subsection{Mobile Unit Design}

\subsubsection{Process Description}

To meet the solvent recovery needs of applications typical to NYS, a mobile heat pump unit for the desorption of fixed base, solvent concentrating (carbon bed) adsorbers was established. As previously discussed, a key feature of this approach is that it spreads the high cost of the solvent recovery system over a large number of users. These users may also lease the site-based adsorbers, thersby eliminating all capital costs.

Figure 5-15 shows a schematic of the mobile unit for inert desorption. As shown, three system connections to the host site via a flexitle hose are required: natural gas supply, inert gas supply, and inert gas return. A truck.mounted service module interfaces the solvent-concentrating adsorioer with the heat pump system and provides all of the services required to operate the system.

A natural gas fueled, internal combustion engine drives a 40-pole, synchronous generator, providing the variable, high-frequency power required by the Brayton-cycle turbomachine. An electric drive control system corttrols reverse Rankine refrigeration system speed and provides 60 -cycle power to the balance of plant equipment.

Engine jacket cooling water is used in conjunction with a blower (B1) and a heat exchanger ( $\mathrm{H} \times 6)$ to provide process heat at high volumetric flow to the fixed-bed adsorber for rapio heat-up. Engine exhaust heat is used in conjunction with another heat exchanger $(H \times 7)$ to vaporize the solvent from the bed. The exhaust is also used to supply oxygen-deficient, noncombustible inert gas to the system. 


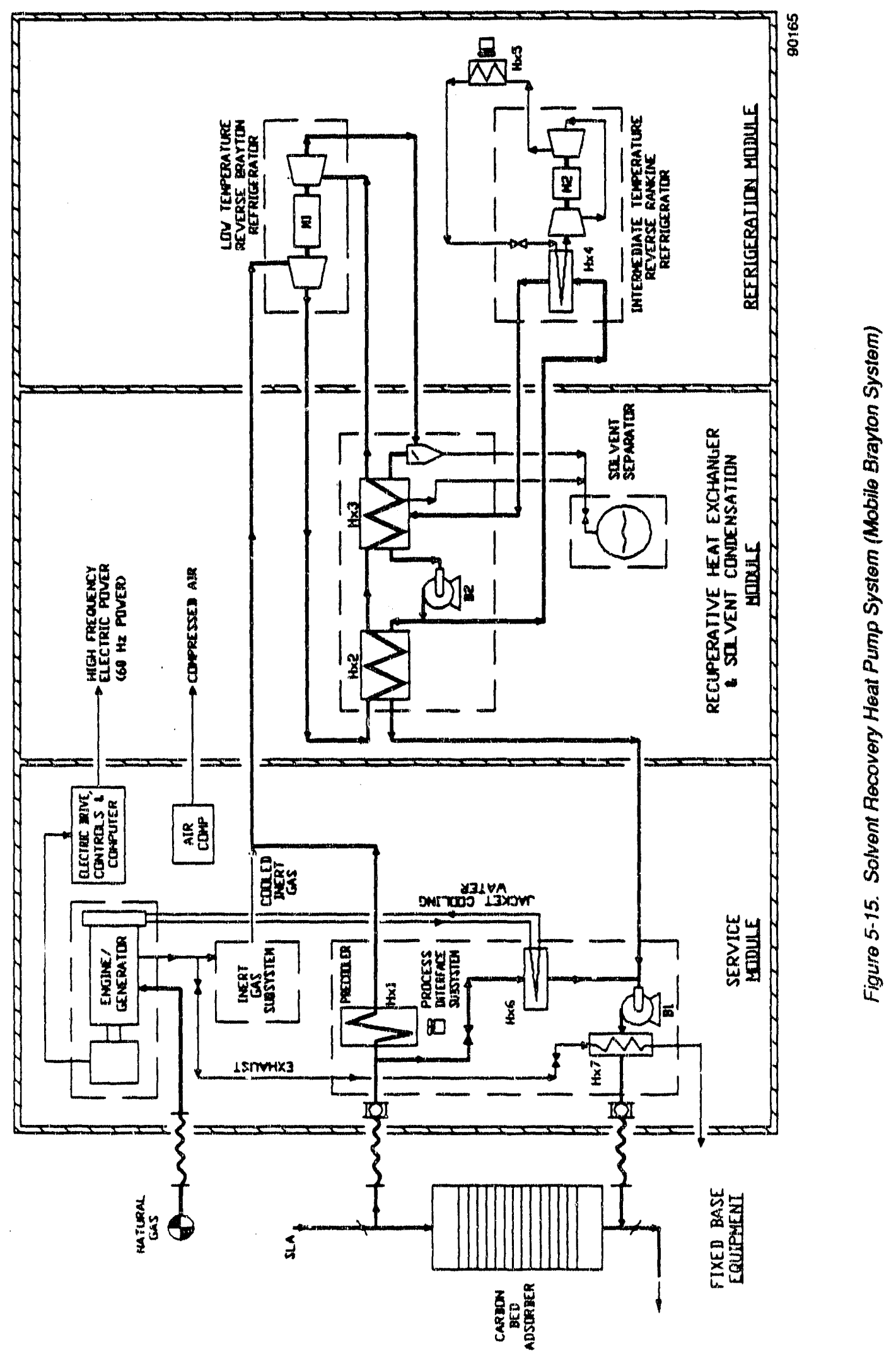


Key subsystems of the service module include the following:

- A natural-gas-fueled engine-generator supplying $170-\mathrm{kW}, 700-\mathrm{Hz}$, 3-phase electrical power.

- An electric drive and control subsystem that distributes high-frequency power and converts inigh-trequency power to $60 \mathrm{~Hz}$ for small motors. Also used for control and data acquisition purposes.

- An inert gas subsystem used to purge oxygen from the system prior to desorption.

- Process interface subsystem used to increase rate of heat input for sesorption. The equipment consists of two heat exchangers ( $H X 6$ and $H X 7)$ and one blower (B1) along with appropriate ducting and diverter valves.

\subsubsection{Mobile Unit Packaging}

The packaging concept for the mobile unit is shown roughly to scale in Figure 5-16. The complete system is housed in a standard $28-\mathrm{ft}$ box van, allowing $5 \mathrm{ft}$ of space near the rear of the van for storage of the flexible duct work.

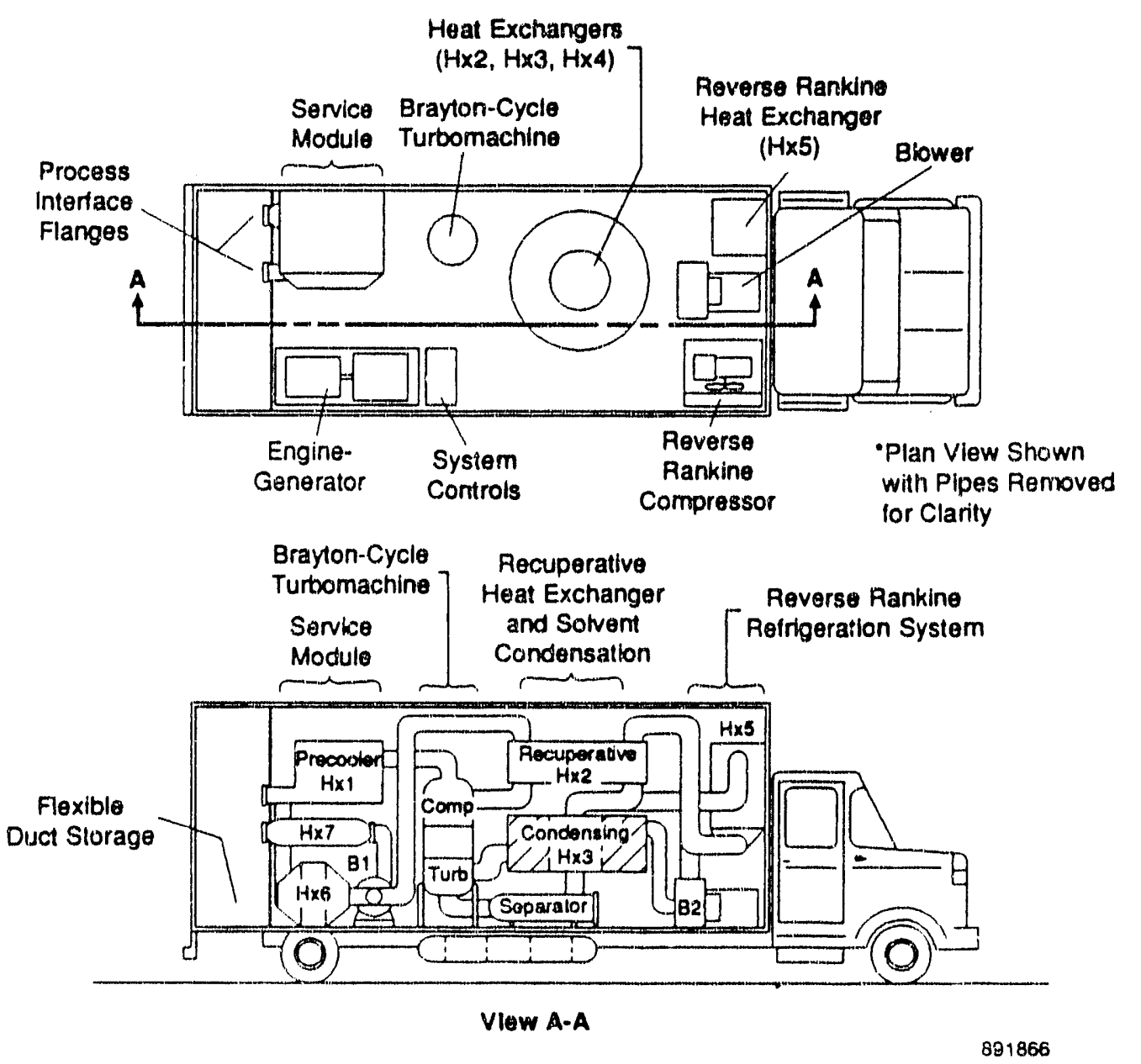

Figure 5-16. Packaging Concept for Mobile Unit 


\subsubsection{System Controls}

The operational procedure for fixed-bed desorption using the mobile unit consists of five phases:

- Phase 1 - Site Connection. The adsorber is isolated from the emission source and connected to the mobile unit with flexible duct work. The internal combustion engine is also connected to the natural gas stub up.

- Phase 2 - System Inerting. An inert gas blanket is generated through the operation of the intemal combustion engine. The refrigeration equipment is put on line to provide a load for the engine and to remove the water vapor produced in the combustion process via condensation. Oxygen concentration is monitored, and the purge is complete when oxygen content is below $4 \%$ by volume.

- Phase 3-Bed Heat-up and Water Removal. The Brayton-cycle turbomachine compressor heat plus heat rejected from the engine exhaust and water jacket are diverted to the bed. The bed temperature slowly rises. With concurrent desorption, water is desorbed first from the bed and is removed from the system via condensation in a recuperative heat exchanger module.

- Phase 4 - Solvent Recovery. High-temperature engine exhaust heat is diverted to the bed. As the bed temperature rises, the mass transfer zone moves and solvent is released from the bed in high concentration. Brayton pressure ratio and reverse Rankine capacity are modulated for maximized solvent recovery.

- Phase 5-Cool Down and Water Replacement. Heat input to the bed is stopped, cool dry inert gas is retumed for cooling the bed. Water previously removed from the bed in Phase 3 is vaporized and returned to the bed.

An elementary piping and instnumentation drawing showing all of the active components in the mobile unit is presented in Figure 5-17. Figure 5-18 presents the operating logic diagram defining the sequential operations of the system during start-up and shutdown, identifying operator actions and automated functions, and indicating safety shutdown and warning sequences, as well as displays and operator indications.

\subsection{Balance of Plant Equipment}

The Phase I preliminary design effort included performance definition of the balance of plant equipment and the establishment of commercial availability for this equipment. The major system modules include the refrigeration module, which combines a reverse Rankine refrigeration system with the Brayton-cycle turbomachine, the recuperative heat exchanger and solvent condensation module, and the service module, which includes the engine/generator, electrical power distribution, and inert gas cleanup equipment. The performance requirements of each of these modules, with the exception of the Braytoncycle turbomachine and the system controls described eartier, is presented in the following subsections. 


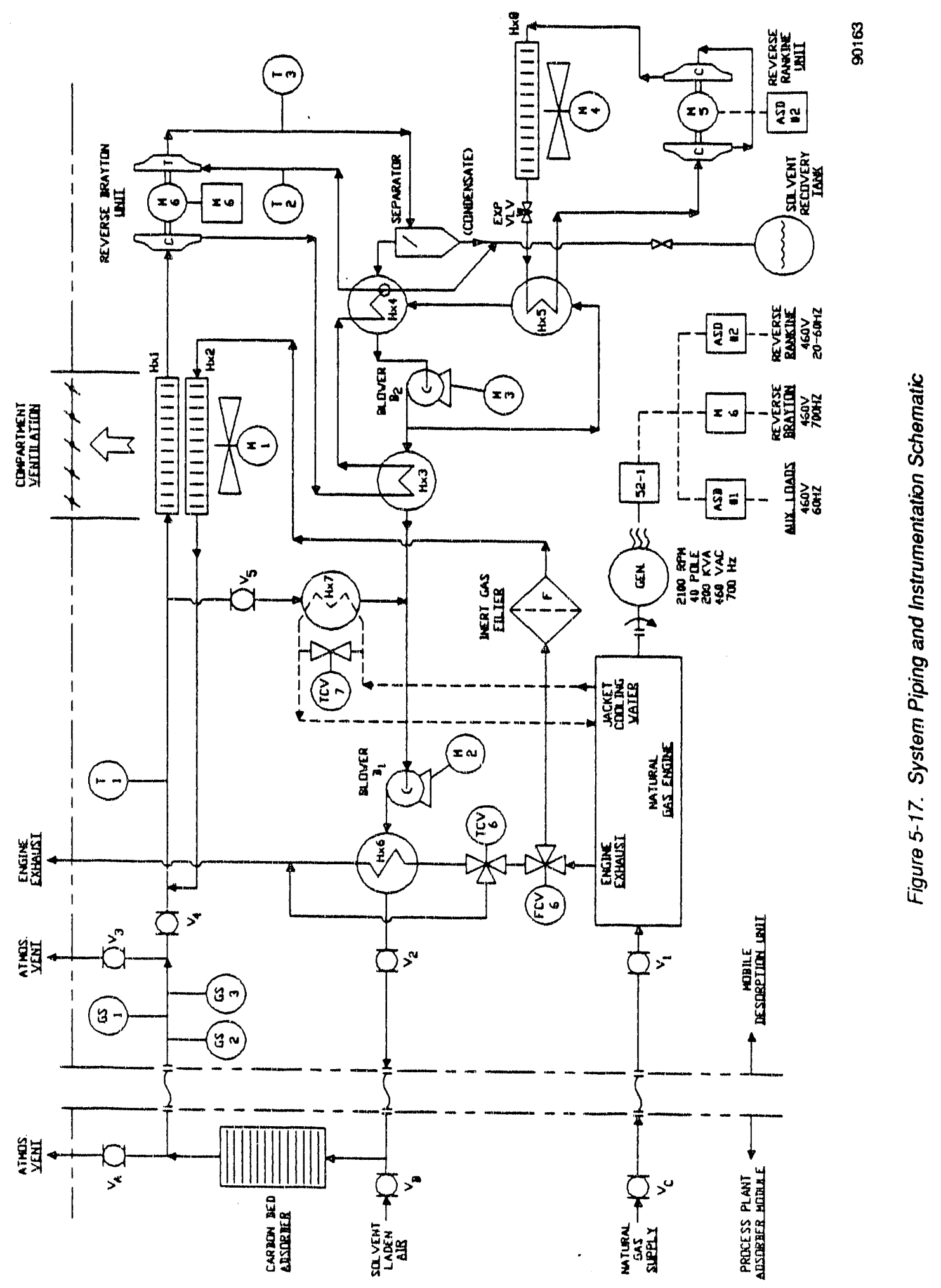




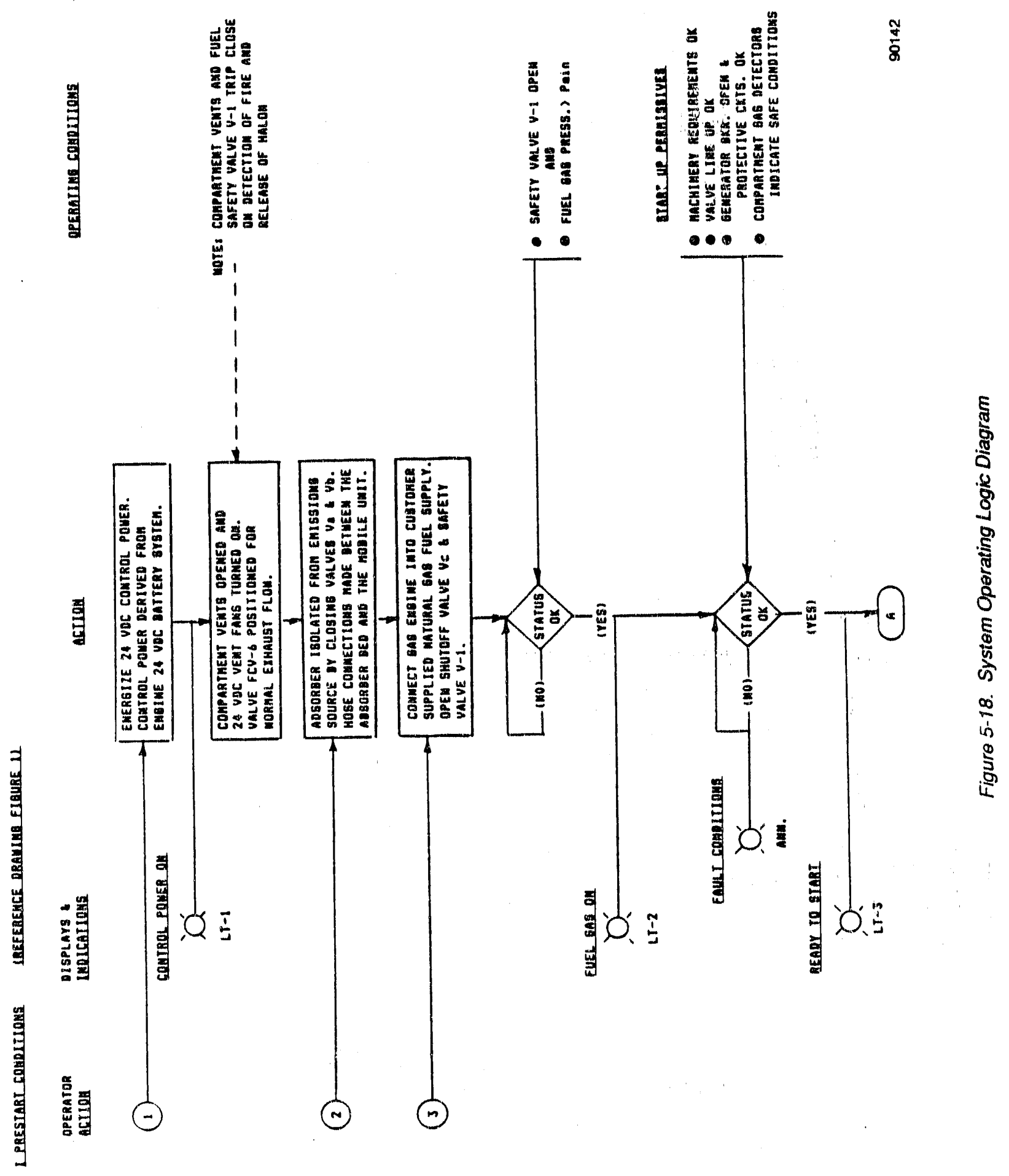


Mechanical Technology Inc.

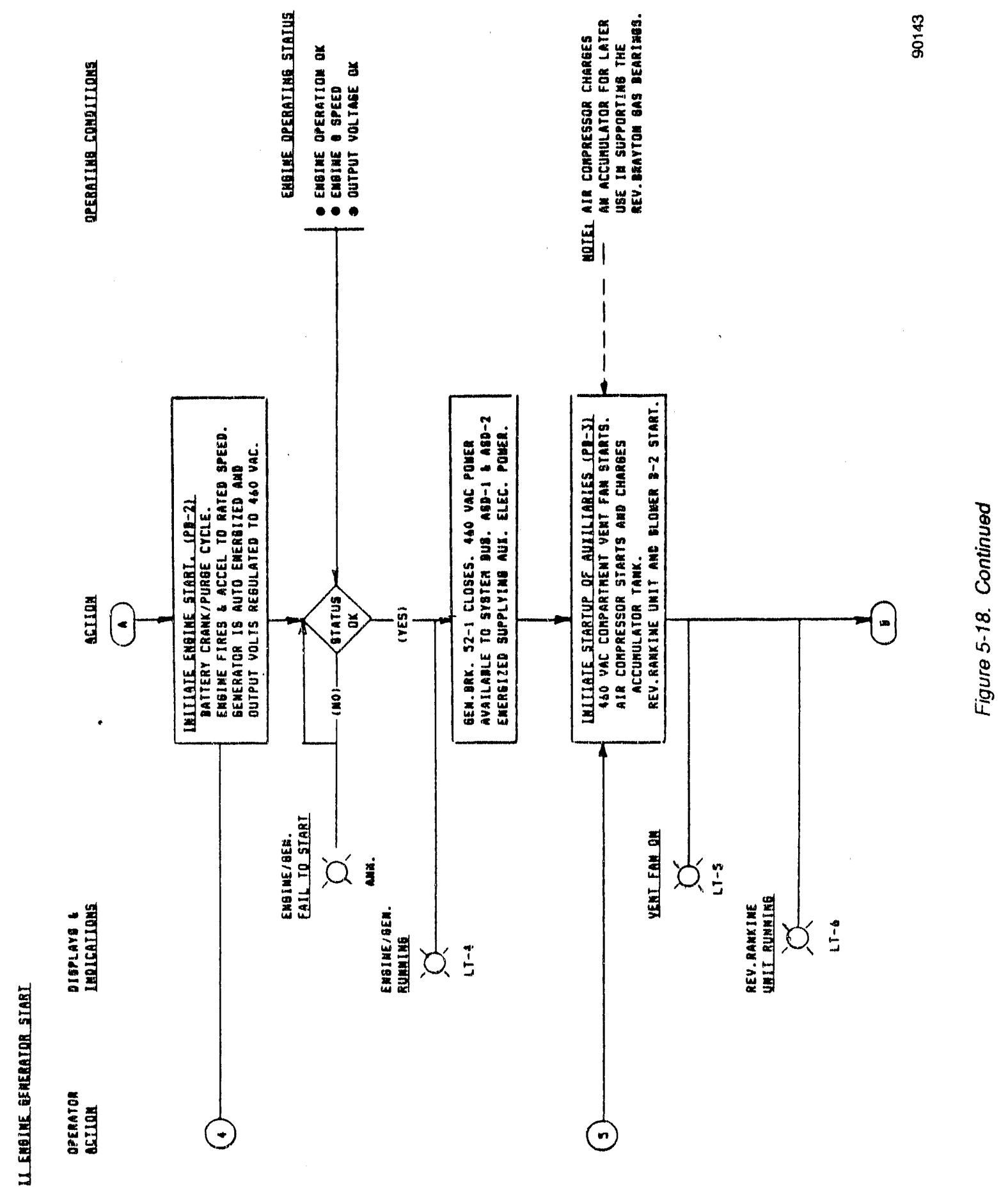




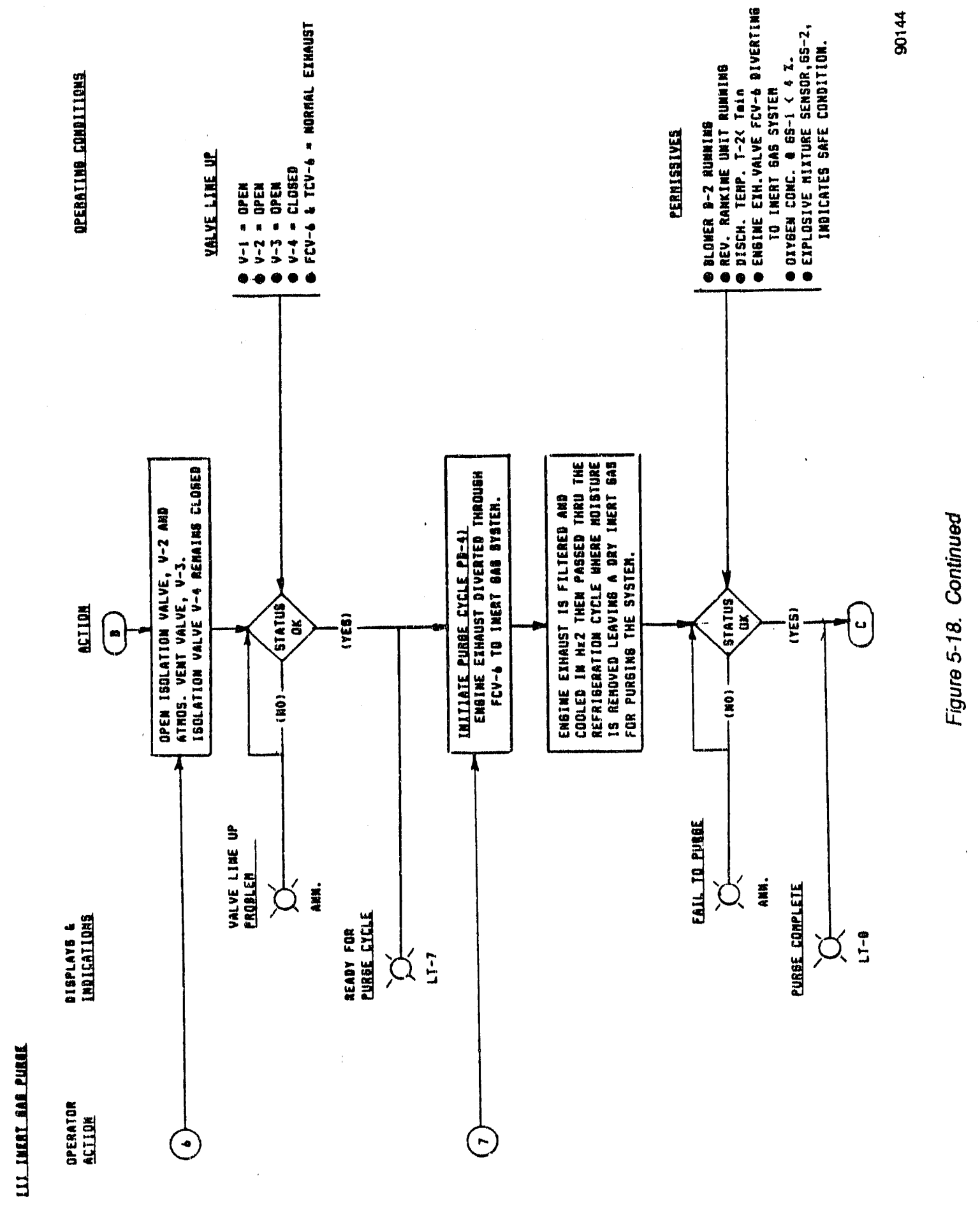




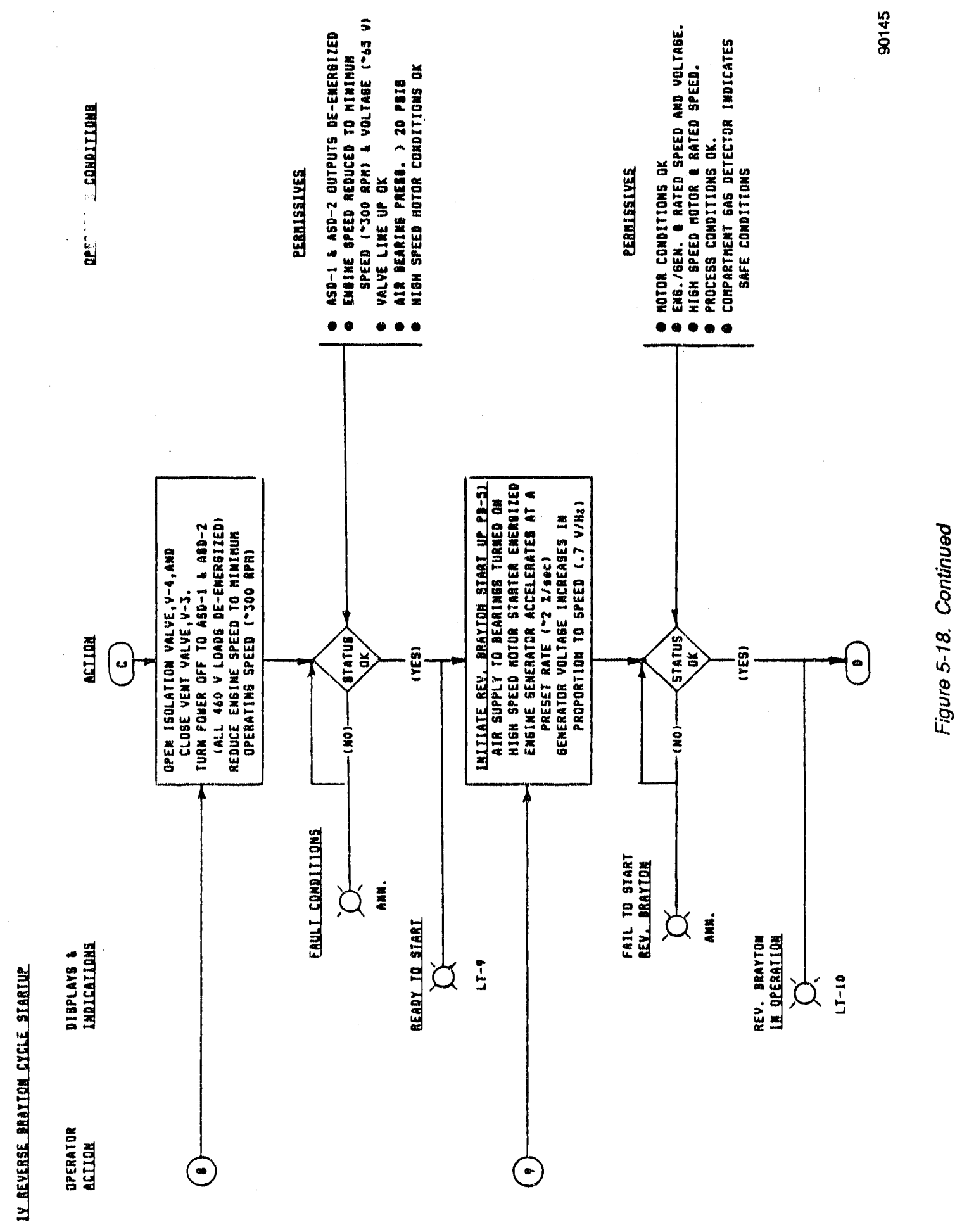




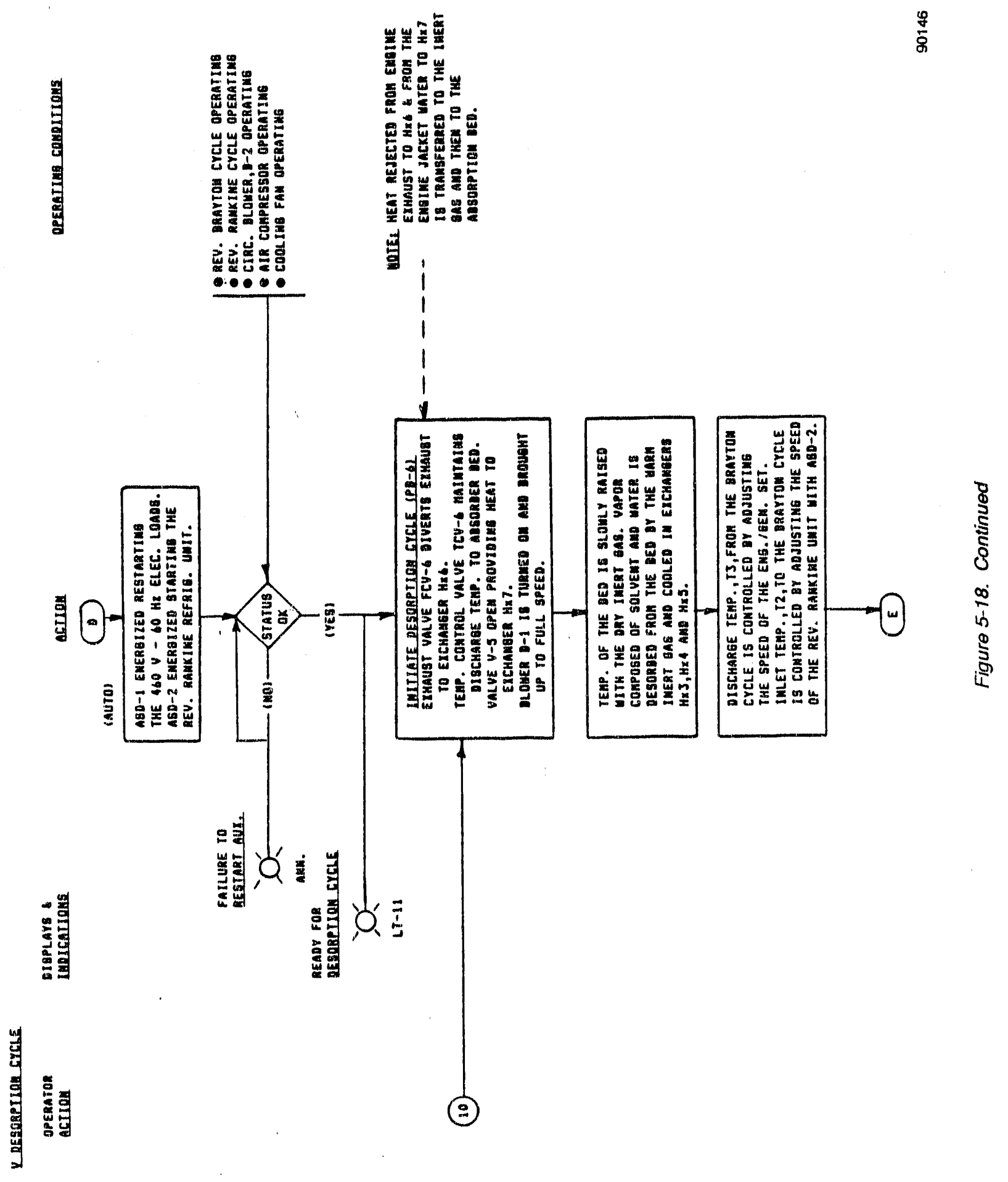


Mechanical Technology Inc.

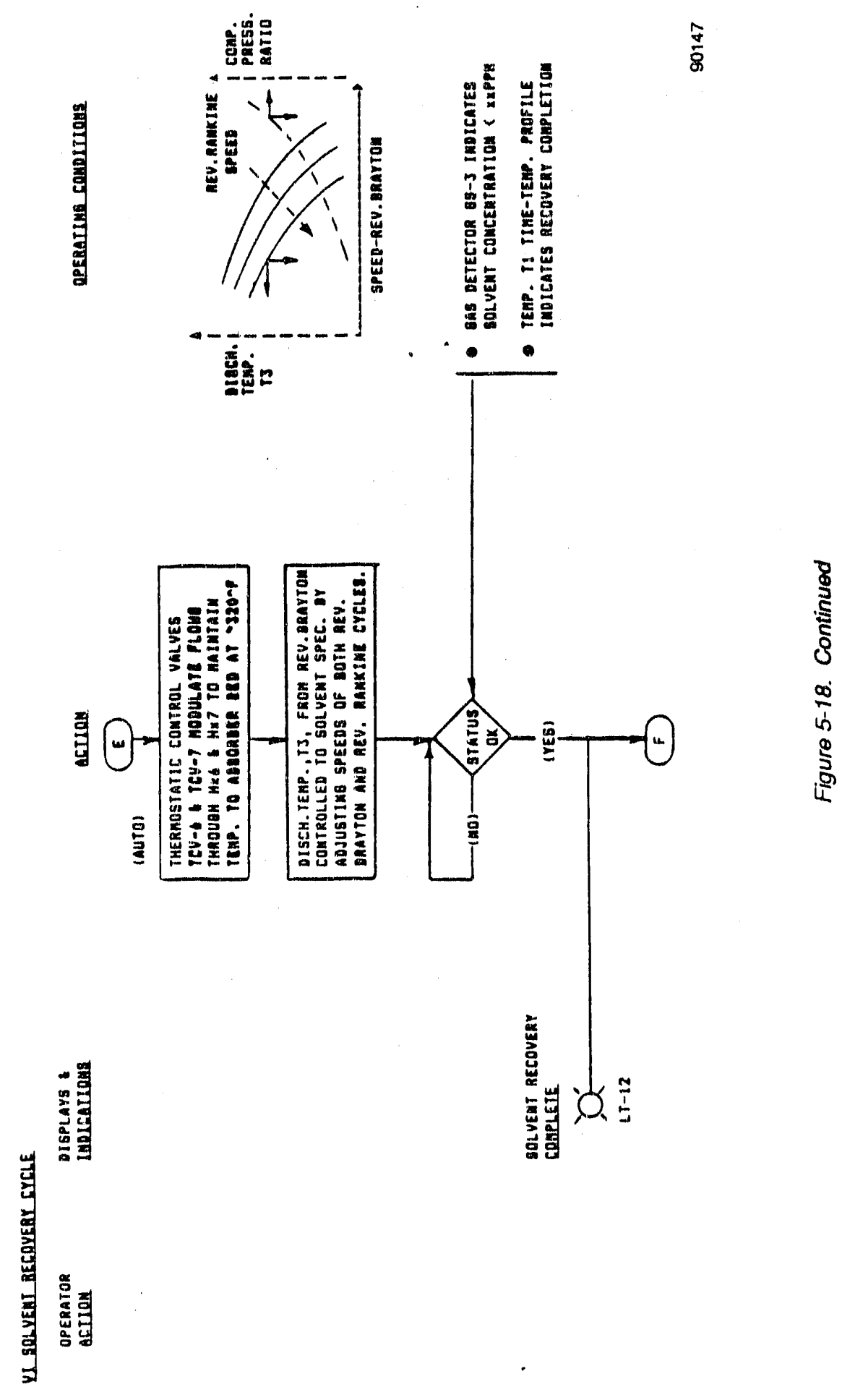


Mechanical Technology Inc.

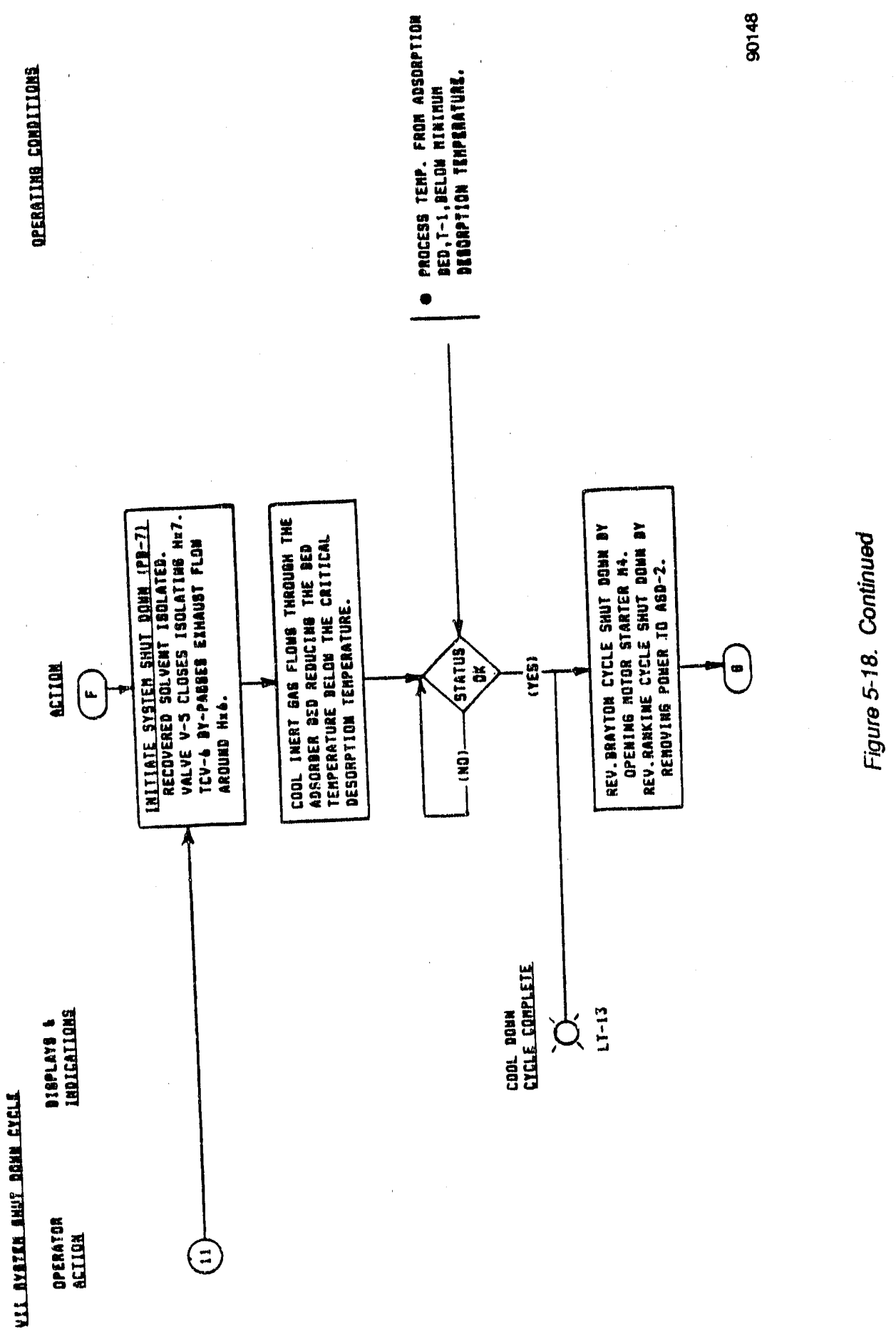


Mechanical Technology Inc.

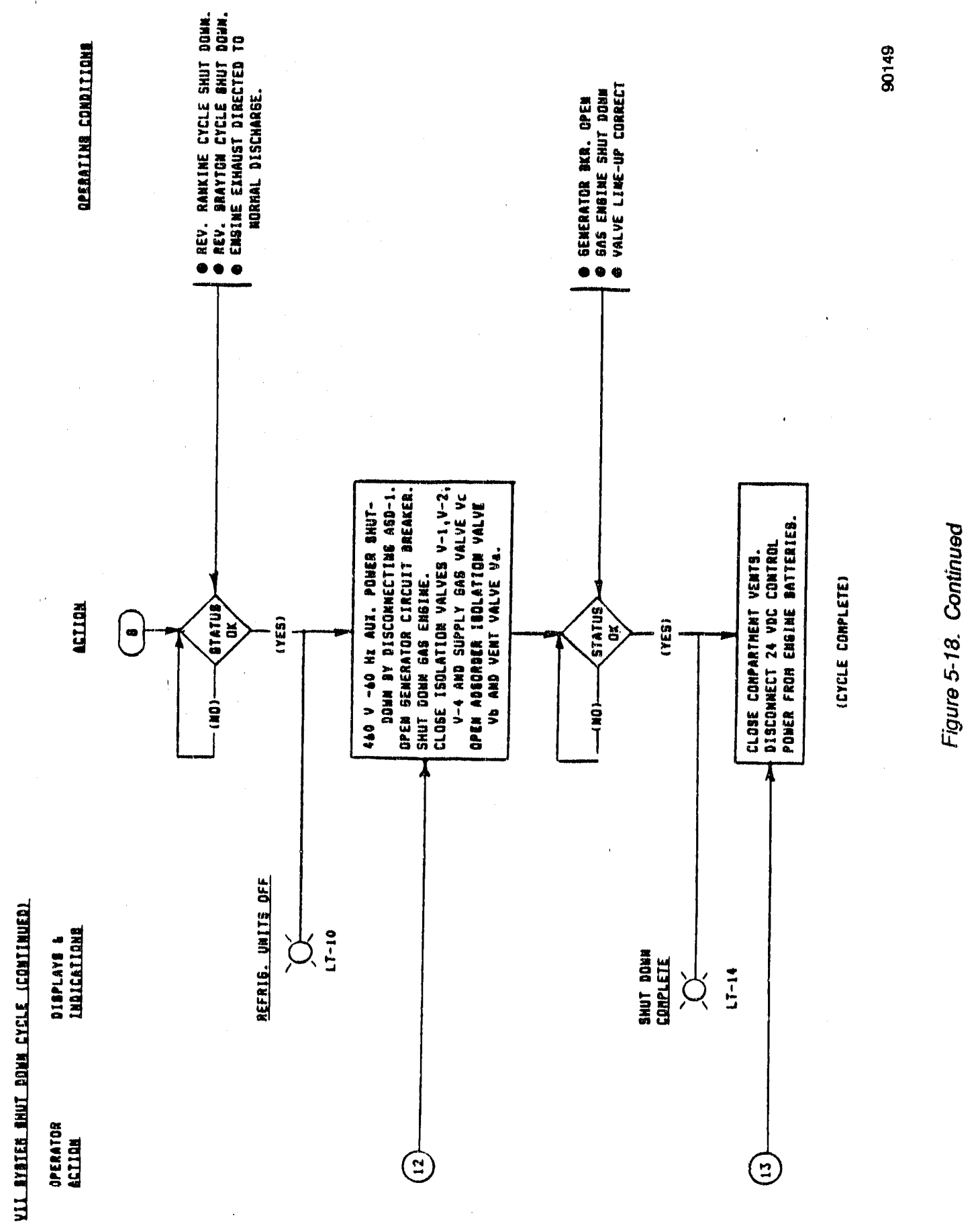




\subsubsection{Reverse Rankine Refrigeration System}

The reverse Rankine refrigeration system is a standard, skid-mounted refrigeration unit consisting of a two-stage positive-displacement compressor and an air-cooled condenser capable of providing 10 tons of refrigeration at an evaporator temperature of $-30^{\circ} \mathrm{F}$ and of rejecting heat at $115^{\circ} \mathrm{F}$. Refrigerant $\mathrm{R}-22$ was selected as the process fluid because it has been determined to be one of the most environmentally safe chlorinated fluorocarbons (CFC) and is not scheduled to be removed from production in accordance with the Montreal protocol that limits global CFC manufacture. The prepackaged unit is to be supplied with unloaded start capability, oil separator, suction/liquid heat exchanger, air-cooled condenser with fan and head pressure control, high-pressure receiver system, pressure and temperature limit safeties, and electric motor drive.

This system is capable of capacity modulation via both hot gas bypass and variable speed operation resulting from variable frequency input to the compressor drive motor. The system is to be capable of operation at temperatures as low as $-50^{\circ} \mathrm{F}$ evaporator temperature. The nominal design point is to be 9.8 tons of refrigeration at $-30^{\circ}$ evaporator temperature $/ 115^{\circ} \mathrm{F}$ condenser temperature. Proposals for equipment meeting these requirements stiowed that the required motor horsepower at this design point is 31.1 bhp.

\subsubsection{Service Module Equipment}

Shown schematically in Figure 5-19, the power supply system is the heart of the service module and includes the following equipment:

- A 175-kW, 460-V ac, 700-Hz, synchronous generator equipped with brushless exciter

- A 250-hp, natural gas fueled, internal combustion engine with all necessary engine accessories and controls for service

- A generator circuit breaker together with overcurront protective relays necessary to safeguard the ecuipment and personnel from electrical fault malfunctions

- A suitable rigid frame skid on which the engine/generator is mounted together with all the auxillary equipment needed for proper operation

- A size 5 motor starter suitable for connecting 140-hp, 460-V, 3-phase Brayton turbomachine to the electrical bus

- A 460-V, 3-phase, 25-kW inverter capable of outputting $0-$ to $60-\mathrm{Hz}$ power for variable speed drive of the reverse Rankine refrigeration system. The input power is to be $700 \mathrm{~Hz}, 460 \mathrm{~V}, 3$ phase

- A 460-V, 3-phase, 10-kW power supply capable of converting 700-Hz, 3-phase power to $60-\mathrm{Hz}$ power.

The natural gas fueled, internal combustion engine will be capable of alternative propane operation. During the initia, start sequence, the electrical load will be disconnected from the generator by means of the generator circuit breaker. After the engine has reached its idle speed rating, the generator breaker will be closed and the highspeed motor drive will be energized. The engine-generator set will then be accelerated to rated speed. The electrical load on the generator during the acceleration cycle to 


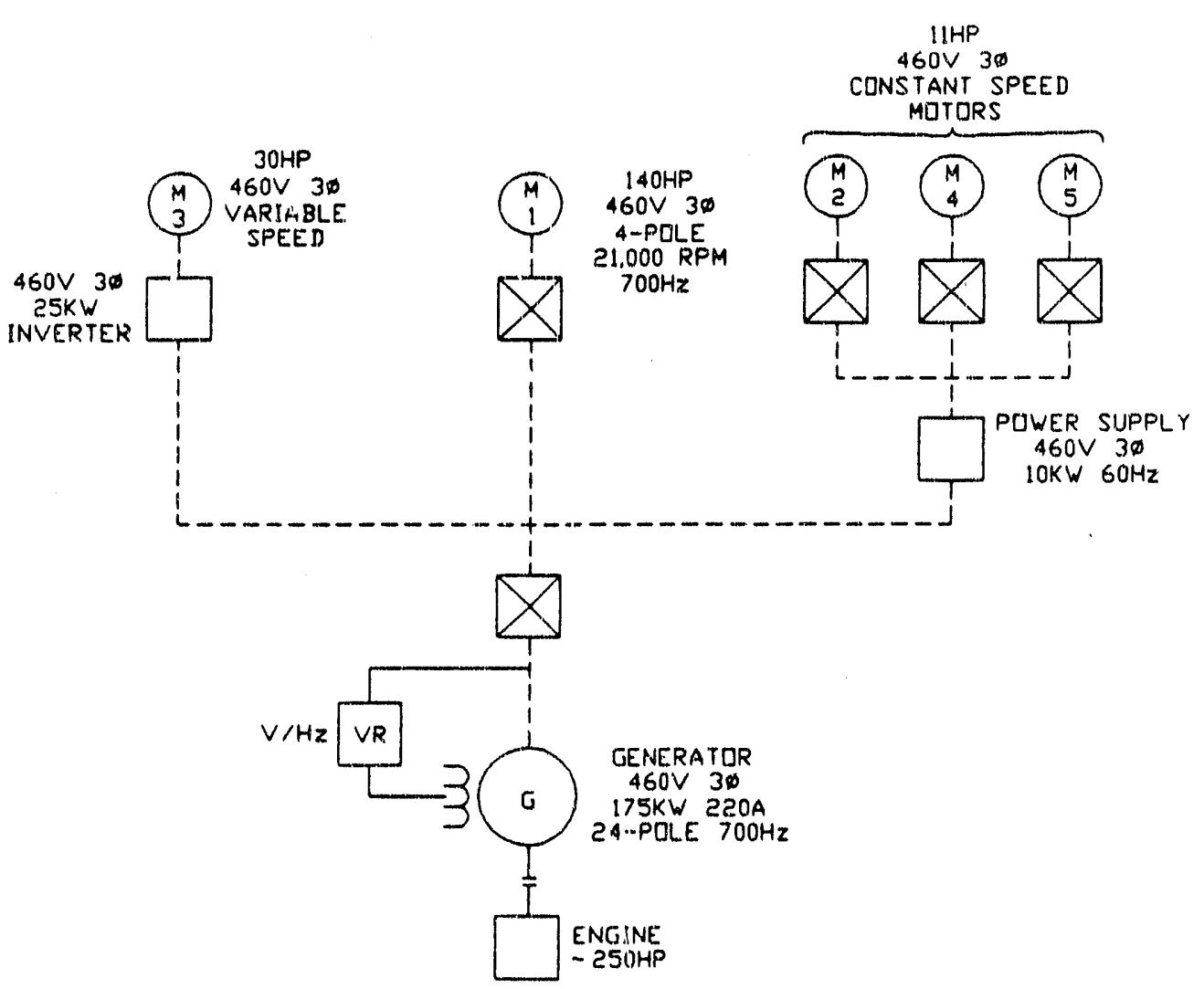

$\$ 0167$

Figure 5-19. Power Supply System

rated speed will vary as the cube of the speed from approximately $20 \mathrm{~kW}$ at idle to $100 \mathrm{~kW}$ at full rated speed. The generator will be equipped with a voltage regulator capable of maintaining a constant ratio of voltage output to frequency (volts divided by Hertz) during the start-up cycie.

The following performance is typical of several commercial offerings that meet the system requirements.

- Maximum Input: $2380 \mathrm{sctm}$ of low pressure (8- through 12-in. WC) natural gas or propane

- Maximum Output: electrical: $200 \mathrm{~kW}, 480 \mathrm{~V}, 3$ phase, $700 \mathrm{~Hz}$ at $2000 \mathrm{rpm}$ with 40-pole synchronous generator

- Maximum Thermal: $774,000 \mathrm{Btu} / \mathrm{hr}$ hot water at $200^{\circ} \mathrm{F}$ and $408,000 \mathrm{Btu} / \mathrm{hr}$ steam at $350^{\circ} \mathrm{F}$

- Efficiency: electrical $31.7 \%$ (lower heating value, LHV) combined electrical and thermal $86.6 \%$ (L.HV). 


\subsubsection{Recuperative Heat Exchanger and Solvent Condensation Module}

The solvent recovery heat pump system incorporates four primary process heat exchangers. $\mathrm{HX1}$ is a nonpressure vessel heat exchanger that provides precooling to the solvent-laden inert gas entering the Brayton-cycle compressor at atmospheric pressure. Recuperative heat exchangers $H X 2, H X 3$, and $H X 4$ handle the solvent-laden gas at compressor discharge pressure. This requires that these heat exchangers be designed and built in compliance with Section VIII of the ASME Boiler and Pressure Vessel Code.

Two solvent liquid separators (S1 and S2) are also included in the recuperative heat exchanger module. The purpose of separator $S 1$ is to prevent liquid droplets larger than 5 micron from entering the turbine. Droplets or particles smaller than 5 micron have been shown not to contribute to turbine erosion. The purpose of separator $\mathrm{S2}$ is to collect and recover condensed solvent vapor from the turbine exhaust. Separator S1 is a pressure vessel operating at compressor discharge pressure, while separator $\$ 2$ is an atmospheric vessel. Both separators operate on a combined centrifugal and coalescing principal. The second-stage coalescer provides high removal efficiency, while the upstream centrifugal portion removes ice particles that would otherwise plug the second stage.

Table 5-3 provides the design thermal duties and performance of the heat exchangers and separation equipment. In summary, roughly $45 \%$ of the recuperative thermal duty is handled (at temperatures above $40^{\circ} \mathrm{F}$ ) in the high-temperature heat exchanger $\mathrm{HX} 2$. In this heat exchanger, there is generally no condensation and no concern for frosting. Heat exchangers $\mathrm{H} \times 3$ and $\mathrm{HX} 4$ are designed for both condensing and frosting service. All of the process heat exchangers in the solvent recovery heat pump system have been designed with a temperature effectiveness in the $75 \%$ range.

Table 5-3. Thermal Duties and Performance of Heat Exchanger and Separation Equipment

\begin{tabular}{|c|c|l|}
\hline $\begin{array}{c}\text { Heat } \\
\text { Exchangors }\end{array}$ & $\begin{array}{c}\text { Duty } \\
\text { (Btu/hr) }\end{array}$ & \multicolumn{1}{|c|}{$\begin{array}{c}\text { Temperature Elfectiveness } \\
\text { (Duty) }\end{array}$} \\
\hline$H X 1$ & 127,598 & 0.75 (Procooler) \\
$H X 2$ & 411,080 & 0.77 (Sensible Heat Recuperation) \\
$H X 3$ & 297,568 & 0.74 (Condensing and Frosting) \\
$H X 4$ & 177,561 & 0.72 (Condensing and Frosting) \\
\hline
\end{tabular}

\begin{tabular}{|c|c|c|}
\hline $\begin{array}{c}\text { Solvent Lquid } \\
\text { Separatora }\end{array}$ & $\begin{array}{c}\text { Dealred } \\
\text { Filtration Lovel }\end{array}$ & $\begin{array}{c}\text { Preseure Drop } \\
\text { (psi) }\end{array}$ \\
\hline S1 & $99 \%>5$ micron & $<0.7$ \\
$S 2$ & $99 \%>5$ micron & $<1.0$ \\
\hline
\end{tabular}


Frost formation in heat exchangers $\mathrm{HX} 3$ and $\mathrm{HX} 4$ may be handled by parallel redundant heat exchangers or by special continuous defrosting heat exchanger designs.* Parallel redundant heat exchangers represent the baseline case for commercial performance verification. These heat exchangers may be of the shell-and-tube or plate type. In general, fin pitch and thickness are greater than normal for air-to-air heat exchangers of this type to minimize mechanical problems with ice formation. Heat exchangers of the type required are available from a large number of commercial sources. Tables 5-4 through 5-7 present the specified performance for the four process heat exchangers described above.

Table 5-4. Data Sheet for Precooler Heat Exchanger (HX1)

Designation: HXI Procooler; Duty: 127,598 Btu/hr; Typo: Air to Air

\begin{tabular}{|c|c|c|}
\hline & Hot Side & Cold SIde \\
\hline Pressure in (psia) & 14.7 & 15.11 \\
\hline Temperature $\ln \left({ }^{\circ} \mathrm{F}\right)$ & 150 & 70 \\
\hline Temperature Out $\left({ }^{\circ} \mathrm{F}\right)$ & 90 & 118 \\
\hline Fluid & & \\
\hline - Air (lb/hr) & 9372 & 12,560 \\
\hline $\begin{array}{l}\text { - Water (lb/hr) } \\
\text { - Solvent (lb/hr) }\end{array}$ & $\begin{array}{l}100 \\
138\end{array}$ & - \\
\hline Sensible Heat Duty (Btu/lb) & 145,000 & 145,500 \\
\hline Condensing Heat Duty (Btu/b) & - & - \\
\hline Allowable Pressure Drop (psia) & 0.25 & 0.1 \\
\hline \multicolumn{3}{|c|}{$\begin{array}{l}\text { Design } \\
\text { - Materials - corrosion resistant } 316 \text { stainless steol } \\
\text { - Provision for condensation collection and drainage (hot side) } \\
\text { - Provision for temperature and pressure monitoring for } \\
\text { inlet and outlet on hot and cold sides }\end{array}$} \\
\hline
\end{tabular}

'Baseline solvent is methylene chloride; latent heat $\sim 160 \mathrm{Btu} / \mathrm{lb}$; $\mathrm{Cp} \sim 0.3 \mathrm{Btu} / \mathrm{kb} \mathrm{O}^{\circ} \mathrm{F}$

- Not described herein due to patent restrictions. 
Table 5-5. Data Shoet for Aftencooler Heat Exchanger (HX2)

Designation: HX2 Aftercooler; Duty: 41 1,080 Btu/hr; Type: Air to Air

\begin{tabular}{|c|c|c|}
\hline & Hot Side & Cold Side \\
\hline Pressure In (psia) & 33.2 & 15.0 \\
\hline Temperature in ( $\left.{ }^{\circ} \mathrm{F}\right)$ & 275 & 40 \\
\hline Temperature Out ( $\left.{ }^{\circ} \mathrm{F}\right)$ & 100 & 222 \\
\hline $\begin{array}{l}\text { Fluid } \\
\text { - Air (lb/hr) } \\
\text { - Water (lb/hr) } \\
\text { - Solvent (lb/hr) }\end{array}$ & $\begin{array}{l}9372 \\
99 \\
138\end{array}$ & $\begin{array}{l}9372 \\
- \\
-\end{array}$ \\
\hline Sensible Heat Duty (Btu/b) & 411,080 & 411,080 \\
\hline Condensing Heat Duty (Btu/b) & - & - \\
\hline Altowable Pressure Drop (psia) & 0.25 & 0.3 \\
\hline \multicolumn{3}{|c|}{$\begin{array}{l}\text { Design } \\
\text { - Materials - corrosion resistant } 316 \text { stainless steol } \\
\text { - Provision for condensation collection and drainage (hot side) } \\
\text { - Provision for temperatire and pressure monitoring for } \\
\text { inlet and outlet on hot and cold sides }\end{array}$} \\
\hline
\end{tabular}

'Baseline solvent is methylene chloride; latent heat $160 \mathrm{Btu} / \mathrm{lb}$; $\mathrm{Cp} \sim 0.3 \mathrm{Btu} / \mathrm{b}{ }^{\circ} \mathrm{F}$ 
Table 5-6. Data Sheet for Recuperative Condenser Heat Exchanger (HX3)

Designation: HX3 Recuperative Condenser; Duty: 297,568 Btu/hr

\begin{tabular}{|c|c|c|}
\hline & Hot Slde & Cold Slde \\
\hline Pressure In (psia) & 33.2 & -14.0 \\
\hline Temperature $\ln \left({ }^{\circ} \mathrm{F}\right)$ & 100 & 40 \\
\hline Temperature Out ( ${ }^{\circ} \mathrm{F}$ ) & 15 & 40 \\
\hline $\begin{array}{l}\text { Fluid } \\
\text { - Air (lb/hr) } \\
\text { - Water (lb/hr) } \\
\text { - Solvent (lb/hr) }\end{array}$ & $\begin{array}{l}9372 \\
99 \\
138\end{array}$ & $\begin{array}{l}22,960 \\
- \\
-\end{array}$ \\
\hline Sensible Heat Dury (Btu/b) & 198,493 & - \\
\hline Condensing Heat Duty (Btu/b) & $99,075^{2}$ & - \\
\hline Allowable Pressure Drop (psia) & 0.5 & 0.35 \\
\hline \multicolumn{3}{|c|}{$\begin{array}{l}\text { Design } \\
\text { - Materials - corrosion resistant } 316 \text { stainless steel } \\
\text { - Design for cyclic defrost duty } \\
\text { - Provision tor condensation collection and drainage (hot side) } \\
\text { - Design for ease of cleaning } \\
\text { - Provision for temperature and pressure monitoring for } \\
\text { inlet and outlet on hot and cold sides }\end{array}$} \\
\hline
\end{tabular}

'Baseline solvent is methylene chloride; latent heat $\sim 160 \mathrm{Btw} / \mathrm{b}$; $\mathrm{Cp}-0.3 \mathrm{Btu} / \mathrm{b}{ }^{\circ} \mathrm{F}$

${ }^{2}$ Water 
Table 5-7. Data Sheot for Recuperative Condenser Heat Exchanger (HX\&)

Designation: HX4 Recuperative Condenser; Duty: 177,561 Btu/hr

\begin{tabular}{|c|c|c|}
\hline & Hot Slde & Cold SIde \\
\hline Pressure In (psia) & 32.5 & 15.3 \\
\hline Temperature $\ln \left({ }^{\circ} \mathrm{F}\right)$ & 15 & -104 \\
\hline Temperature Out ( $\left.{ }^{\circ} \mathrm{F}\right)$ & -60 & -20 \\
\hline $\begin{array}{l}\text { Fluid } \\
\text { - Air (lb/hr) } \\
\text { - Water (lb/hr) } \\
\text { - Solvent (lb/hr) }\end{array}$ & $\begin{array}{l}9372 \\
5.5 \\
138\end{array}$ & $\begin{array}{l}9372 \\
- \\
-\end{array}$ \\
\hline Sensible Heat Duty (Btu/lb) & 120,000 & - \\
\hline Condensing Heat Duty (Btu/b) & $5760^{2}$ & - \\
\hline Allowable Pressure Drop (psia) & 0.1 & 0.3 \\
\hline \multicolumn{3}{|c|}{$\begin{array}{l}\text { Design } \\
\text { - Materials - corrosion resistant } 316 \text { stainless steel } \\
\text { - Design for cyclic detrost duty } \\
\text { - Provision tor condensation collection and drainage (hot side) } \\
\text { - Provision for temperature and pressure monitoring for } \\
\text { inlet and outlet on het and cold sides }\end{array}$} \\
\hline
\end{tabular}

'Baseline solvent is methylene chloride; latent heat $\sim 160 \mathrm{Btw} / \mathrm{b}$; $\mathrm{Cp} \sim 0.3 \mathrm{Btu} / \mathrm{b}^{\circ} \mathrm{F}$

${ }^{2} 36-$ tb soivent

90TR7 
The direct material cost breakdown for the 2500-cfm mobile unit is presented in Table 6-1. This estimate was made for a production unit in quantities of 100 units per year. No profit margin is included. Until manufacturing drawings are made, the system costs in Table 6-1 should be considered a study estimate with a probable error of $\pm 30 \%$. The turbomachine, which makes up $7 \%$ of the system cost, is composed of many parts that are in commercial production for which the costs are well defined. Therefore, the turbomachine estimate is within the narrower range of $\pm 20 \%$. The effect of production quantities is shown in Figure 6-1, with the first unit (configured as shown in Figure 4-2) estimated at $\$ 83,000$. This cost includes inspection, pressure testing, balancing, cleaning, painting, and assembly. Figure 6-2 estimates the cost of the turbomachine as a function of flow capacity (quantities of 100 units per year). A 5000cfm unit would cost approximately $\$ 100,000$ or about $7 \%$ less per unit of capacity than the $\$ 54,000$ production unit. A greater economy of scale is evidenced between the half-size unit and the production unit $(2500 \mathrm{cfm})$. The half-size unit is estimated at $\$ 34,000$ or $26 \%$ more per unit of capacity than the production unit.

Table 6-1. Preliminary Production System Cost Estimate

\begin{tabular}{|c|c|}
\hline Turbomachine & $\$ 54,000$ \\
\hline $\begin{array}{l}\text { Heat Exchangers (See Figure 5-6) } \\
\text { Heat Exchanger }(H x) 1 \\
\text { Heat Exchanger }(H x) 2 \\
\text { Heat Exchanger }(H x) 3 \text { (Quantity: 2) } \\
\text { Heat Exchanger }(H x) 4 \text { (Quantity: 2) } \\
\text { Heat Exchariger }(H x) 5 \\
\text { Heat Exchanger }(H x) 6 \text { (see Figure 5-17) } \\
\text { Heat Exchanger }(H x) 7 \text { (See Figure 5-17) }\end{array}$ & $\begin{array}{r}\$ 18,000 \\
28,000 \\
102,000 \\
79,000 \\
12,000 \\
19,000 \\
19,000\end{array}$ \\
\hline Subtotal & $\$ 277,000$ \\
\hline $\begin{array}{l}\text { Service Module } \\
\text { Engine } \\
\text { Generator } \\
\text { Controls } \\
\text { Power Distribution } \\
\text { Gas Subsystem } \\
\text { Air Skid and Accessories } \\
\text { Piping, Wiring, and Assembly }\end{array}$ & $\begin{array}{r}\$ 12,000 \\
8,000 \\
20,000 \\
12,000 \\
35,000 \\
15,000 \\
138,000\end{array}$ \\
\hline Subtotal & $\$ 240,000$ \\
\hline Truck Package & $\$ 100,000$ \\
\hline Balance of Plant & $\$ 107,000$ \\
\hline Total & $\$ 778,000$ \\
\hline
\end{tabular}

90TR7 


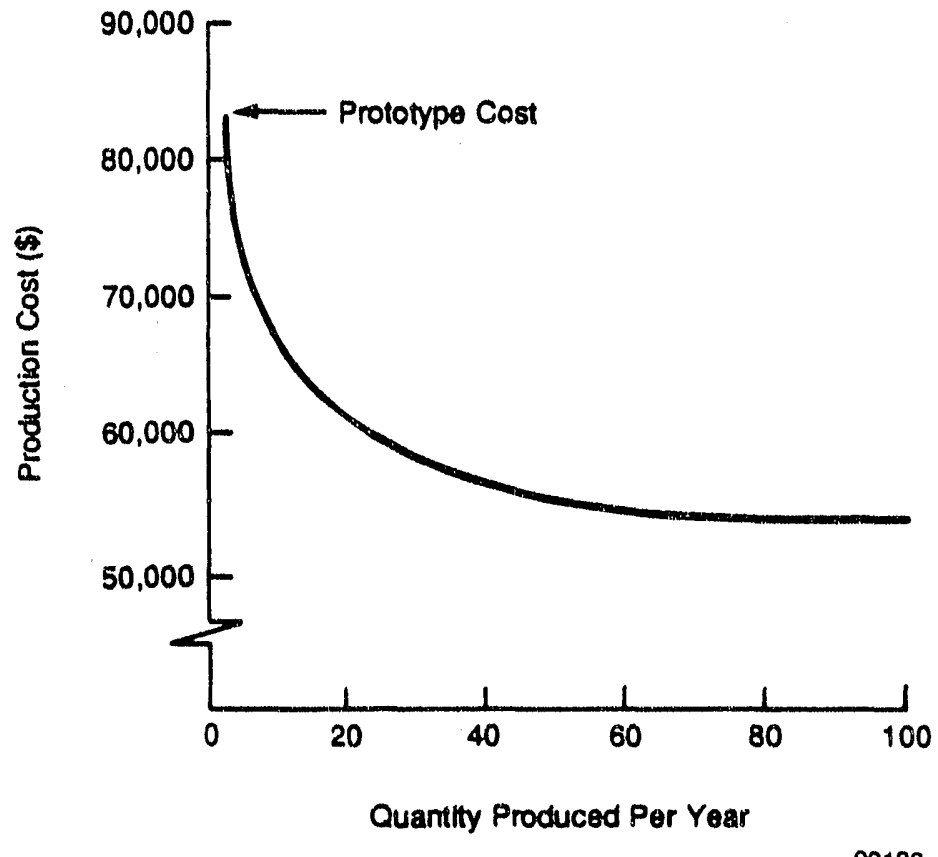

Figure 6-1. Turbomachine Cost in Production Quantities

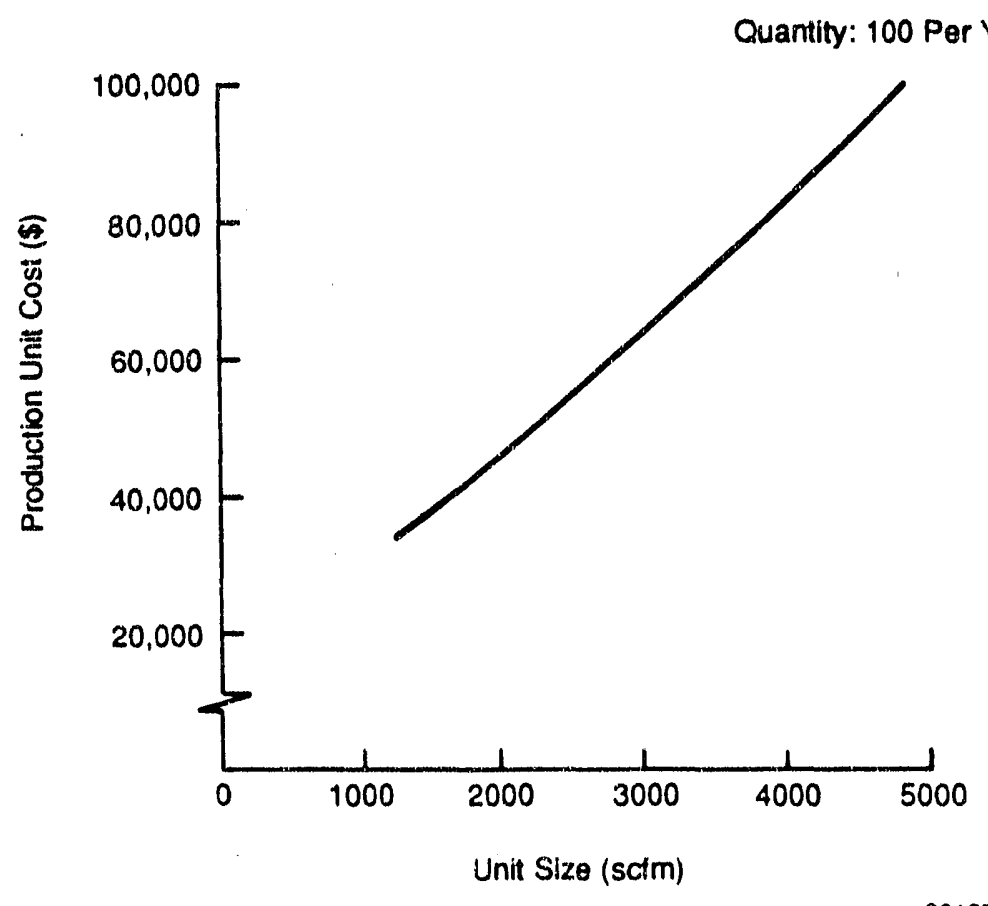

Figure 6-2. Production Unit Cost versus Capacity 
The heat exchanger costs are based on vendor quotations and are also in the $\pm 20 \%$ range. With $35 \%$ of the system cost being devoted to heat exchangers, this is an important area for future cost reduction. The cost estimate in Table 6-1 includes redundant heat exchangers to accommodate a defrost cycle. Elimination of these duplicate heat exchangers could save approximately $\$ 120,000$.

The balance of the estimate for the system is based on a combination of engineering estimates and historical cost figures for comparable hardware. 


\subsection{FEASIBILITY ASSESSMENT}

Since the solvent recovery heat pump mobile unit must be applicable to a wide variety of VOC emissions, this section presents a general feasibility assessment. For an analysis of the heat pump and its compatibility with processes see Section 5.0.

Regarding risk, the systems and components of the preliminary design are made up of commercially available components and existing designs and therefore do not represent high development risks. The major risk identifiable at this time lies in operating the system over a broad spectrum of solvents and processes. This operating profile raises two important issues: material compatibility and flow path fouling. Materials selection will be a critical step in the detailed design process, since system cost is extremely sensitive to the materials used in the heat exchangers, duct work, valves, and rotating machinery. The selection of titanium throughout can result in a fourfold cost increase over conventional materials. Therefore, the corrosion risks must be carefully weighed against cost benefits. A second operating risk is flow path fouling from particulates, plasticizers, resins, or other compounds that exhibit buildup in duct work, heat exchangers, or turbocompressor components. The full impact of this phenomenon will only be known with operating experience on various processes. However, provision can be made in the design phase to moderate the effect on system operation and maintenance. These features will include prefilters, separators, and cleanable components, particularly heat exchangers, where many of the high boilers will tend to condense out.

The amount of VOC solvent recovered and left unrecovered is dependent on the application. Solvent recovery efficiency and heat recovery are discussed in Section 5.0. Waste heat is recovered from both the engine-generator and the electric motor.

Aiternative technologies for VOC control include carbon adsorption, condensing systems, and incineration. The following are important factors influencing the selection of a particular control lechnology:

- Process exhaust volume flow

- Process exhaust temperature

- Solvent concentrations

- Solvent composition

- Hours of operation per year

- Energy costs.

\subsection{Incineration}

Incineration is a technique that relies on oxidation (burning) of the solvent to carbon dioxide and water, which can be released safely to the atmosphere. This technique has proven effective for many hydrocarbons, but compounds that contain halides (such as chlorine or bromine), sulfur compounds, silicon, or heavy metals may require additional treatment to produce satisfactory emission streams. Incineration systerns may be designed to handle a few hundred scim, or may be designed to handle as much as $15,000 \mathrm{scim}$. Larger systems have been designed with two incineration units in parallel. 
Incinerators are used on a wide range of industrial products such as printing, drying, metal coating, and systems where odor is a problem. If simple, easily purifiable compounds are in the gas stream, other techniques such as carbon adsorption may be preferred. However, for low VOC-concentration systems, or for chemicals that are difficult to purify to a level suitable for reuse, incineration may be the process of choice. Incineration falls into two broad categories: thermal and catalytic.

\subsubsection{Thermal Incineration}

Thermal incineration is one of the simplest air pollution control techniques. The waste gas stream (with sufficient oxygen) is raised to a temperature of 1250 to $1500^{\circ} \mathrm{F}$ and held for a period of about 0.3 to $0.5 \mathrm{sec}$. Reduction of solvents may be expected to be in the range of 90 to $95 \%$, and the technique may be used in a wide range of applications. For low VOC concentrations, a natural gas or fuel oil flame is the usual source of heat. Solvent concentration of typical sources is limited by safety considerations. Fire underwriters usually limit solvent concentration in ovens and dryers to $25 \%$ of the lower flammability limit (LFL) if there are no controls, and to $50 \%$ of the LFL if there are adequate controls, alarms, and shuidowns installed. As a rule, the temperature rise from combustion of solvent in a gas stream is $25^{\circ} \mathrm{F}$ for each percent LFL.

Thermal oxidation usually incorporates recuperative or regenerative heat recovery to reduce the purchased fuel required to maintain the required oxidation temperature. A recuperative system is shown in Figure 7-1. These systems utilize surface-type heat exchangers to preheat the SLA.

Regenerative systems use high density media or packed beds to preheat the inlet stream to the incinerator. These systems have the ability to achieve $95 \%$ heat recovery and are often recommended for flows over 10,000 scfm and solvent concentrations below $10 \%$ LEL.

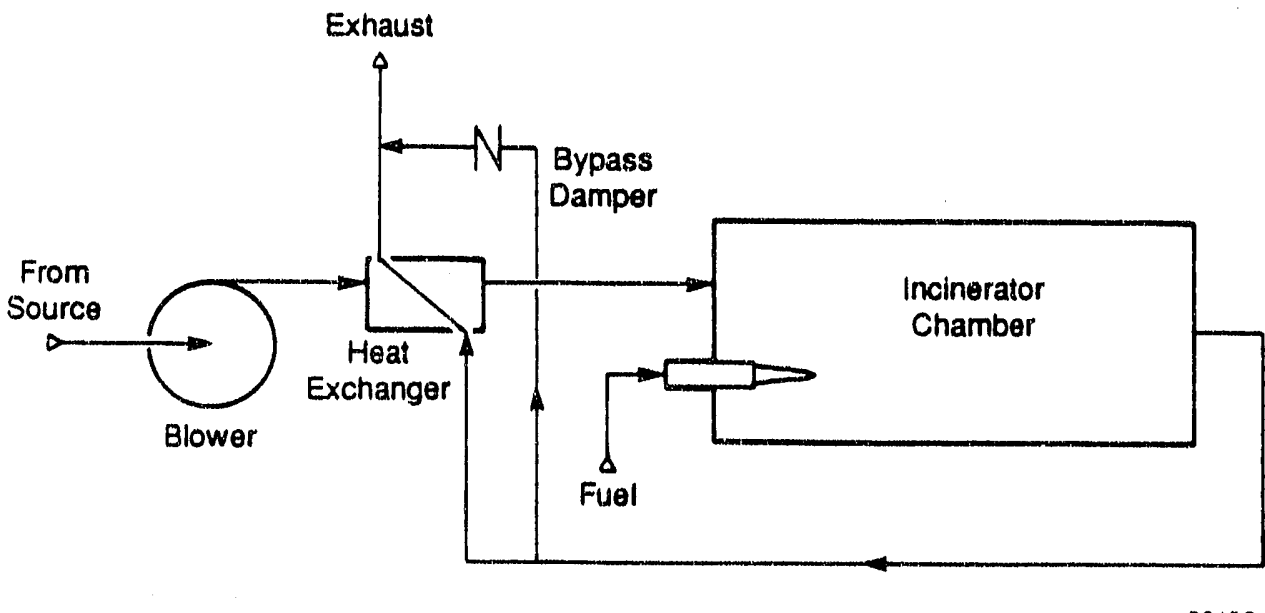

Figure 7-1. Thermal Incineration with Primary Heat Recovery 


\subsubsection{Catalytic Incineration}

The primary difference between thermal and catalytic incineration systems is that the reaction chamber of a thermal system is replaced by a cataiyst bed for the catalytic system. The catalyst bed permits satisfactory oxidation of the solvents at input temperature as low as $500^{\circ} \mathrm{F}$. Less fuel is required to heat the gas to the incinerator or lower percent LFL feed can be accepted with minimum fuel use. There are, however, some negatives to catalytic incinerators compared to thermal incinerators - first cost of catalytic incinerators is higher, overheating may reduce the catalyst activity, and certain elements such as chlorine, silicon, zinc, and tar may cause rapid degradation of the catalyst. In addition, Figure 7-2 shows a catalytic incineration system with a primary heat exchanger and a heat exchanger bypass. As in the case for thermal incineration, additional fuel savings can be achieved by installation of a primary heat exchanger for preheating the SLA mixture.

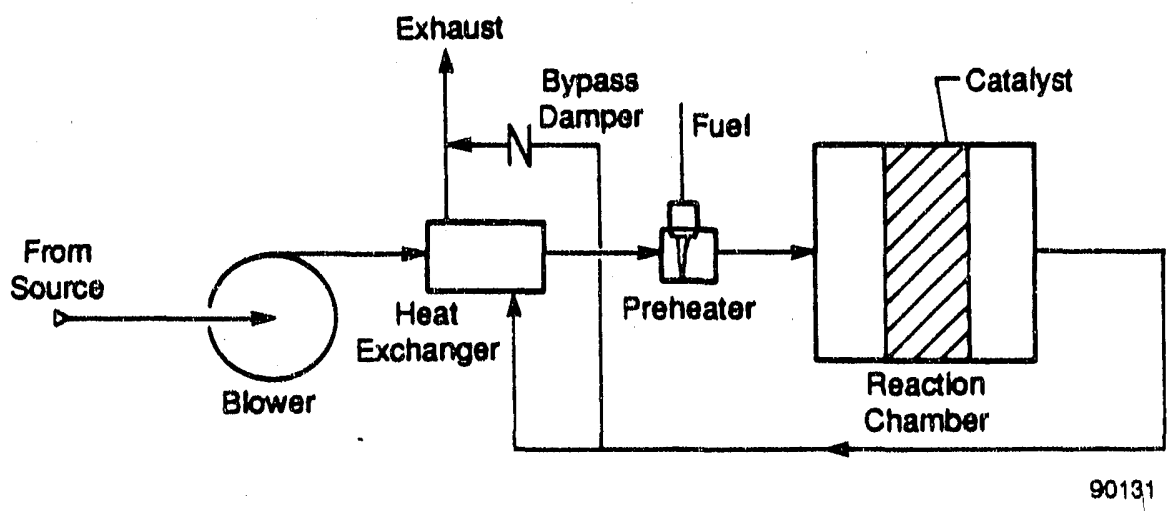

Figure 7-2. Catalytic Incineration with Primary Heat Source

The low first cost of thermal incineration makes it an attractive alternative. However, the potential user must consider a life-cycle cost with energy and maintenance costs included. Some representative first costs are given in Table 7-1.

Table 7-1. Estimated Incinerator Cosis ${ }^{1,2,3}$

\begin{tabular}{|c|c|c|c|c|}
\hline $\begin{array}{c}\text { Size } \\
\text { (cfm) }\end{array}$ & $\begin{array}{c}\text { Thermal } \\
\text { without } \\
\text { Heat Exchanger }\end{array}$ & $\begin{array}{c}\text { Thermal } \\
\text { wlth 70\% } \\
\text { Heat Exchanger }\end{array}$ & $\begin{array}{c}\text { Catalytic } \\
\text { Wilthout } \\
\text { Exchanger }\end{array}$ & $\begin{array}{c}\text { Catalytic } \\
\text { with 74\% } \\
\text { Exchanger }\end{array}$ \\
\hline \hline 4000 & 64 & 178 & 80 & 143 \\
8000 & 90 & 260 & 100 & 233 \\
\hline
\end{tabular}

${ }^{1}$ All costs in thousands of dollars.

21989 dollars.

3 installation costs not included. 


\subsection{Conventional Condensation Technology}

Conventional condensation technology is based on the fact that air can hold a limited amount of a given solvent in the vapor state at a given temperature. Less vapor is held at lower temperatures, and the excess will condense out as mist or rain.

A commonly used, direct-cooled condensation system is shown in Figure 7-3. Such a direct-cooled system consists of a blower, a cooler, and a device such as a demister to collect the condensed material. The blower is usually a conventional centrifugal unit operating at a few inches of water discharge pressure. The cooler may be a water- or air-cooled heat exchanger, but Freon-cooled refrigeration systems are more common. The final section to collect the condensed material may be an electrostatic precipitator, a demister packed with metal or plastic mesh, a cyclone, or another similar device.

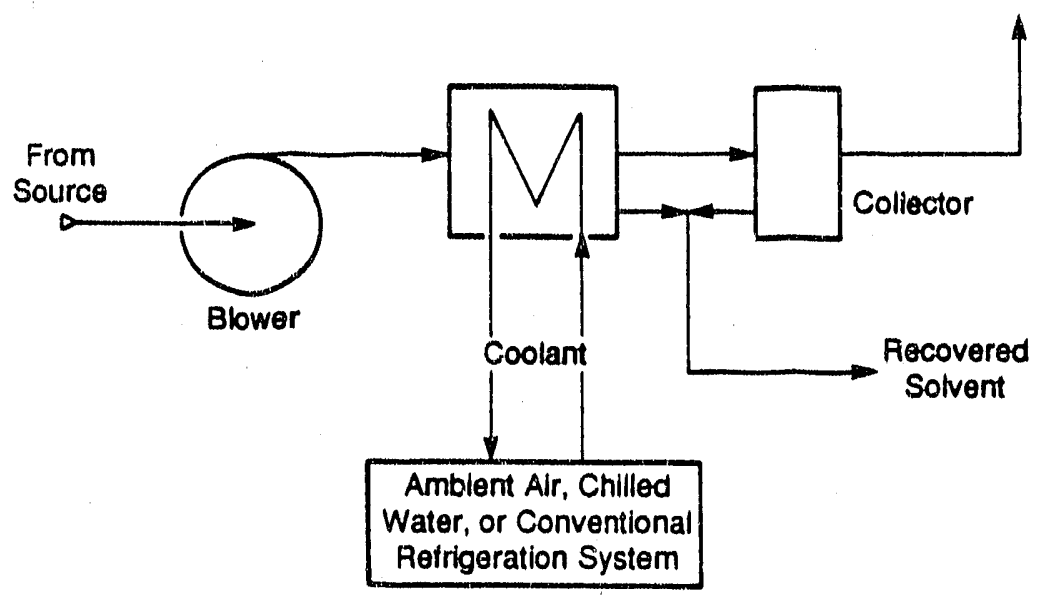

$\$ 0130$

Figu:e 7-3. Direct-Cooled Condensation System

Operation of direct-cooled systems is usually limited by the degree to which the gas stream can be cooled. Most gas streams contain water vapor. Experience demonstrates that the water will freeze on the cooling surface of a standard heat exchanger and build up to the point that, if the gas temperature is below about $40^{\circ} \mathrm{F}$, gas flow is impeded or stopped. Simple systems have found their broadest application in lower vapor pressure solvents (higher condensing temperatures), i.e., solvents in the offset web printing process.

Reverse Rankine refrigeration systems are currently used in solvent recovery applications at temperatures as low as $-90^{\circ} \mathrm{F}$. These systems have a distinct energy advantage over Brayton refrigeration systems. However, they tend to be more complex and require sophisticated means of handling frost.

In general, the technology is best suited to closed-loop, direct-process connection in applications where the VOC concentration level is above $5000 \mathrm{ppm}$. The technology may also be well suited to solvent recovery when combined with inert gas desorption of solvent concentrators. 


\subsection{Carbon Adsorption - Steam Desorption}

Carbon adsorption systems depend on the fact that carbon granules can be treated so that vapors and gases will be held at the carbon surface. By proper treatment, the surface may be increased so that a pound of activated carbon contains many thousand square feet of surface. Because the activity (ability to adsorb) varies with temperature, a mass of carbon may be made to alternately hold and release the adsorbed material.

A typical adsorbing system consists of two or more carbon beds: one is in the adsorbing cycle, and the other is in the regeneration (release) cycle. The inlet gas stream flows through the blower and through the bed where the solvents are captured. Capture efficiencies in excess of $99 \%$ have been achieved, but capture levels of 90 to $95 \%$ are more common. The discharge from the bed is exhausted to atmosphere.

To release the solvent, steam is made to flow through the bed, raising the bed temperature and carrying off the desorbed solvent. Steam and desorbed solvent flow to a condenser, and the condensed steam and solvert flow to a separation system. The separation system may be a simple decanter if the solvents are not soluble in water, otherwise a complex distillation system may be required. In some cases, a combination of distillation and decantation may prove to be the optimum system. The desorption cycle is usually time controlled, and, when desorption is complete, the bed is placed in a standby mode.

The cycie of the active bed may be controlled by a timer, but it is more usually controlled by a sensor in the exhaust duct that reacts to an increase in solvent concentration. At the appropriate time or signal, the beds are switched from adsorbing to regeneration.

Carbon bed systems have been designed over wide flow ranges. Systems as small as a few hundred scfm have been designed for small dry cleaning stores, while larger systems have been designed to handle $20,000 \mathrm{scfm}$. Multiple bed systems may economically handle $100,000 \mathrm{scfm}$.

Capital cost of carbon adsorption systems varies widely. Table 7-2 lists cost estimates of basic systems for varying flow rates.

Table 7-2. Cost of Cartoon Adsorption Systems, Not Installed (September 1989)

\begin{tabular}{|c|c|}
\hline $\begin{array}{c}\text { S1ze } \\
(\text { scfm })\end{array}$ & $\begin{array}{c}\text { Cost } \\
\text { (dollars) }\end{array}$ \\
\hline 2000 & $\$ 100,000$ \\
4000 & $\$ 150,000$ \\
8000 & $\$ 205,000$ \\
\hline
\end{tabular}

90TR7 
The system selected for this cost comparison is suitable for capturing toluene from gravure printing presses. Other systems may cost two to three times as much. For example, a system to adsorb the solvents from a magnetic tape drying system might require stainless steel beds, special carton, and a complex distillation system to provide reusable solvents. Systems to handle chlorinated solvents may require titanium vessels.

Chlorinated solvents tend to break down to form hydrochloric acid in small quantities. Partially oxidized compounds such as methyl ethyl ketone oxidize readily and may cause bed fires or may produce strong smelling aldehydes in the discharge. Materials such as epoxy monomers, which can polymerize, may blind the carbon, requiring early replacement of the carbon bed. Similarty, silicones in small quantities may blind the carbon bed.

The primary operating cost of a simple carton adsorption system is steam for regeneration. This cost is not related to the gas flow rate, but is a function of the captured solvent. Three to five pounds of steam are typically required for each pound of recovered solvent. If the solvent must be distilled, the stearn rate may double or triple.

The activity of a carbon bed decreases with time because the carbon adsorbs heavy molecules, present in small amounts in the atmosphere, and does not release them during regeneration. Thus, the carbon bed must be replaced periodicaily depending on the service.

The inert gas desorption system will have certain advantages cver the steam description system primarily related to the separation of water from the solvent. This is an energy advantage that can double the energy input, since the distillation step is eliminated with inert gas desorption. Secondly, the solvent quality is improved by elininating water contamination, which can have a deleterious effect on many solvents.

Another major advantage to the user of inert gas desorption is the elimination of waste water disposal downstream of the distillation plant. This potential disposal problem is a concerr for sites considering solvent recovery that do not want to trade one environmental release for another.

The description of emission control technologies provides a basis for comparison, but each application must be evaluated with regard to the many variables that can influence the final selection. Key advantages of the advanced heat pump systern as either Brayton, Rankine, or a combination of ine two, will be its ability to recover solvent at low condensing temperatures and to mairtain solvent quality by minimizing contamination of the recovered solvent. 


\subsection{MARKET ASSESSMENT}

The market assessinent utilized the EPA Toxic Release Inventory (TRI) in conjunction with factors derived from the detailed NYS study described earlier and other judgments. The EPA TRI reports that about 2.7 billion Ib of pollutants were released in 1987. Of this total, point source and fugitive emissions comprised $68 \%$ and $32 \%$, respectively.

In preparing the market assessment, detailed information was available only for NYS. It was therefore necessary to make the assumption that NYS is typical of the U.S. average, even though other states' industrial mix may differ. Ideally, the "macroscopic" NYS study should be replicated in at least six additional states (Texas, Ohio, Louisiana, Tennessee, Virginia, and Michigan) to increase the confidence level of the assessment.

\subsection{Multipliers}

Six multipliers were generated for application to the EPA TRI data. The product of these multipliers and the basic EPA data then provide a state-by-state estimate of VOC releases addressed by the proposed technology.

M1: Ellmination of VOCs. Some manufacturers have the option of modifying their processes to eliminate the need for solvents and other VOCs. For example, within the printing industry, the potential exists for switching from solvent to water-based inks. Based or a limited number of interviews, our judgment is that very few manufacturers will elect to institute process changes If low-cost VOC recovery methods are available. Both the cost of process modifications and compromises in product quality are the important considerations. This multiplier is estimated at 0.90 (i.e., only $10 \%$ of existing manufacturers would elect to change their basic processes).

M2: CompetIng Technology. Incineration, other condensing systems, and new recover approaches are assumed to capture $50 \%$ of the market. This multiplier is estimated at 0.50 .

M3: EmIssion Levels within Regulation. Based on recent proposals for Clean Air Legislation, industry will be required to reduce their present emissions by $90 \%$. Therefore, this multiplier is estimated at 0.90 .

M4: VOCs as Fraction of Total Emissions. The EPA TRI lists 89 million lb/yr total NYS toxic releases. The VOC data base generated from air quality permit data showed that $66 \%$ of that total comprised VOCs suitable for recovery by the proposed technology (i.e., about 59 million lb/yr). This multiplier is estimated at 0.66 .

M5: Slze of Source. With the mobile concept, no source is too small. Small sources will simply need desorption at a low frequency. Desorption rates as low as a few times per year can be handled adequately by appropriate scheduling of the mobile desorption unit. The upper limit frequency for mobile desorption was set at once per day. Statistical analysis of the NYS data shows that systerns above 40000-cfm inlet flow, at average concentration levels, will require desorption at rates greater than once per day. This limit eliminates about $26 \%$ of the NYS applications. This multiplier is estimated at 0.74 . 
M6: Retroflt Market. The EPA TRI data does not cover VOCs that are now being captured by existing pollution control systems. Penetration of this market, because of improved technology, therefore generates a multiplier greater than 1.0.

The NYS data base provides information on pollutant quantities from incineration processes, as well as quantities emitted from other nonincineration control means (namely, condensing systems and others). Assuming an average $95 \%$ capture efficiency for the latter systems, the input quantity of VOCs would be estimated at 19 times the quantity emitted. It was assumed that $50 \%$ of the incinerator applications and $10 \%$ of the nonincinerator applications would be penetrated by the technology proposed herein. This calculation procedure results in a favorable multiplier of 1.30. The retrofit market is, therefore, estimated at an additional $30 \%$ over the new installation market.

The above six faciors produce a combined multiplier of:

$$
(0.90)(0.50)(0.90)(0.66)(0.74)(1.30)=0.26
$$

This is the multiplier applied on a state-by-state basis to the EPA TRI. As stated earlier, the assumption inherent in this analysis approach is that all states are similar to New York. Additional detailed information, particularly for the six states mentioned, will greatly improve the quality of the market assessment.

A second phase of the analysis examined the geographic distribution of the market. This is an important consideration when a mobile concept is to be implemented. Three significant territories emerged: North, South, and California. Figure 8.1 shows the geographic grouping, which covers 17 of the top 18 states and about $70 \%$ of the total U.S. VOC releases.

Table 8-1 shows the estimated breakdown by state based on the EPA TRI and the derived multiplier.

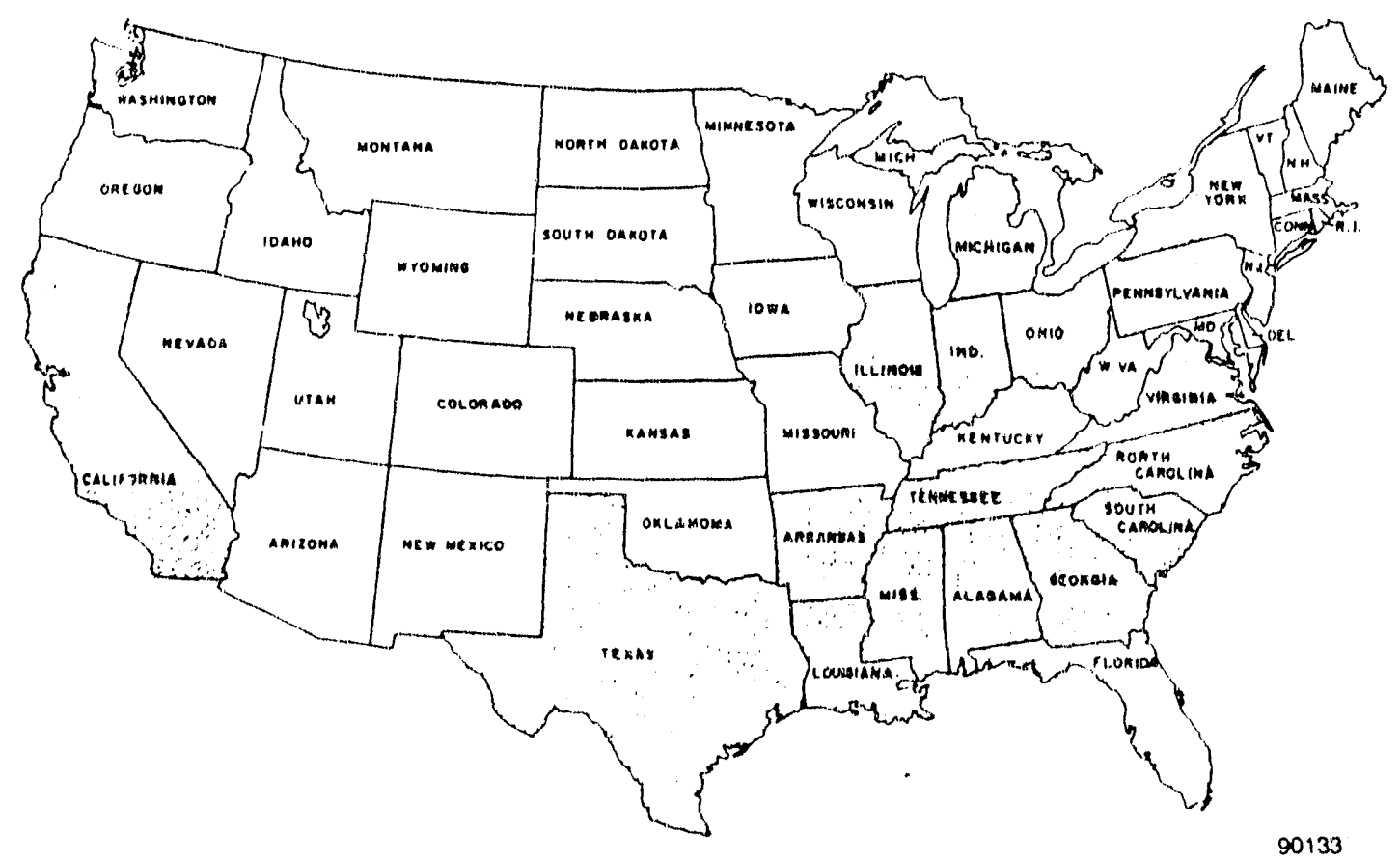

Figure 8-1. Principal Market Areas 


\subsection{Urgency of RD\&D Program}

The market buildup rate will be extremely rapid. This results from the near-term compliance datos associated with impending clean-air legislation. If the June 1989

White House press release outlining the Administration's clean-air plan is used as an estimate, $75-90 \%$ of the VOC potential market listed in Table 8-1 should be acquired by the end of 1995. This means that systems capable of recovering approximately 400 million $\mathrm{lb} / \mathrm{yr}$ need to be in place by that date.

Table 8-1. Annual Emissions in Selected States

\begin{tabular}{|l|c|c|c|}
\hline U.S. Rank & $\begin{array}{c}\text { Total Toxic } \\
\text { Roleasea, } \\
\text { million Ib }\end{array}$ & $\begin{array}{c}\text { Voc Potentlal } \\
\text { Market, } \\
\text { million Ib }\end{array}$ & $\begin{array}{c}\text { Cumulative } \\
\text { Market, \% }\end{array}$ \\
\hline 1. Texas & 239 & 62 & 9.0 \\
2. Ohio & 173 & 45 & 15.5 \\
3. Lovisiana & 138 & 36 & 20.7 \\
4. Tennesse日 & 135 & 35 & 26.0 \\
5. Virginia & 132 & 34 & 30.7 \\
6. Michigan & 116 & 30 & 35.1 \\
7. Indiana & 113 & 29 & 39.3 \\
8. Illinois & 99 & 26 & 43.0 \\
9. Alabama & 98 & 25 & 46.7 \\
10. North Carolina & 95 & 25 & 50.3 \\
11. Goorgia & 94 & 24 & 53.8 \\
12. Now York & 89 & 23 & 57.1 \\
13. Pennsylvania & 88 & 23 & 60.4 \\
14. California & 83 & 21 & 63.5 \\
16. South Carolina & 64 & 17 & 65.9 \\
17. Mississippi & 57 & 15 & 68.1 \\
18. Arkansas & 56 & 14 & 70.1 \\
Subtotal & 1869 & 484 & 70.1 \\
U.S. Balance & 797 & 206 & 100.0 \\
\hline U.S. Total & 2666 & 690 & 100.0 \\
\hline
\end{tabular}

90TR7

Legislative slippage in the proposed compliance dates and a softening of the $75-90 \%$ emission abatement requirements will probably occur. Notwithstanding, the task of building market presence (a sales network), production capacity, and service facilities is enormous. If the efficient recovery technologies now being pursued by MTI and others are to have an impact on this market, the applied level of resources must be significantly increased and, most importantly, the time frame for development must be shortened. If this is not done, pivate enterprise will not have the technical data available at the time investment decisions regarding the necessary marketing, rnanufacturing, and service facilities are to be made. 
The need for early technology demonstration relates to business risk. The manufacturing business requires a large initial investment to capture nearly a step increase in sales (driven by legal compliance dates). This large initial investment results from both inventory buildup and tooling requirements. Depending on the exact structure of the business, an investment range of $\$ 20-40$ million can be anticipated in order to serve the national market at a rate consistent with the time frame certain to be imposed by clean-air legislation. This investment gamble becomes too risky if an adequate technology demonstration program has not occurred. This is especially true given the sophistication of the recovery technologies being pursued and the impending 1995 compliance dates. 
Based on the NYS applications study and contacts with host site candidates, MTI concludet thial $V O C$, solvent recovery technology will be driven by environmental regulations culrently, the economics of solvent recovery alone are not sufficient inducement to control emissions. Therefore, VOC emitters are inclined to maintain the status quo. As regulations become more stringent, as it appears they will, ernitters will eliminate the use of organic solvents, recover and reuse the solvents, or go out of business. Incineration and other disposal techniques that create their own envirsimental problems will probably not be an option. For those processes that continue to use organic solvents, a decision will be made between alternative methods of recovery based on cost to maintain product quality. A near-term need for new solvent recovery equipment was identified in two broad areas: small users and low concentration emissions. The small user (under $20,000 \mathrm{lb} / \mathrm{yr}$ ) will not be able to afford the high first cost of the solvent recovery heat pump system, nor wili they be comfortable with the operation and maintenance of this relatively sophisticated equipment.

The second area of interest is that of low concentration emissions (air streams with less than 200-ppm solvent). These streams are not practical for direct-coupled condensing systems because the energy requirement per pound of solvent recovered is very high. In addition, based on conversations with these sites, solvent recovery by steam desorption is prohibitively expensive for these applications.

The mobile system for inert gas desorption of carbon adsorption modules proposed herein offers a practical solution to both the small user and the low concentration dilemmas. The concept is to share the expensive equipment among a number of users by a fee-for-senvice plan. The relatively low-cost carbon adsorption module would be purchased and optimized for the specific site. Because the module will be desorbed by inert gas at low pressure, its cost is much less than that required for steam desorption, thus moderating one of the principal barriers to recovery from low concentration SLA. In addition, when a company has a small low concentration source, the desorption and distillation equipment is not required on site. Instead, the mobile unit visits as required, once a day or once a month.

Large permanent installations are viable for systerns directly coupled to the process (no concentrator) when SLA concentrations are high enough (generally less than $40 \%$ LEL). 

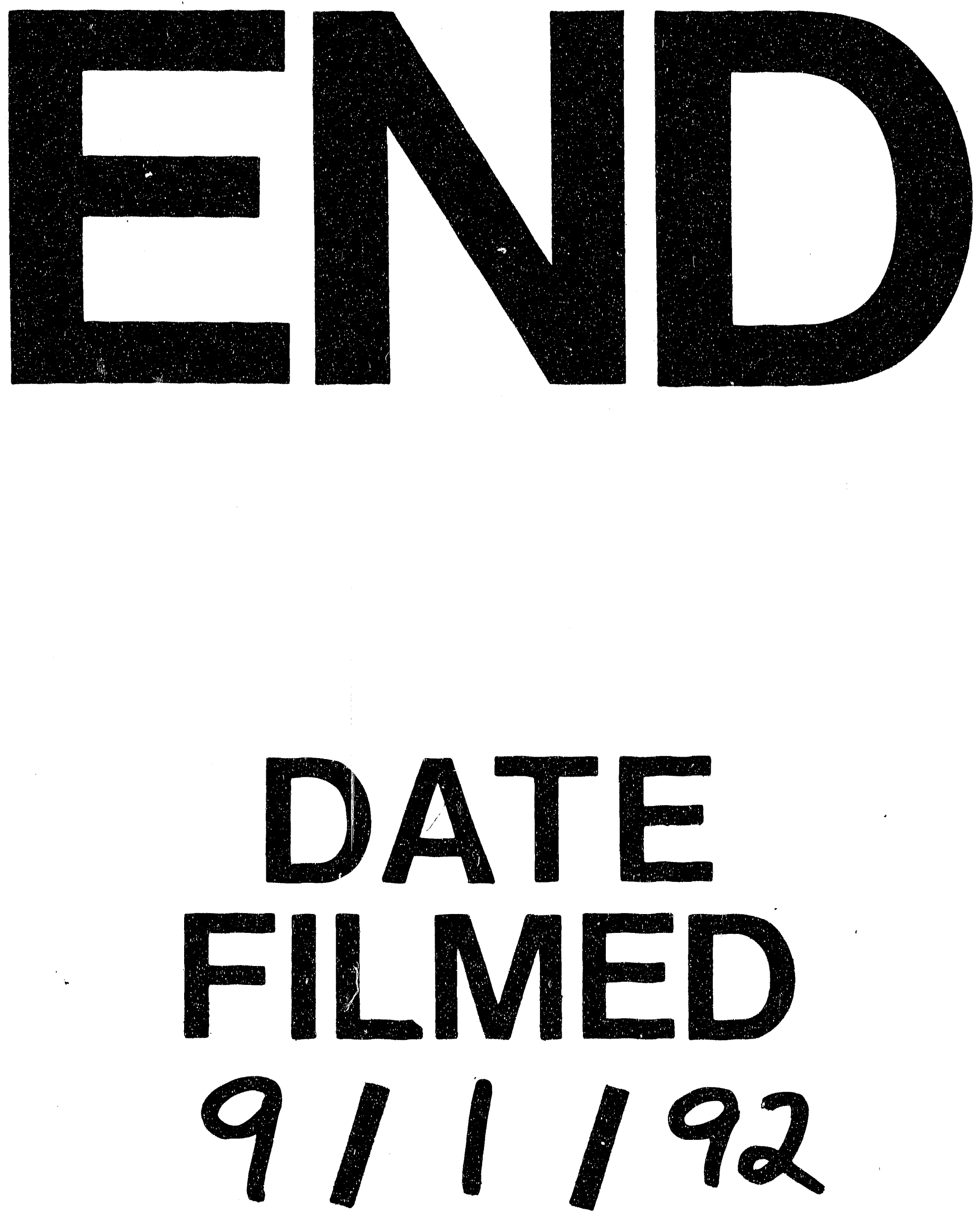
